
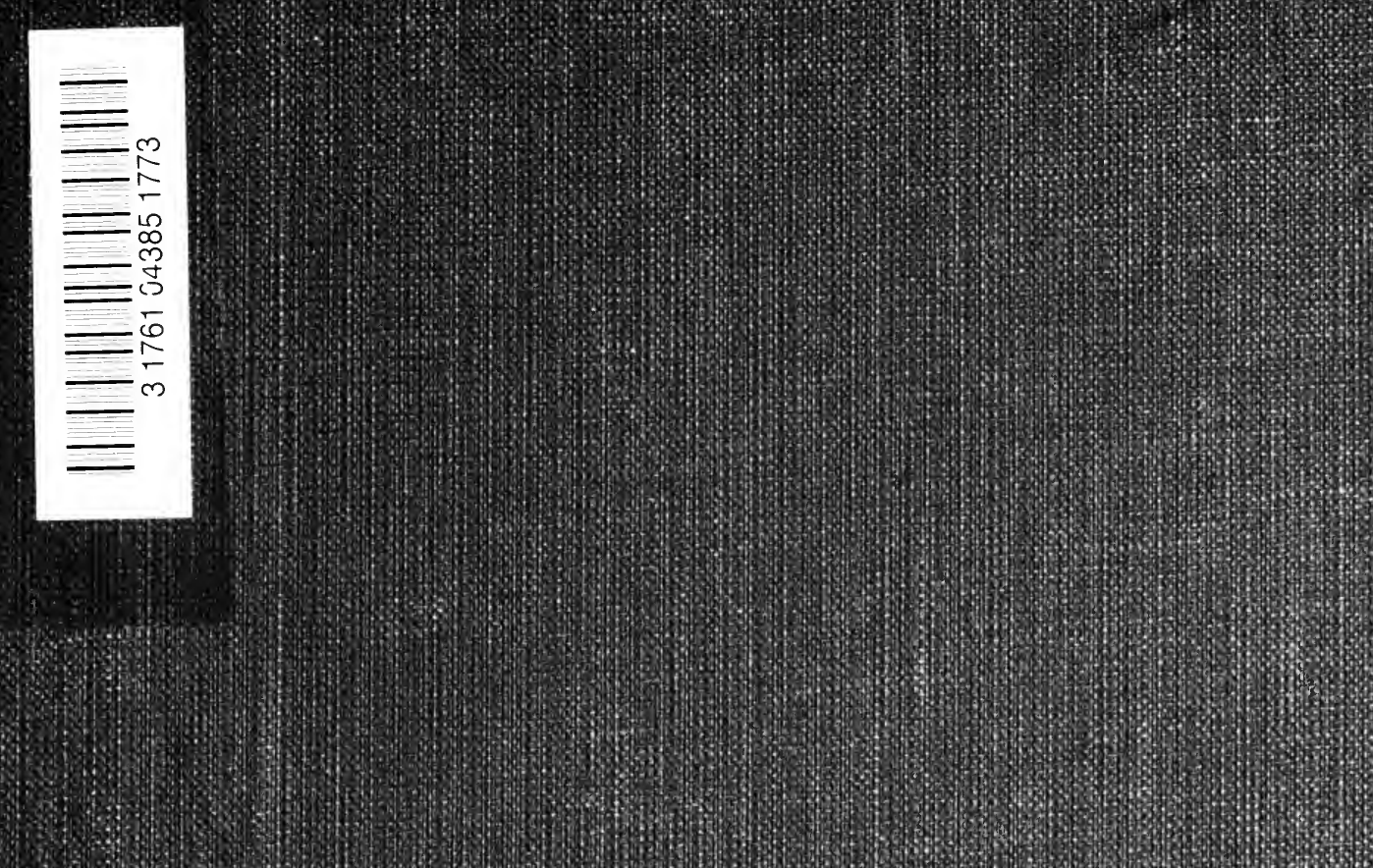

UWvar TaRakTO UBRARY 





\section{Cornell Studies in Philosophy No. 15}

\section{THE LOGIC OF CONTEMPORARY ENGLISH REALISM}

BY

\section{RAYMOND P. HAWES, A.M.}

FORMERLY SCHOLAR IN THE SAGE SCHOOL OF PHILOSOPHY, CORNELL UNIVERSITY

Submitted to the Faculty of the Graduate School of Cornell University as a thesis for the degree of Doctor of Philosophy

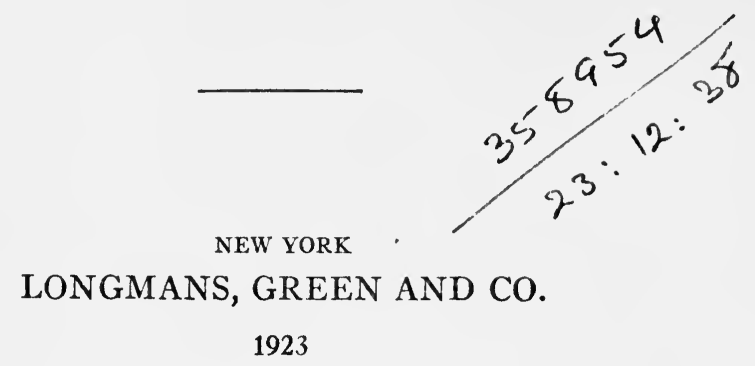


Jhe Oallegiate Freas

George Banta Publishing Company

Menasha, Wisconsin 


\section{PREFACE}

$\mathrm{T}$ HE present work is primarily a study in method, and should be judged as such. No attempt is made, for example, to present systematically or to determine the relative merits of the various and ever varying solutions of special problems proposed by the different types of Realism or by different Realists. Rather, attention is centered throughout on what might be called in the broader sense of the term the 'logic' of Realism, that is, the point of view taken, the fundamental assumptions made, and the processes of thought relied upon in the Realist's efforts to know reality. In the belief that a writer can always state his own position better than another can state it for him, direct quotation is employed in presenting the views studied wherever the requirements of space permit. It is hoped that the criticisms offered from time to time will not be without their value. The main purpose of the work will have been achieved, however, if it contributes to a better understanding of the presuppositions of contemporary Realism and to a clearer definition of the issue between the newer Realism and the Idealism against which, in part, it arose as a protest.

Chapter I deals with the historical antecedents of contemporary Realism. Chapter II contains a study of the Realistic criticism of Idealism. Chapter III sets forth the fundamentals of the Realistic method.

I am most grateful to Professor J. E. Creighton, under whose direction this study has been carried on, for invaluable suggestions and criticisms. I am also under obligations to Professor Creighton for first pointing out to me the importance of the newer English Realism and for first directing my interest to a study of the leaders of this movement. 



\section{CONTENTS}

\section{CHAPTER I}

Historical BACKGROUND

Section

PAGE

I. The Rise of Realism....................... I

2. Realism a Protest against Idealism................. 6

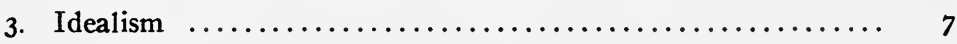

\section{CHAPTER II}

The Realistic Criticism of Idealism

I. English Philosophy at the Appearance of Realism........ 38

2. The Realistic Criticism of Idealism............... 39

CHAPTER III

The Realistic Method

I. Intellectualistic Tendencies..................... 60

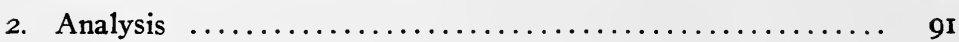

3. Universals and Wholes........................ 122

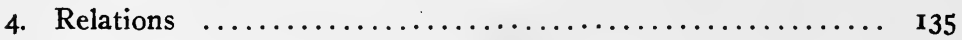

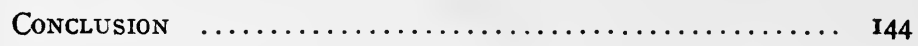





\title{
The Logic of Contemporary English Realism
}

\author{
CHAPTER I \\ HISTORICAL BACKGROUND \\ I. The Rise of Realism
}

$\mathrm{C}^{\mathrm{o}}$ ONTEMPORARY English Realism as a distinctive method of thought may be said to have come into existence during the last decade of the nineteenth century and the first decade of the twentieth century. It was of course not the first realistic reaction in the development of English thought. In the eighteenth century the philosophy of Reid (1710-1796) and Price (1723I79I) had been to a large extent a realistic reaction against the idealism of Berkeley and the skepticism of Hume. ${ }^{1}$ A little later, Hamilton (I788-I856) had reasserted "Reid's doctrine of Natural Realism or Dualism," and had quarreled not only "with the skepticism of Hume and the 'ideal' or 'representative' theory of knowledge, of which it is the consequence, but also with the opposite type of philosophy, that absolute idealism or 'omniscience' which the German successors of Kant have developed out of the Kantian Transcendentalism."' Reid and Hamilton held (though not unequivocally, and perhaps not in thorough consistency with some of their other contentions) that in perception, if not also in memory, imagination, and thought, the mind (as act) is in direct contact with an independently real object; no duplicative, representative, or mediating 'ideas' being present. The starting point of this Realism is psychological; its "center of gravity," "an empirical observation of the human mind." It makes frequent

${ }^{1}$ Dugald Stewart (I753-I828) and Thomas Brown (I778-1820) were greatly influenced by Reid.

${ }^{2}$ James Seth, English Philosophers and Schools of Philosophy, pp. $300 \mathrm{f}$. Of course Hamilton's debt to Kant was nevertheless great. 
appeals to 'immediacy,' in various of its forms, and to the 'common sense' of mankind. In the immediate deliverances of consciousness or mind, and in certain common sense beliefs, themselves unprovable and underivable, it finds an absolute basis for provable knowledge. It thus represents an extension of the 'solid foundation' and 'demonstrational' logic of the pre-Kantians, and, in a measure, a revival of rationalism. It has been characterized as marked by "a plodding patience of analysis rather than by any inspired sense for the vitalities of the human spirit," and by a more than occasional misunderstanding of the positions it criticized, and as suffering from "the faults of mistaking description for explanation, and of subordinating theoretical standpoints to description." 3

In France and America, as well as in England, Scottish Realism has exerted no small influence. ${ }^{4}$ In England its point of view is conspicuous in the works of Calderwood, Martineau, and Fraser, while even Spencer and Huxley did not escape the influence of Hamilton's doctrine of the relativity of knowledge. The empiricistic, associationistic thought of Bacon, Hobbes, Locke, Berkeley,

${ }^{3}$ A. K. Rogers, English and American Philosophy since I800, pp. 2, $\checkmark$ Io; Höffding, A History of Modern Philosophy, Vol. II, p. 390, Vol. I, p. 449; J. Seth, loc. cit.

'It will be recalled that, during the life-time of Hamilton, a number of German thinkers were engaged in a vigorous criticism of post-Kantian Idealism and in an attempt to work out a system of thought which has much in common with both Scottish Realism and Contemporary English Realism. The most influential of these thinkers was Herbart (I776-184I), although Fries (1773-I843), and perhaps also Beneke (1798-1854), should not go unmentioned. With reference to the purpose of the present work it is especially interesting to note: (I) the interest of these philosophers in the special sciences and their thorough knowledge of the sciences; (2) their insistence that philosophy meet what they regarded as the requirements of scientific method: the "regressive, analytic" method, which, starting from the "given," leads on to the discovery (deductive) of fundamental concepts: "first, psychological description, then analysis and abstraction, and only after this has been done, and where possible, construction (which, however, can never be more than hypothetical)"; (3) the emphasis of Fries and Beneke, and, to a less extent, Herbart on the importance of empirical psychology for philosophy (see comparison of Fries, Beneke, and Hamilton in this and other respects in Höffding, op. cit., Vol. II, p. 390); (4) the hold of 'formal logic' on Herbart's thinking; in particular, his "obstinate adherence to the principle of identity, to the 
and Hume had been continued in England by Hartley, Priestley, Bentham, James Mill, John Stuart Mill, and Bain; while Herbert Spencer had constructed a philosophy of evolution which had furnished a scientific grounding for associationistic psychology and in general had brought traditional empiricism into closer alliance with the development of the special sciences. Shortly before the rise of the 'New Realism,' Shadworth Hodgson, following the "traditional method of English philosophy," had worked out "on experiential lines" an anti-Idealistic metaphysics. And, in a way, a still more important expression of the empirical reaction against Idealism had appeared in Robert Adamson's Development of Modern Philosophy. The special significance of these volumes lies in the fact that Adamson's "earlier works on the philosophies of Kant and Fichte and his article on 'Logic' in the Encyclopaedia Britannica (ninth edition) are written from the standpoint of a convinced adherent of idealism." 5 But in his Development of Modern Philosophy, Adamson expresses his conviction that Idealism does not keep close enough to experience, in particular, to the facts of science, and that consequently the future course of philosophy must be "from idealism to realism, from rationalism to empiricism or naturalism." 6

Prior to Adamson's change in point of view, Samuel Alexander, one of the most prominent exponents of Realism at the present time, had contributed a number of articles to the Journals and

axiom that everything is what it is," with (5) the consequent repudiation of activity, change, and development, and (6) the making of the causal relation a timeless relation, and (7) the conception of "reals," i.e., of reality as a manifold of self-identical, unchangeable, simple, independent particulars, or atomic absolutes, and (8) the interpretation of relations as unessential and contingent; (9) Herbart's retention of unknowable thingsin-themselves; (10) the tendency of Fries and Herbart to interpret mechanistically both inner experience and the process of knowing, as well as outer reality; (II) Herbart's atomistic, associationistic, and mathematical interpretation of the mind, "the total force which expresses what we call our ego" (though he also speaks of soul-substance) being regarded as a resultant or product of the interaction of the manifold of particular simple elements, and not as a principle; and (12) Herbart's divorcing of reality and worth, and of theory and practice. (Cf. loc. cit., Vol. II, pp. 238-65.)

s James Seth, op. cit., p. 36r.

- Vol. II, pp. 9ff.; cf. p. 317, and Vol. I, p. xl. 
had published his Moral Order and Progress (1889). ${ }^{7}$ One finds in these early writings of Alexander little to distinguish his thought at this time from the evolutionary philosophy which for several decades had constituted a dominant strain in British thinking. But with the appearance of a number of articles by G. E. Moore, the most important of which are "The Nature of Judgment" (Mind, I899) and "The Refutation of Idealism" (Mind, 1903), and with the publication of Bertrand Russell's $A$ Critical Exposition of the Philosophy of Leibniz (1900) and The Principles of Mathematics (1903), it became evident that a development of thought was taking place which promised to be something different from contemporaneous anti-idealistic philosophies. In these writings one could detect a more intellectualistic mode of approaching philosophical problems than had been common in English thought, i. e., one could detect a tendency to look at philosophical problems through the eyes of the formal logician or the mathematician, and an attempt to solve the problems of philosophy by means of the concepts, principles, and methods of abstract logic and mathematics. Moreover,Moore's conception of the object's independence of the subject and the importance which Russell attached to the method of analyzing all complexity into ultimate 'simples,' seemed prophetic of a pluralism more extreme than any that British thought had witnessed since the time of Hume.

From these beginnings Realism has grown apace both in England and in the United States. ${ }^{8}$ The underlying assumptions of

${ }^{7}$ It is interesting to note that in the preface of his Moral Order and Progress Alexander says: "I have come to the ideas, borrowed from biology and the theory of Evolution, which are prevalent in modern ethics, with a training derived from Aristotle and Hegel, and I have found not antagonism, but, on the whole, fulfilment." "I am proud to have my work connected, however indirectly, with the name of T. H. Green; and I feel this all the more because, though, as will be obvious, my obligations to him are very great, I have not scrupled to express my present dissent from his fundamental principles." However, in the preface of Space, Time, and Deity we read: "My work is part of the widely-spread movement towards some form of realism in philosophy, which began in this country with Messrs. Moore and Russell, and in America with the authors of The New Realism."

${ }^{8}$ The most important developments of the movement in England are to be found in: (I) G. E. Moore's Principia Ethica (1903) and "The Nature 
English and American 'New Realism' appear to be the same, but the solutions of special problems offered by the two movements not infrequently differ. Although the fundamental standpoint of the 'New Realism' seems to have been worked out slightly earlier in England and in isolation from American Realistic thought, the detailed development of the movement in England has obviously been influenced by the distinctive contributions of American Realists. A consideration of the latter, however, does not fall within the purpose of the present study, in which attention will be confined to English Realism and will be centered upon the fundamental assumptions and standpoint of the 'New Realism' in their contrast to those of Idealism. ${ }^{9}$ The intellectualistic and pluralistic tendencies mentioned above, the latter of which has been made more explicit in a theory of the externality of relations and in the position which Russell calls "Logical Atomism," have been perhaps the two most conspicuous features of the 'New Realism' in its development to date.

and Reality of Objects of Perception" (Proc. Arist. Soc., 1906; reprinted in Philosophical Essays, I922); (2) B. Russell's Philosophical Essays (1910), The Problems of Philosophy (1912), Our Knowledge of the External World as a Field for Scientific Method in Philosophy (1914), Mysticism and Logic (1918), and The Analysis of Mind (1921); (3) S. Alexander's "On Sensations and Images" (Proc. Arist. Soc., 1910), The Basis of Realism (1914), and Space, Time, and Deity (1920); (4) T. P. Nunn's “Are Secondary Qualities Independent of Perception?" (Proc. Arist. Soc., 1909) ; and (5) C. D. Broad's Perception, Physics, and Reality (1914), and Scientific Thought (1923). In 1912, in the Journal of Philosophy, Psychology, and Scientific Method, six American Realists (E. B. Holt, W. T. Marvin, W. P. Montague, R. B. Perry, W. B. Pitkin, and E. G. Spaulding) set forth their "Program and First Platform of Six Realists," which they followed up in the same year with a volume of "coöperative studies in philosophy" entitled The New Realism. Other important works by American Realists are: Present Philosophical Tendencies (1912) by R. B. Perry; A First Book in Metaphysics (1912) by W. T. Marvin; The Concept of Consciousness (1914) by E. B. Holt; and The New Rationalism (1918) by E. G. Spaulding.

'It would be interesting to compare English 'New Realism' with the contemporaneous development of Continental thought of which Meinong and Husserl may be regarded as the leading representatives; but such a study lies beyond the bounds of the present work. The following cliaracteristics of the movement, however, may be noted in passing, 


\section{Realism a Protest against Idealism}

As the title of one of G. E. Moore's early articles suggests, Realism arose largely as a protest against and a criticism of Idealism. ${ }^{10}$ The Realist found himself unable to assign much meaning to some of the fundamental notions of Speculative Idealism, such as the notions of identity in difference, organic whole, concrete universal, and individuality. ${ }^{11}$ Other principles of Idealism, as for example the theory of the internality of relations, seemed to him to be largely or utterly false. ${ }^{12}$ In general, it was maintained that Idealism had not kept close enough to experience: that it had failed to take sufficiently into account certain obvious

because of the close analogy which they bear to certain traits of English 'New Realism': (I) the importance attached to analyzing (to the discovery of 'ultimates,' 'simples,' 'indefinables,' or 'inexplicables'), to classifying, and to labeling; (2) the combination of intellectualistic (a prioristic, formalistic, etc.; cf. Bosanquet, Implication and Linear Inference, Ch. VII, for critical discussion of this tendency) and empiricistic tendencies (e.g., what has been aptly termed "credulity in the coerciveness of particular introspective findings," H. Parkhurst, Recent Logical Realism, p. I8) ; (3) the almost complete divorce of logic from psychology, based on the severance of the ideal from the real (temporal process or fact; cf. Bosanquet, op. cit.) ; (4) the attempt to conceive meanings atomistically, and as independent of mind and subject ("meanings" include: concepts and propositions whether true, false, fictitious, negative, self-contradictory, impossible, etc.), i.e., as (a) self-identical and unalterable, (b) self-subsistent, self-contained, atomic entities (or complexes of these) having no essential relation to mind or subject or to one another, (c) coordinate with one another, (d) neither mental nor physical, neither in time nor in space, and yet as 'subsistents' and universals, just as real and objective as existents (such as sense-data), which are also atomistically conceived, (e)' invariable correlates of acts of conception and judgment, if not of every psychological phenomenon, (f) known a priori; (5) the apparent vacillation between the conception of truth as (a) an intrinsic quality or property which pertains to a meaning in its own right or in isolation from all other meanings-a quality that is indefinable and inexplicable, and (b) a relation of correspondence (or identity) between a proposition and the actual or factual, or between the 'meant' and the 'given'; (6) the doctrine of the immediate apprehension of truth; ( 7 ) the theory that consciousness is 'relational' and 'intentional'. (For this movement, see H. Parkhurst, Recent Logical Realism.)

10 "The Refutation of Idealism," Mind, 1903.

${ }^{11}$ See Ch. III, Sec. 3 below.

${ }^{12}$ See Ch. III, Sec. 4 below. 
distinctions, such as the difference between the mental act and the object experienced, and that it had not kept sufficiently in touch with the recent progress of science and mathematics. ${ }^{13}$

In view of the fact that Realism has been to a large extent a polemic against Idealism, something should be said of the nature and rise of Idealism itself. How essential this is becomes obvious as soon as one recalls that very different types of philosophy, in fact philosophies as different as the early thought of Berkeley and the speculation of Hegel, are termed Idealism, and that even the Critical Idealism of Kant as well as the Speculative Idealism of Hegel believes that it has refuted or transcended the earlier Berkeleyan type of Idealism. It is desirable then to distinguish clearly between different types of Idealism, to enquire why the Critical and Speculative Idealism of the nineteenth century became dissatisfied with both the rationalistic and empiricistic idealisms as well as with other rationalistic and empiricistic philosophies of pre-Kantian times, and to determine whether the Realistic criticism is a valid criticism of all Idealism or whether it allows certain types of Idealism to go unscathed.

The following section will be devoted to a consideration of nineteenth century Objective (Critical and Speculative) Idealism as a constructive criticism of the method of pre-Kantian philosophy.

\section{Idealism}

(a) Objective Idealism received its initial impetus from the labors of Kant and was developed in Germany by the so-called Post-Kantians, the most important of whom for our purposes is Hegel. During the latter part of the nineteenth century it was further developed in England, principally by J. H. Stirling, ${ }^{14}$ T. H. Green, ${ }^{15}$ Edward Caird, ${ }^{16}$ F. H. Bradley, ${ }^{17}$ Andrew Seth, ${ }^{18}$ R. B.

${ }^{13}$ See Ch. II, Sec. 2 below.

${ }^{14}$ Cf. The Secret of Hegel (1865, 2nd ed., I898).

${ }^{15} \mathrm{Cf}$. Introduction to the Philosophy of Hume (1875), Prolegomena to Ethics (1883), Works (1885-1888).

${ }^{16} \mathrm{Cf}$. The Philosophy of Kant (1877), The Critical Philosophy of Immanuel Kant, 2 vol., (1889), Hegel (1883).

${ }^{17} \mathrm{Cf}$. Ethical Studies (1876)', Logic (1883), Appearance and Reality (1894), Essays on Truth and Reality (1914).

${ }^{18} \mathrm{Cf}$. The Development from Kant to Hegel (1882), Essays in Philosoplical Criticism (in collaboration with Haldane, 1883 ). 
Haldane, and B. Bosanquet. ${ }^{19}$ To avoid confusion it will be well to note at once certain important differences between this Objective Idealism and Idealisms like that represented by Berkeley's early thought or like that which has come to be known as Panpsychism. The latter types of Idealism assume that "all reality must be reduced to a single form or mode of existence," and that the mind can know only itself or what is in itself. It follows that the object must be reduced to terms of mind and that reality consists of (I) states of mind, and (2) finite minds, and, perhaps, (3) an infinite or absolute mind. Furthermore, these "mentalisms," as in the case of Berkeley's early thought, frequently conceive minds as substances, and ideas as passive, particular existences, related mechanically or externally. In opposition to these psychological idealisms, Objective Idealism holds that the mind is in an organic relation with an object, an 'other,' which cannot be reduced to mind; that the mind can know this 'other'; that reality thus comprehends a genuine externality, hence, qualitatively diverse modes of existence. Objective Idealism conceives minds as interpreting, appreciating subjects, i. e., as significant systematic wholes, in organic relations with other minds; and conceives ideas as meanings which can be understood only as they are regarded as differentiations or less inclusive wholes within a more inclusive coherent whole of meaning. In a word, as against psychological idealisms, with their tendencies toward existential, atomistic, mechanistic interpretations and toward monisms of stuff, Objective Idealism takes the standpoint of meaning, of the whole, of development, and of a diversity of stuffs. The contrast between these two types of Idealism will become more explicit as we proceed with the characterization of Objective Idealism as a constructive criticism of the method of pre-Kantian philosophy. ${ }^{20}$

(b) To many thinkers of the seventeenth and eighteenth centuries Mediaeval thought seemed neither sufficiently disinterested

${ }^{10}$ Cf. Logic, 2 vol., (I888), The Principle of Individuality and Value, Gifford Lectures for I9II, The Value and Destiny of the Individual, Gifford Lectures for 1912, Some Suggestions in Ethics (1919), Implication and Linear Inference (1920), What Religion Is (1920), The Meeting of Extremes in Contemporary Philosophy (1921).

${ }^{20}$ Cf. J. E. Creighton, Phil. Rev., Vol. XXVI (1917), "Two Types of Idealism." 
nor sufficiently critical and complete. Indeed much of it appeared to be bound up with most unreliable mystical and magical methods of investigation. Furthermore, the Mediaeval mind had been wont to explain phenomena in terms of abstract occult essences and souls which were conceived of as acting more or less capriciously and irrationally in accordance with some transcendent end. But on such assumptions it seemed impossible to find any ground on which knowledge or rational explanation could secure a foothold.

Consequently, seventeenth and eighteenth century thinkers, in the interests of greater intelligibility, came more and more to demand methods of attaining knowledge and a set of initial assumptions which were very different from those that were characteristic of Mediaeval speculation. They insisted that systematic investigation of fact and disinterested critical thought replace dependence upon tradition, revelation, and magic as methods of attaining truth. Also, for a supernatural, mystical interpretation of phenomena as the manifestation of the activities of occult spirits or 'substantial forms,' they sought to substitute a natural or rational explanation in terms of (I) causal sequences, laws, and mathematical and logical relationships discoverable among phenomena themselves, or (2) principles whose ultimate source and ground is reason. ${ }^{21}$

This change from a supernatural and uncritical to a more positivistic and rationalistic point of view did not of course take place suddenly. On the contrary it may be regarded as a gradual outgrowth of tendencies to be found in the Middle Ages themselves, as for example: the Scholastic emphasis on reason leading to the emancipation of philosophy from theology, the Nominalistic emphasis on observed particulars, the Arabian Philosophers' interest in a knowledge of external nature, and the ever-increasing

${ }^{21}$ For the new attitude and point of view, see: (I) Francis Bacon, Preface to The Great Instauration, and Works (Bohn's Library Ed.), pp. I28ff., I4I, 145, 207ff., 380ff.; but note also the survival of the doctrine of "substantial forms," pp. I25f., I38f., I44f., 377; (2) Descartes, Works (Cambridge University Press), Vol. I, pp. 5-9, I4f., 29, 8I, 86, 21 I, 305f.; (3) Locke, Works (Bohn's Library Ed.), pp. 24-34, 38ff., 49-57, 76, 129; Vol. 2, pp. 252-63, 304-8, 320; on essences, cf. Vol. 2, pp. I9, 47, 5I-5, 73; (4) Hume, Treatise (Selby-Biggs Ed.), pp. xxi-xxiii, 219-27, 271; and Enquiry (Open Court Ed.), pp. 8, II, II4ff., I76. 
general interest in the thought and life of Ancient Greece and Rome.

(c) From the first the elaboration of the new point of view contained two distinguishable moments, the Rationalistic and the Empiricistic. ${ }^{22}$ Passages in the writings of Descartes suggest that the origin of the seventeenth and eighteenth century Rationalistic ideal of knowledge is to be sought for in the Rationalist's admiration for the nature and procedure of Mathematics. ${ }^{23}$ Mathematics was indeed undergoing an unparalleled development in the hands of such men as Kepler and Galileo. Descartes himself contributed the Analytic Geometry, and Leibnitz and Newton were soon to add the Calculus. Moreover, Mathematics was proving an invaluable instrument of verification and prediction in the physical sciences.

Mathematics seemed to reduce all initial complexity analytically to absolutely simple and precise elements (ideas and propositions), and then to ascend synthetically or deductively to a knowledge of other propositions. ${ }^{24}$ The edifice of complex propositions seemed to be based upon a solid foundation of impeccable ideas and axioms: ideas that could be once for all clearly and exactly defined at the outset of investigation, and axioms the absolute validity of each of which could be ascertained in its isolation from all other truths. Each of the isolated experiences

${ }^{22}$ It is not of course maintained that any writer of the period represents purely the one moment or purely the other: e.g., note Descartes's recognition of the value of sense experience and experimentation, Works, Vol. I, pp. 4, I5, I20f., I88, I9I, I97f., 249, 254f.; and note the rationalistic ideal of knowledge of Locke and Hume: Locke, Essay, B. IV, Ch. I-4, 7, I0, 12, 17, and Conduct of the Understanding, Sec. 6 and 7; Hume, Treatise, Part IV, Sec. I, Enquiry, Sec. IV, Part I, and Sec. XII, Part III.

"E.g., "its firm and solid" basis; its starting with that which is "most simple and most easy to apprehend"; "the certainty of its demonstration and the evidence of its reasonings"; its "long chains of reasoning, simple and easy," which "caused me to imagine that all those things which fall under the cognizance of man might very likely be mutually related in the same fashion; and that, provided only that we abstain from receiving anything as true which is not so, and always retain the order which is necessary in order to deduce the one conclusion from the other there can be nothing so remote that we cannot reach to it, nor so recondite that we cannot discover it"; cf. Works, Vol. I, pp. 85, 9If., 4f., I2I.

${ }^{24}$ Cf. Works, Vol. I, pp. I4, 49, 92. 
that constituted the solid foundation, so far as it was 'clear and distinct,' 'indubitable,' or 'manifest to the natural light,' appeared to be true in its own right. It appeared to carry a guarantee of its worth in the form of a characteristic of 'self-evidence,' or in the form of a claim to have come from a certain source or by means of a particular channel, e. g., the 'natural light.' Also, every proposition, after the first, appeared to follow with irresistible necessity from the preceding proposition or propositions and ultimately therefore from the incontestable logical prius with which the whole sequence commenced. Propositions nearer to the 'solid foundation' did not seem to be dependent upon those further away, as the latter were obviously dependent upon them..$^{25}$ There seemed to be truths, related by what might be called a relation of one-sided dependence, but not truth. Moreover, each proposition seemed to contain all that could be known about some particular matter. ${ }^{26}$ It seemed possible to get not only absolutely certain truths, in no wise relative, mediated, or hypothetical, but also absolutely unchangeable, self-complete truths, requiring no supplementation and reinterpretation with the growth of knowledge. Hence all truths seemed equally true, and the attaining of truth appeared to be not a growth or fluent expansion from within, but a somewhat mechanical piling up or adding of deduced, selfcomplete units ('blocks' or 'links').

It is to be noted that for the Rationalist not only must there be a necessary logical relation between each proposition after the first and the proposition that precedes it, but also the simple ultimate axiom, the first proposition itself, must be grounded in reason. Therefore all knowledge proceeds ultimately from reason, i. e., from ideas and principles in some sense innate or from an intellectual intuition which recognizes the clarity and distinctness,

${ }^{25} \mathrm{So}$, it would seem, in the Meditations the proposition 'God exists as a being who does not deceive' is supposed to be dependent upon the proposition 'I doubt, therefore I am,' but the latter is not supposed to be dependent upon the former,-despite the fact that the truth of the latter is apprehended by a God-given faculty which we could hardly trust were not God already presupposed to be veracious.

${ }^{20} \mathrm{Cf}$. Works, Vol. I, p. 94. "It is the same as with a child, for instance, who has been instructed in arithmetic and has made an addition according to the rule prescribed; he may be sure of having found as regards the sum of figures given to him all that the human mind can know." 
the indubitableness, or the validity of ideas and propositions. ${ }^{27}$ Moreover, the origin and justification of interpreting things causally are to be sought for in reason; and the causal relation itself appears to be not only a necessary productive relation, but also a logical relation. ${ }^{28}$ Hence the extreme Rationalist tends to envisage reality as a chain or edifice of logically (demonstrably or deductively) related elements. ${ }^{29}$

Cartesian Rationalism however tended to regard as absolute or ultimate, instead of as a distinction within a unity, the opposition between mind and body, thus setting up a dualism between thinking substance and extended substance which seems ever to threaten with disruption what would otherwise be a formally unified world whole. ${ }^{30}$ This dualism appears to be the source of a great many problems which occupied the later seventeenth and the eighteenth centuries, for example, a host of epistemological problems arising out of the separation of subject and object, of psycho-physiological problems arising out of the assumption of the utter disparateness of the natures of mind and body, of logical problems arising out of the divorce of truth and reality, of ethical problems arising out of the divorce of meaning and existence, and the metaphysical problem of regaining the lost unity in reality.

The characteristics of seventeenth and eighteenth century Rationalism which need to be called to mind for the purpose of understanding the rise of Objective Idealism and of Contemporary Realism may be summed up under two headings, that of mechanistic tendencies and that of atomistic tendencies. The former include: (I) the mathematical ideal of knowledge, ${ }^{31}$ involving (2) the conception of knowledge as made up of elements which are passive, immutable, and complete (after the analogy of links

${ }^{27}$ Cf. ibid., pp. 7, 10, 104; Meditations (Open Court Ed.), pp. 4I, 47f., $77 \mathrm{f}$.

${ }^{28}$ See Meditations, p. 49: "It is manifest by the natural light . . . ." etc.

${ }^{20} \mathrm{Cf}$. footnote 23 , p. Io above, and Works, Vol. I, pp. I09, I2I : “demonstrating" and deducing effects from causes and "showing from what beginnings and in what fashion Nature must produce them," etc.

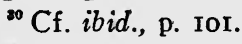

${ }^{31}$ Note Spinoza's attempt in his Ethics to imitate even the external form of mathematics. 
in a chain or building stones in an edifice), and (3) the idea that these elements of knowledge are related to each other in a somewhat mechanical one-two-three order which might be described as a relation of one-sided dependence; (4) the envisaging of reality as a whole as a chain or edifice of such mechanistically, albeit logically, related elements; and (5) the tendency to identify the self and reason with the thinking function of the self conceived somewhat mechanistically as a discursive and ratiocinative faculty which is chiefly engaged in analyzing, abstracting, predicating, and deducing. The atomistic tendencies of this Rationalism include: ( $\mathrm{I}$ ) the analyzing of all complexity into ultimate simple elements; (2) the notion that knowledge needs a solid foundation of one or more self-subsistent elemental particulars which can be known to be true apart from all other truths, and which will furnish a guarantee of the validity of the latter; (3) the recognition of truths but not truth; and (4) the absolute dualism of thinking substance and extended substance, giving rise to the almost complete severance of subject and object, mind and body, truth and reality, and meaning and existence.

(d) Those who may be taken as the foremost representatives of the Empiricistic movement of seventeenth and eighteenth century thought, Locke and Hume, agreed with the Rationalists in regarding mathematical truth as the ideal of knowledge. ${ }^{32}$ The Empiricists came to see however that the portion of truth which is intuitively or demonstratively certain is far smaller than the Rationalists had supposed. Locke held that there can be no science of bodies, much less of spirits $;^{33}$ while according to Hume not a single demonstrative science is absolutely to be depended upon. In Hume's words: "in all demonstrative sciences the rules are certain and infallible; but when we apply them, our fallible and uncertain faculties are very apt to depart from them, and fall into error ... By this means all knowledge degenerates into probability . . ." Moreover, according to Hume, were our faculties ever so reliable, we should be able to obtain intuitively and demonstrably certain knowledge only of the relationships of

${ }^{32}$ Cf. above, p. Io, footnote 22.

ss Essay, B. 4, Ch. 3, especially Sec. 26 and 27.

${ }^{34}$ Treatise, p. 180 . 
our own ideas, never of matters of fact. ${ }^{35}$ In short, the dogmatism of seventeenth century Rationalism gives way to the skepticism of eighteenth century Empiricism.

Like the Rationalists, too, the Empiricists tried to find among particular experiences a solid foundation for knowledge, an epistemological and logical prius. Employing his "historical plain method" of investigating the "ways whereby our understandings come to attain those notions of things we have," Locke concluded that there are no innate ideas or principles in the mind which can serve as a foundation of knowledge. The foundation is to be sought for, not in the rational or the universal, but in the particular immediate data of sense, introspection, and intuition, i. e., in atomic simple 'ideas' ${ }^{36}$ and in atomic perceptions of particular agreements and disagreements of ideas. For Hume the ultimate foundation consists of 'impressions of sensation'; even 'impressions of reflexion' are derivative, while all complex ideas can be resolved by analysis into simple ideas, which are but fainter copies of simple impressions and derived from them. ${ }^{37}$ Intuitions, according to Locke, yield an almost infinite number of truths, which are "all known by their native evidence, are wholly independent, receive no light, nor are capable of any proof one from another." ${ }^{38}$ Knowledge consists merely in "the perception of the agreement or disagreement of our particular ideas"; but for knowledge to be real, there must be "a conformity between our ideas and the reality of things." For "the mind knows not things immediately, but only by the intervention of the ideas it has of them." ${ }^{39}$ The attaining of truth is a process of accumulating self-complete units. Strictly there is not truth, but only truths. For the Lockean Empiricist the mind in perceiving is non-contributory, passive, and mechanically impressed by independently existing external objects. The activity of the mind as understanding is confined to a mechanical repeat-

${ }^{35}$ Enquiry, p. 23.

${ }^{3}$ Cf. Essay, B. 2, Ch. I, Sec. 2. "All our knowledge is founded" and "ultimately derives itself" from "experience," etc. Cf. also Berkeley, Principles of Human Knowledge (Open Court Ed.), p. 29.

${ }^{37}$ Cf. Treatise, pp. 212, I, 4, 7, 8; Enquiry, p. 16.

${ }^{38}$ Essay, B. 4, Ch. 7, Sec. Io. See p. I7 below, footnote 53, for Hume.

${ }^{39}$ Ibid., B. 4, Ch. 4, Sec. 3 ; Ch. I7, Sec. 8. 
ing, comparing, combining and separating of elements forced upon it. ${ }^{40}$ Reason's work is to exhibit a demonstrable or probable connection between ideas, the agreement or disagreement of which is not immediately discernible, by the discovery and interposition of intermediate ideas.

For Locke, universals are abstract and "universality is but accidental" to knowledge. General ideas are merely abstract ideas formed by a process of "leaving out something that is peculiar to each individual." Only particulars exist and can be the "immediate object of all our reasoning and knowledge." ${ }_{41}$ Berkeley takes a further step in the direction of the atomistic standpoint of Nominalism in his attempt to show "the impossibility of abstract ideas." ${ }^{2}$ In this attack on abstract ideas Berkeley provides a powerful weapon with which to assail Locke's notion of substance and thus bring empiricistic thought to a phenomenalistic and solipsistic standpoint. Berkeley himself concludes that there can be no material substance; that a thing is but a combination of sẹnsible qualities; that all qualities are secondary; that qualities are "nothing else but sensations or ideas, which exist only in a mind perceiving them"; and that "the existence of an idea consists in being perceived." Berkeley further contends that "bare observation" informs us that ideas are passive and inert, and that therefore "there can be no idea formed of a soul or spirit." ${ }_{43}$ For the same reason ideas are incapable of producing, altering, or causing anything; "there is nothing of power or agency in

${ }^{40}$ Cf. Essay, B. 4, Ch. 2, Sec. II and Ch. 17, Sec. 2, 3, 15; B. 2, Ch. I, Ser. 25 and Ch. 2, Sec. 2. Cf. Berkeley, Principles, p. 29. Berkeley's theory of knowledge is scarcely less 'mechanical' than Locke's, the main difference being that for Berkeley, since he has "shown that there is no corporeal or material substance," "the cause of ideas is an incorporeal active substance or Spirit" (p. 44).

${ }^{41}$ Ibid., B. 3, Ch. 3, Sec. 6-16; cf. Sec. 9, "leaving out something that is peculiar to each individual, and retaining so much of those particular complex ideas of several particular existences as they are found to agree in ;" cf. B. 4, Ch. 7, Sec. 9, and Ch. I7, Sec. 8.

${ }^{42}$ Principles, p. 23.

${ }^{43}$ Ibid., p. 44. But in the 2nd ed., Berkeley says that one can have a 'notion,' though not an 'idea' of a soul, spirit, operations of the mind, relations, etc., pp. 44,82 , I 16, I 18 . 
them" and no necessary connection between them. ${ }^{44}$ Berkeley thus furnishes Hume with the means of demolishing everything but the outer husk of reality, and also points the way to the destruction of all necessary relations between the atomic bits of that husk.

Hume accepted Berkeley's nominalistic conclusion that "all general ideas are nothing but particular ones, annexed to a certain term, which gives them a more extensive signification, and makes them recall upon occasion other individuals, which are similar to them." 4. It follows that ideas are but fainter copies of impressions, differing from impressions "in the degrees of force and liveliness with which they strike upon the mind." 46 From this supposed copy relationship between impressions and ideas, Hume derives his test of the validity of an idea, namely, the possibility of assigning any supposed idea to an impression from which it could have been derived. ${ }^{47}$ This test he applies to the ideas of material substance, spiritual substance, and necessary connections. He concludes that "the idea of a substance . . . is nothing but a collection of simple ideas, that are united by the imagination, and have a particular name assigned to them"; that "everything, which appears to the mind, is nothing but a perception, and is interrupted, and dependent on the mind"; and that "we never really advance a step beyond ourselves, nor can conceive any kind of existence, but those perceptions." 48 Moreover, we must not suppose that the mind or self has any internality, or anything of a permanent nature in it. It is "nothing but a bundle or collection of different perceptions," having "no simplicity in it at one time nor identity in different." 49

${ }^{44}$ Ibid., pp. 43, 46, 68; cf. p. 67 : "The connexion of ideas does not imply the relation of cause and effect, but only of a mark or sign with the thing signified." "Experience. . . teaches us that such and such ideas are attended with such and such other ideas," and we learn thus what "to expect from such and such actions. ..."

${ }^{45}$ Treatise, p. 17.

${ }^{46}$ Ibid., p. I. Perhaps this was also suggested to Hume by Berkeley. Cf. Principles, p. 46, "the ideas of Sense are more strong, lively, and distinct than those of the imagination."

${ }^{47}$ Enquiry, p. 19.

${ }^{48}$ Treatise, pp. 16, 193,67.

18 Ibid., pp. 252-3. "They are the successive perceptions only, that constitute the mind." Cf. pp. 207, 634 . 
Hume thus presents us with a phenomenalistic world of fleeting appearances, a world without internality and permanence, and, as we shall next see, a world largely without unity and continuity. For no necessary connections are discoverable among appearances: "all events seem entirely loose and separate . . conjoined, but never connected." "50 The only bond between events would seem to be the somewhat unstable principles of the association of ideas, a bond "not to be considered as an inseparable connexion." ${ }_{51}$ Everything appears what it is, and is what it appears. $^{.2}$ All perceptions are distinguishable, hence, different, "may exist separately, and have no need of any thing else to support their existence"; each, and every distinct part of each, is a "substance' in the sense of being "something that can exist by itself." "53 In short, Humian Empiricism culminates in an almost completely atomistic world view, in a phenomenalism and solipsism, and in a subjectivism and skepticism. "All knowledge degenerates into probability," Hume tells us, and "all probable reasoning is nothing but a species of sensation. 'Tis not solely in poetry and music, we must follow our taste and sentiment, but likewise in philosophy. When I am convinc'd of any principle, 'tis only an idea, which strikes more strongly upon me. When I give the preference to one set of arguments above another, I do nothing but decide from my feeling concerning the superiority of their influence." ${ }_{54}$

The features of seventeenth and eighteenth century Empiricism which it is desirable to recall in order better to understand the rise of Objective Idealism and Contemporary Realism may be summed up under the two captions employed above in the characterization of the Rationalism of the period, viz., mechanistic tendencies and atomistic tendencies. The mechanistic tendencies of Empiricism include: (I) the Empiricist's adherence to the Rationalist's mathematical ideal of knowledge; (2) the mechanicalphysiological theory of knowledge, involving (3) the conception of a mind which in knowing is non-contributory, largely passive,

\footnotetext{
${ }^{5}$ Enquiry, p. 76 ; cf. pp. 64, 72. Cf. Treatise, p. 635 .

${ }^{\circ 1}$ Treatise, pp. Iof.; Enquiry, p. $5 \mathrm{I}$.

${ }^{52}$ Treatise, p. 190. Cf. pp. 189, 194, 233.

${ }^{63}$ Ibid., pp. 233f., 222ff., 25If., 634.

${ }^{54}$ Ibid., pp. 103, I80; cf. pp. I4f., above.
} 
and mechanically impressed from without $;^{55}$ and (4) the mechanistic interpretation of an idea, of judgment, and of the work of the understanding and of reason. ${ }^{56}$ The atomistic tendencies of Empiricism include: (I) the analyzing of all complexity into ultimate simple elements; (2) the assumption of (I) that the part is prior to the whole and that the whole is merely a combination, aggregate, or sum-total of the parts; (3) the idea that knowledge must have a solid foundation in isolated, particular (perhaps fleeting), immediate experiences, which are self-existent and unalterable and are as they appear; (4) the conception of truth and knowledge as an aggregate of self-complete units, and the attaining of truth and knowledge as an adding of such units; (5) the sensationistic and associationistic interpretations of the nature of mind; (6) the nominalistic treatment of universals in the early thought of Berkeley, and in Hume; and (7) the phenomenalistic, subjectivistic, and skeptical issue of Hume's fundamental ăssumptions, such assumptions as: the infallibility of the immediacy of sense, the necessity of finding an impression capable of serving as the original of any given idea, and the capacity for self-existence of everything that is distinguishable.

(e) Contemporaneously with the application of this atomistic, mechanistic logic by Locke, Berkeley, and Hume to the problems of empirical psychology and epistemology, and through these to the problems of other philosophical disciplines, Newton and others were employing a somewhat similar logic in their investigations of external nature. Newton's point of view is that of the external observer and experimenter. ${ }^{57}$ In opposition to the mediaeval nature students, he urges all, in the spirit of the new science, to "abandon substantial forms and occult qualities and reduce nat-

${ }^{65} \mathrm{C} f$. the tabula rasa, empty receptacle, building, mirror, reflection, and other mechanical analogies of the mind which are associated with this conception.

${ }^{56} \mathrm{Cf}$. the passive imprint, reflection, picture, and other mechanical analogies of an idea. Also cf. Locke: truth signifies "nothing but the joining or separating of signs, as the things signified by them do agree or disagree with one another. The joining or separating of signs here meant, is what by another name we call proposition" (Essay, B. 4, Ch. 5, Sec. 2).

${ }^{57}$ Cf. Locke's "historical plain method" (Essay, B. I, Ch. I, Sec. 2) and Hume's "An attempt to introduce the experimental method of reasoning into moral subjects" (Treatise, title page). 
ural phenomena to mathematical laws." He counsels against the invention of "dreams, which contradict the evidence of experience," and even adds, "I do not allow myself to invent hypotheses." He gives physics "an express warning to beware of metaphysics." Yet, despite Newton's apparent intentions of maintaining himself on a phenomenalistic level of explanation, in terms of mathematical laws verifiable by observation, we find him departing so far from the phenomenal and relative as to champion an absolute space, time, and motion. ${ }^{58}$ "A mathematical abstraction is made into a true reality." The attempt to explain experienced nature by reducing all natural phenomena to mathematical laws involves the reduction of all qualitative distinctions to mere differences of quantity, and thus affords a parallel to Hume's reduction of all reality to one kind of stuff, impressions and their fainter copies. And just as everything in the one world happens in accordance with the laws of association, everything in the other world takes place in accordance with the law of gravitation; every phenomenon is merely the result of an alteration in the spatial position of immutable ultimate units, the alteration having been brought about by the action of some external force, or by the impact of one particle on another, in accordance with an inflexible mathematical formula. In either case, reality is compounded of largely homogeneous, uniformly acting parts, a multiplicity of externally or mechanically related existents, i. e., mental images, or motions, particles, and forces. ${ }^{59}$ In either case reality becomes dismembered, devitalized, and despiritualized. ${ }^{60}$

(f) It should now be noted that neither the Rationalists nor the Empiricists seem to have recognized the importance of the notions of the concrete universal and internal relation, two notions, which, as we shall see below, have been stressed by the

${ }^{58} \mathrm{Cf}$. the definitions of 'substance' and 'cause' offered by the Rationalists and Locke.

${ }^{59}$ This might be called the 'billiard ball' analogy of reality.

${ }^{60}$ Of course Newton also departed from his phenomenalistic maxims to the extent of attempting to prove the existence of a supernatural deity, but, as Hegel remarks, "God sinks to the level of a leisurely onlooker, surveying this play of forces," "the abstract infinity of an unknowable supreme Being in some other world far away," Logic (tr. by Wallace), pp. 250, 183. Cf. Falckenberg, History of Modern Philosophy, pp. I82f.; Höffding, History of Modern Philosophy, Vol. I, pp. $408 \mathrm{ff}$. 
Objective Idealists. On the contrary, the Rationalists and the Empiricists tended to envisage the universe as a medley of abstract universals and abstract particulars related to one another either deductively (by what may be called a relation of one-sided dependence) or entirely externally.

An explanation of this tendency may be sought for in the fact that the thought of both the Rationalists and the Empiricistsin spite of their opposition to the School-men-seems to have presupposed the ultimate validity of the three fundamental laws of the Aristotelian, formal or abstract, Logic. These principles are: (I) that each element of a thought process remain identical with itself throughout that process (A must be A) ; (2) that nothing be assigned two opposite predicates, i. e., that each element be distinct from every other element, or be self-existent (A cannot at the same time be A and not A); and (3) that there can be no middle ground between contradictories (A must be either A or not A). The first of these laws, when taken as final, excludes development and leads to a mechanistic interpretation of everything in terms of passivity and immutability or abstract identity. The second law excludes wholeness and leads to an atomistic interpretation of everything in terms of externally related and self-existent or abstract particulars. The third law excludes qualitative difference and degrees of worth and leads, like the first, to relatively undifferentiated identities.

Further light may be thrown upon this tendency of the Rationalists and the Empiricists to substitute for concrete reality a medley of one-sidedly or externally related abstract universals and abstract particulars, by reflecting upon the fact that the thought processes which these thinkers stress are those of analysis, abstract definition, deduction, generalization, and, in the case of the Empiricists, observation by an external spectator. Now these are just the processes which seem incapable by themselves of penetrating to the inwardness and meaning of reality: of grasping any object of study in its wholeness, of apprehending its unity and continuity, its development, its qualitative differences, its uniqueness, and its relative worth. On the contrary, these are the very processes which tend to fix all objects of study, to shatter their unity and continuity, to reduce all to the lowest common denominator of some class to which abstract definition has as- 
signed them, and to regard all as just 'facts' on the same plane of significance. In other words, these are the very processes, which, if taken as final, tend to universalize particulars, i. e., to yield a plurality of atomic absolutes, or tend to particularize universals, i. e., to yield one or more identities which are comparatively undifferentiated, and which are perhaps thought of as capable of existing apart from particulars or as not necessarily connected with particulars.

Taking the laws of Formal Logic as final and universally applicable, or employing solely these analytic and abstracting processes of thought, makes impossible the retention, and even, perhaps, the discovery of internal relations. Analysis resolves all complexity into a number of ultimate simples or atomic fragments. Attention is then confined to these particulars, in disregard of the relationships and wholes as members of which these particulars are alone revealed to us. The ultimate reals are regarded as somehow logically, if not temporally, prior to their relationships with other reals or their memberships in any wholes. Each atomic fragment is supposed to be self-existent and self-intelligible in complete isolation. It is exclusive of all other reals and independent of them and of all wholes. It has a self-identical, immutable nature which belongs to it in its own right, and which it retains, unaltered, in its relationships as in its isolation. The fragment thus ceases to be a fragment, as it were, and becomes an absolute. The particular is universalized. ${ }^{61}$

Next, the attention is shifted from these ultimate products of analysis to the universals, relations and wholes, which are now considered as something added externally to the 'given' particulars. Relations and wholes are treated as if they were things exclusive of, and perhaps severable from, the 'given' atomic entities, or as if they in no way conditioned or entered constitutively into particulars. A particular is thought of as not in the least modified

"Illustrations in point are Descartes's innate ideas and principles, and "truths clearly and distinctly perceived," and Locke's self-evident truths which are "wholly independent, receive no light, nor are capable of anv proof one from another" (Essay, B. 4, Ch. 7, Sec. Io). For "absolute" things and ideas, cf. ibid., B. 2, Ch. 25, Sec. 6, 10, and, for apparent exception, Sec. 2. Cf. Hume, "every perception" and "every distinct part of a perception," in fact, "every thing which is different" is a self-existent, atomic real (Treatise, pp. $244,233,222,207$ ). 
upon entering or leaving a relationship with other reals, or upon acquiring or losing membership in a whole. That is, its relations are a secondary factor added to its original self-contained and self-complete nature; whether they are relations to other reals or to a whole, they are alike accidental and unessential. ${ }^{62}$

This abstracting of relations from particular entities results in a particularizing of the universal. The universal seems to be put on the same plane with the particular, and to have a nature very much like that of the particular. Relations no longer seem to relate; hence, they seem to require other relations ad infinitum to connect them with the particulars. Wholes no longer appear to include their own parts; but seem to require, as it were, other wholes ad infinitum to include both them and their parts. In short, in this abstract Logic, both particular and universal have lost their specific natures; they seem to have been leveled to a third sort of being which is neither genuinely particular nor genuinely universal.

(g) Kant began the work of subjecting to a thorough-going criticism the methodological assumptions of the Rationalistic and Empiricistic tendencies of the period which he closed, and of constructing a new system of principles sufficiently comprehensive to include the seeming contradictions in a single coherent whole. ${ }^{\text {os }}$ The fuller meaning of this constructive criticism has found ex-

${ }^{a}$ Cf. Locke: "This further may be considered concerning relation, that though it be not contained in the real existence of things, but something extraneous and superinduced . . " (op. cit., B. 2, Ch. 25, Sec. 8). If either of two related things "be removed or cease to be, the relation ceases,. . . though the other receive no alteration at all; v.g., Caius, whom I consider to-day as a father, ceases to be so to-morrow only by the death of his son, without any alteration made in himself" (Sec. 5). "When I give Caius the name husband, I intimate some other person" (Sec. I). Cf. Berkeley, Principles, p. 82. Cf. Hume: "Now as every perception is distinguishable... and . . separately existent;... there is no absurdity in separating any particular perception from the mind; that is, in breaking off all its relations. . . The same continu'd and uninterrupted Being may, therefore, be sometimes present to the mind, and sometimes absent from it, without any real or essential change in the Being itsel $\mathbf{r}$ " (Treatise, p. 207).

${ }^{\text {s }}$ For the extent to which Kant succeeded in this task, see E. Caird, Critical Philosophy of Kant; also A. Seth, "Philosophy as Criticism of Categories," in Essays in Philosophical Criticism by A. Seth and R. B. Haldane. 
pression in the thought of Hegel and in the more recent Idealistic developments of the critical and speculative philosophies in England and America. ${ }^{64}$ The Idealistic criticism of the method of pre-Kantian philosophies will be considered first, and, then, the more important of the new constructive principles.

The keynote of the Idealistic criticism of the method of preKantian philosophies is apparently struck in Kant's first Critique. The difficulty with the Humian philosophy is, Kant tells us, that it renders impossible pure mathematics and physics; but, that these sciences "must be possible is proved by their reality." the Critique of Pure Reason, Kant seems reluctant to admit that the possibility of anything except these abstract sciences is proved by its reality. However, in the Critique of Practical Reason it turns out that the moral life, and in the Critique of Judgment the aesthetic life, must also be accepted as genuinely real, and that an attempt must be made also to discover the rationale of their possibility. Even in the first Critique Kant appears at times to have gone beyond a consideration of pure mathematics and physics to "a whole theory as to the nature of experience in general." ${ }^{86}$ Kant's method, the same in the three Critiques, is, in Seth's words: "an analysis of certain experiences with a view to determine the conditions of their possibility." ${ }^{67}$ This method involves a principle of criticism which may be stated as follows: any theory which, were it true, would render experience, knowledge, morality, and art impossible, must be regarded as inadequate, hence must be transcended. Kant's rejection of Hume's philosophy, referred to above, illustrates the application of this principle. Another illustration in point may be found in a relatively recent article by Watson on "The Idealism of Edward Caird." Watson says: "Thus the supposition of an 'experienced' world absolutely desti-

${ }^{a} \mathrm{Cf}$. works listed above, pp. $7 \mathrm{f}$.

${ }^{\circ}$ Critique of Pure Reason (tr. by Müller, 2nd ed.), p. 723. Cf. E. Albee, Phil. Rev., Vol. XVIII (1909), p. 302.

${ }^{68}$ For example, according to Andrew Seth, "his ultimate proof of the necessity of conceptions like substance and cause is simply that without them experience would be impossible. They are the most general principles on which we find a concatenated universe to depend." They "derive their necessity from their relation to experience as a whole," "not from any 'schematism' or 'table of judgments'” (A. Seth, op. cit., pp. 15f.).

or Ibid., p. 23. 
tute of order, or absolutely irrational, is one that cannot be entertained without self-contradiction; in other words, the irrationality of the universe is an hypothesis which, by making all experience impossible, makes itself impossible." ${ }^{88}$

In short, it would seem that the Idealist's most forceful criticism of the method of pre-Kantian philosophies lies precisely in showing that, were these abstract philosophies true, experience (knowledge, knower, morality, etc.) would have been impossible. Hence, the state of affairs which these philosophies describe could never have been known, and these philosophies themselves would never have been in existence. These philosophies must therefore be considered self-contradictory and self-refuting. Their very existence appears to be a sufficient proof that reality is more than they maintain. It becomes necessary to search for a more comprehensive and stable point of view than either that of the abstract identities and mechanistic connections of early Rationalism or that of the externally related aggregate of atomic existences of pre-Kantian Empiricism. ${ }^{69}$ For what is required as a condition of the possibility of even the minimum of experience? "At least the distinction of 'this' from 'that,' and such a distinction is impossible unless there is something identical in 'this' and 'that.' " 70 Of these two conditions, the method of pre-Kantian Rationalism, because it tends to lead to undifferentiated identities-owing largely, no doubt, to its undue dependence upon the abstract, discursive processes of the reflective understanding, fails to meet the first; hence it must be considered inadequate. The method of pre-Kantian Empiricism must be regarded as unsatisfactory, because, in so far as it tends to lead to an aggregate of selfexistent particulars as the result of undue reliance upon the process of analysis, it fails to meet the second condition.

Doubtless other lines of attack upon the method of pre-Kantian philosophies deserve more than the mere mention which alone, in consistency with our present purpose, can be given them here. Hegel and others have called attention to the host of irrationali-

"Phil. Rev., Vol. XVIII (1909), p. 272.

- Cf. Kant, Critique of Pure Reason, Transcendental Dialectic, for a criticism of Rationalism; cf. Hegel, Logic (tr. by Wallace), pp. 14, 58-109, I 27 ff., I39-46, 158f., 208-22, 356, 366-70.

${ }^{70}$ Watson, lac. cit. 
ties, absurdities, and insoluble puzzles which appear to be involved in the elaboration of the older method, e. g., the irrationality of the conceptions of an infinite regress or progress, a first cause or last effect, an ultimate simple, a logical prius, or an atomic absolute; the absurdity of a unity which unites nothing, or a relation which requires something to relate it to its terms; the problem of constructing a significant, orderly, developing world out of an aggregate of immutable, meaningless self-existents; or the problem of deriving concrete experience from undifferentiated static absolutes. Again, the older logic seemed to necessitate the acceptance of many experiences as enigmatic, self-existent facts, never to be understood because never seen in their functional relationships with other experiences and more inclusive wholes. It has further been pointed out that the older logic tended to render experience static, to fix it in abstract classifications, schema, and rigid laws, hence, to falsify reality to the extent to which it is changing and growing. ${ }^{71}$ Once more, the method of pre-Kantian philosophy tended to level up or level down, to reduce all things to an identical 'stuff' or to a lowest common denominator, and to interpret one level in terms of another. This tendency failed to do justice to the sui generis character of many types of experience, thus depriving them of their distinctive meaning. In other words, it seemed to explain these experiences away instead of explaining them, and seemed to substitute for concrete reality one or more lifeless abstractions. As was noted above, it has been made fairly apparent that the explanation of most of these defects of pre-Kantian logic is to be discovered in the undue extent to which it relies upon the laws of formal logic, the point of view of the external observer, and certain abstract thought-processes (such as analysis, generalization, and genusspecies definition) which are of such a nature as to prevent the grasping of an object in the continuity of its development, its uniqueness, its wholeness, and its meaning. ${ }^{72}$

This Idealistic criticism of pre-Kantian logic, then, seems to imply that whatever claims to superiority over previous methods

${ }^{1}$ This point is well developed in Bergson's Introduction to Metaphysics, but appears to be used there in support of an irrationalism rather than a higher rationalism.

${ }^{72}$ See pp. 2of., above and references to Hegel's Logic, p. 24 above. 
are advanced for the method of Objective Idealism must be based on its ability: (I) to render comprehensible the possibility and nature of experience, especially the varied expressions of the evaluative life; (2) to lead to fewer irrationalities, absurdities, contradictions, and insoluble puzzles; and (3) to discover and employ processes of thought which, while making use of the results yielded by the processes relied upon by the older method, are yet able to grasp reality in its wholeness, development, qualitative difference, and meaning. The more important of the constructive principles of the method of Objective Idealism, which, it would seem, have enabled it, to a degree, to establish certain such claims, will next be considered in the following order: (I) the conception of philosophy as a criticism of categories; (2) the standpoint of meaning; (3) the conception of truth as hypothetical; (4) synthesis and mediated immediacy; (5) the notions of organic unity or wholeness, concrete universal, and system of internal relations.

(I) Kant sums up his relation to his predecessors in the statement: "The critique of reason leads, therefore, necessarily, to true science, while its dogmatical use, without criticism, lands us in groundless assertions, to which others, equally specious, can always be opposed, that is, in scepticism." ${ }^{73}$ Thus, the critical philosophy came into existence as a "third and more excellent way, capable of leading us out of contradiction and doubt into a reasoned certainty." ${ }^{74}$ The fact that Kant held from first to last that the possibility of pure mathematics and physics at least, "is proved by their reality," ${ }^{75}$ shows that the critical philosophy does not set out from any initial doubt concerning the validity of all knowledge. Nevertheless, it must be admitted that Kant often conceives of the critical method as starting with an epistemological enquiry into the trustworthiness of mental faculties or with an attempt to determine the source, extent, and limits of human knowledge. ${ }^{76}$ Kant's indecision on this point may be attributed to his failure to carry out with sufficient thoroughness his own idea of philosophy as a criticism of assumptions, standpoints, and

${ }^{78}$ Critique of Pure Reason, p. 725.

${ }^{74}$ A. Seth, Essays in Philosophical Criticism, p. 9.

${ }^{75}$ Op. cit., p. 724 .

${ }^{76}$ Cf. ibid., pp. xxiii, 715, If. Cf. A. Seth, op. cit., pp. 9, 36. 
conceptions. As Seth remarks, "Kant unfortunately left the most fundamental conception of all uncriticised. He dogmatically assumed the conception of the mind as acted upon by something external to it . . . Hence it comes (in spite of the inferior position to which Kant explicitly relegates empirical psychology) that the 'Critique of Pure Reason' sets out from a psychological standpoint and never fairly gets beyond it." 77

The speculative philosophy, however, seems to have definitely set aside "as antiquated lumber" whatever remnants of the epistemological and psychological standpoints had been taken up into the critical philosophy unmodified. ${ }^{8}$ With reference to the philosophy which "tells us first of all to examine the faculty of cognition and see whether it is equal to" the effort of inquiring "into the true being of things," Hegel says: "The examination of knowledge can only be carried out by an act of knowledge. To examine this so-called instrument is the same thing as to know it. But to seek to know before we know is as absurd as the wise resolution of Scholasticus, not to venture into the water until he had learned to swim." "79 Accordingly, what was undertaken by the speculative movement "was the direct adventure of knowing; of shaping a view of the universe which would include and express reality in its completeness." 80 In this adventure of knowing, the Kantian criticism became a principle "which exhibits and removes the limitations and defects of the earlier experience by the discovery of a deeper and more comprehensive principle of intelligibility." ${ }^{81}$ As a criticism of categories, it may be added,

"Ibid., p. II. Seth shows that this "initial psychological dualism" is the source of a number of other Kantian doctrines to which later Idealism would take exception, e.g., the absolute separation of matter and form, $a$ priori and a posteriori, etc., and the doctrine that the understanding gives laws to nature.

${ }^{78}$ B. Bosanquet, Phil. Rev., Vol. XXVI (1917), p. 8. Cf. J. E. Creighton, op. cit., pp. $5 \mathrm{I} 8,522$.

${ }^{70} \mathrm{Op}$. cil., p. I7.

${ }^{80}$ B. Bosanquet, op. cit., p. 8.

${ }^{81}$ J. E. Creighton, op. cit., p. 530. Cf. A. Seth, op. cit., pp. 37-9, "On the largest scale the advance of knowledge is neither more nor less than a progressive criticism of its own conceptions." Kant's principle of the necessary correlativity of subject and object makes possible this identification of philosophy or the determination of reality with the criticism of 
philosophy has apparently succeeded to no small extent in marshalling all categories into a single system of internal relations, in exhibiting the nature of, and the necessary connections between, the various members of this system, in rendering comprehensible the natural stages of growth from lesser to greater organization and completeness within the system, and in synthesizing all the categories in the single notion of the concrete universal. In philosophy, therefore, thought has been enabled to become to a high degree self-conscious, keenly aware of its own nature, of the powers and limitations of its several moments, and of the presuppositions and implications of its various standpoints and methods.

(2) Philosophy as a criticism of categories, and a speculative adventure of "shaping a view of the universe which would include and express reality in its completeness," has found it necessary to rise above the pre-Kantian standpoint of 'existence' and to adopt at the outset the more inclusive and concrete standpoint of 'meaning.' The method which selects as its starting point bare existence abstracted from significance seemed to be unable to find any pathway to the realm of meaning. The meaning of things tends to be lost sight of amid the supposed innumerable discrete elements of reality and the endless series of causes and effects, as also in the presence of the blank continuity of undifferentiated substance, and even when reality is envisaged as a chain of propositions, or a hierarchy of abstract generalizations and formulas. Or, if not completely lost sight of, meaning tends to be explained away in terms of other particular existents, as for example, associational accompaniments. Again, the single, concrete, significant act of knowing may be split up into a psychical

the categories of experience. Cf. J. E. Creighton, op. cit., pp. 53If., "For these undertakings, though distinguishable, are part and parcel of the same task, and must be carried on together. Since the categories are principles of objective mind, mind in actual commerce with reality, they can be discovered and defined only through their actual employment in the concrete process of knowing. And on the other hand, since reality is in its very nature knowable in terms of mind, that is, in terms of some universal principles, determination of the real necessarily involves the question of the categories and of their systematic relationships." 
'process' and a logical 'reference,' and meaning identified with the latter, i. e., with a quality of a particular process or a static relation to something wholly external to the process. Values, from this standpoint, appear to be merely subjective, merely another set of facts; perhaps the fact that something is desired, is emotionally reacted to in a certain way, or has become a social habit.

In opposition to such a method, Objective Idealism does not abstract from significance and does not divorce meaning and existence. It assumes the unity of existence and value. It assumes that nothing exists which does not play a part in a significant whole and which does not ultimately contribute to the most inclusive of significant wholes, reality. Nothing therefore merely 'is' or possesses meaningless existence, but everything performs a specific, and, to a degree, a unique function, and thereby sustains and enhances the meaning of the whole. The point of departure of this Idealism is concrete experience, "the process of reflective experience taken as a whole." It seeks not among particular experiences for a logical and metaphysical prius. It does not try to show, after the manner of pre-Kantians, how reality may be deduced from an abstraction, or how it may be made out of an aggregate of hypothetical meaningless existents. For it, value belongs to things themselves and is not imposed upon the universe by the subjective mind. The source and standard of value and truth is to be found in concrete reality as a coherent significant whole. It follows that anything is what it shows itself to be, not as 'given' at any particular moment, but "in the whole course of experience," "in its full context," when thought together with everything else, or at its "maximum." 82

(3) Since, because of our finiteness, we can never experience anything as it is, i. e., under ideal conditions, we are forced beyond the solid foundation and demonstrational logic to a hypothetical, developmental, organic logic. All experiences are seen to be selected, organized, and evaluated by an active, contributing, (finite) knower; hence all experiences are, to a degree, abstractions, assumptions, interpretations, relative to the subject's

${ }^{82}$ Cf. B. Bosanquet, The Principle of Individuality and Value, pp. 4I-54; Logic, Vol. II, Ch. 9; Phil. Rev., Vol. XXVI (1917), p. 9; H. Joachim, The Nature of Truth, Ch. 3. Cf. Hegel, op. cit., p. 19. 
powers, purposes, past experience, and methods of coming into contact with them. ${ }^{83}$ There is no presuppositionless, point-ofview-less, or otherwise unconditioned knowledge. It follows that there is no absolutely certain truth, and no absolutely complete truth, for finite beings. It is impossible to find one or more isolated particular experiences capable of serving as a solid foundation for the rest of knowledge. ${ }^{84}$ Truth is not best defined as a quality of isolated experiences, or as a relation of a mental process or a proposition to something external; but as meaning, understanding (in the broad sense), or comprehension. Since every experience involves these, and yet is conditioned, no experience is completely false or completely true. Each experience is to a degree both true and false. No characteristic which an experience possesses in isolation, or in its first appearance (i. e., as given or as immediate) can be taken as a reliable index of the degree of truth which should be assigned to it. Nor does the source of an experience or the channel through which it comes afford such an index. ${ }^{85}$ Nothing short of the whole is true in its own right. No finite experience carries in isolation a guarantee of its worth. When brought into relation with other experiences, a given experience may be assigned a degree of truth in proportion as it is coherent (internally and with the rest of experience), inclusive, conceivable, intelligible, determinate, stable, and selfcontained; and in proportion as it is itself capable of being a significant whole or is capable of entering contributively into a significant whole as a confirming and enriching member. It follows that experiences become facts in proportion as they reveal their capacity of becoming contributing members of a whole of meaning, of sustaining the system as a whole, and of throwing light on other members. Similarly, hypotheses become laws and axioms, and theories become true interpretations and explanations, in proportion as they comprehend experiences, reveal rational relations between them, make intelligible their

\footnotetext{
${ }^{83}$ Involved in Kant's interpretation of the mind as a "synthetic unity of apperception," and in T. H. Green's "spiritual principle in knowledge."

st E.g., 'innate ideas,' 'axioms,' 'eternal verities,' 'self-evidents,' 'pure immediacy,' 'hard data,' 'brute facts,' 'indemonstrables,' 'indefinables,' 'inexplicables,' etc.
}

${ }^{85}$ E.g., sense, intuition, feeling, introspection, intellect, etc. 
possibility and nature, and organize them into coherent wholes of meaning. The attaining of truth or knowledge thus comes to be regarded as an activity, as an expansion from within, as a growth from more restricted, incoherent, and obscure, to more comprehensive, coherent, and illuminated wholes of meaning. Every more concrete (i. e., comprehensive and determinate) whole or level reached includes, but also transforms or reinterprets, the old and lower. Any whole or level attainable by finite beings falls short of perfect understanding or truth, hence, is to a certain extent tentative and provisional, subject to supplementation and reinterpretation. "All necessity is hypothetical or relative and simply expresses the dependence of one thing upon another. No truth is necessary except in relation to certain conditions, which being fulfilled, the truth always holds good. . . . There is no abstract opposition, therefore, between the necessary and the contingent, such as Kant presents us with; the difference is not one of kind but of degree." 86 One is forced to hold, therefore, in direct contrast to what seemed to the pre-Kantians to be involved in their mathematical ideal of knowledge, that such degree of finality and fixity as is attainable at all must be looked for at the end rather than at the beginning of investigation. ${ }^{87}$

(4) Before knowledge could rise to this developmental, organic standpoint of meaning, it was necessary for it to break through the restrictions imposed upon it by the formal 'laws of thought' (the laws of Identity, Contradiction, and Excluded Middle) and by the abstract moments of reason (analysis, generalization, abstract definition, ratiocination) upon which the older logic so

${ }^{88}$ A. Seth, op. cit., pp. I4-15. The necessity in implication and inference is of the character "this or nothing," and is the expression of the connectedness of a systematic coherent whole (B. Bosanquet, Implication and Linear Inference, $C h . I)$. The necessity of the 'Laws of Thought' is to be sought for in the fact that they are universally confirmed and presupposed. "The 'evidence' for them is anywhere and everywhere, but not contained within themselves" ( $\mathrm{H}$. Joachim, Immediate Experience and Mediation, p. 18). 'Axioms' are "stable, not because they, as judgments, hang together of themselves, but because they are but the concentrated expression of a whole of knowledge" (ibid., p. 19).

${ }^{87}$ For this topic, see, in addition to the works mentioned in footnote above, B. Bosanquet, Logic, Vol. II, Ch. 9 and p. 303; H. Joachim, The Nature of Truth, especially Ch. $3 ;$ F. H. Bradley, Appearance and Reality, Ch. 24. 
largely relied. Knowledge is seen to be a self-transcending movement, at once self-differentiating and self-organizing, a growth toward wholeness, concreteness or perfection, containing the mainspring of activity within itself. ${ }^{88}$ Every unit of knowledge appears as an active, developing meaning, making a necessary contribution to the meaning of the whole. A does not remain A. On the contrary, it seems to be its very nature to pass over into its opposite, B, to which it is necessarily related. Although A is distinct and opposed to $B$, it is nevertheless inseparable from $B$, and $B$ from it, since each can be distinguished only within an identity which includes the other. A, therefore, appears to be not necessarily either A or Not-A, but essentially both $A$ and Not-A. In other words, the Laws of Formal Logic appear to have only relative validity. But to grasp A and Not-A in these developmental and organic connections would seem to require the functioning of other processes of thought than the processes of abstraction which pre-Kantian philosophies made the basis of their procedure. It seemed necessary then to regard these processes of abstraction (analysis, predication, subsumption, abstract definition, generalization, ratiocination, etc.) which, because taken by themselves, led pre-Kantians to various types of irrationalities, absurdities, and inadequacies, as indispensable, to be sure, but as only subordinate and preparatory to the more comprehensive moments of synthesis and concretion. Perhaps it does not greatly matter whether this highest stage of mediated immediacy be called interpretation, appreciation, self-consciousness, reason, or spirit, so long as one understands by this stage of thought at least a comprehension of anything in its development, uniqueness, and wholeness, and as meaning; as well as, of course, in its analytic make-up, in its genus-species, inductive, deductive, and quantitative relationships, and as existence.

(5) When experience is approached in this concrete way, it presents itself as an organic unity or organic whole. ${ }^{89} \mathrm{By}$ an

${ }^{88}$ Cf. E. Caird, Hegel, Ch. 7, 8. This of course rules out as final the mechanistic and atomistic interpretations and analogies of the pre-Kantians. Cf. references to Hegel's Logic, p. 24 above.

${ }^{89} \mathrm{On}$ the employment of this notion by Kant in the Critique of Judgment, see A. Seth, op. cit., p. 3I, and by Hegel and Caird, see Watson, op. cit., pp. I59f. Cf. "the category of cause breaks down when applied to the 
organic whole we are to understand a whole which is something more than the sum-total of its parts, and which is necessary to and makes a difference to the parts. The parts of such a whole are interdependent, are parts only through the whole, and can be understood only through the whole, which determines them. But it is also true that the parts make a difference to and are necessary to the whole. A change in any part effects the other parts and the whole..$^{90}$ The whole can be understood only through its parts, and without the latter it is indistinguishable from nothingness. Hence neither a part nor the whole can be separated from the other except by an abstraction. Neither is prior; the concrete reality is a whole of parts. ${ }^{91}$ The whole is in every part, revealing as much of "all it has in it to be" as is possible under the restricted set of conditions which constitute any given part. Since each such set of conditions is unique, the revelation of the whole in each part is unique. These various differentiations, or unique expressions of the whole, are relevant and complementary to one another, vary intelligibly with reference to one another, and sustain and reinforce one another and the whole.

A notion which perhaps covers the meaning of the expression, 'organic unity' or 'organic whole,' without carrying with it the

organism, for all the parts are mutually cause and effect; and the organism as a whole is at once its own cause and its own effect (causa sui). It organizes itself" (A. Seth, loc. cit.).

${ }^{\circ}$ Cf. B. Bosanquet, Implication and Linear Inference, pp. 7-9. "Alter the value of any combination, and some correlatives, and ultimately the whole system, must be altered. If $I$ is 5,2 is Io. All is relevant to all. There is something in each which runs through every point in the system, and makes each of them, though apparently unique and peculiar, respond to every other, and vary, though in its own individual manner, yet correspondingly to the variations of other points or traits. Complexes, in so far as they present this character, are true 'wholes' or 'universals.' You can tell from the modification in which one feature of them is given in what modification another feature, though quite dissimilar in character, must be given at the same time. The essence of its nature lies, to repeat it in a sentence, in being a system with different features or properties, such that without being at all similar or repetitious of each other they present variations connected by law, and therefore the variation of one is an index to the variation of others."

${ }^{01}$ Cf. Kant, op. cit., p. 704, "the whole being there for the sake of every part and every part for the sake of the whole." 
misleading quantitative (and, possibly, to some minds, biological) connotations of the latter ${ }^{92}$ is the notion of the concrete universal. ${ }^{93}$ The expression 'concrete universal' is intended to signify that the organic unity or whole is a one in many, a universal in particulars, a unity in variety, an identity in difference. In Watson's words: "the minimum of experience involves at least the distinction of 'this' and 'that,' and such a distinction is impossible unless there is something identical in 'this' and 'that." "94 "Objects can be recognized as real, only if, and so far as, they have that unity in difference, that permanence in change, that intelligible individuality, which are the essential characteristics of mind." "Particulars involve universals, just as universals involve particulars. Neither is 'prior' to the other, logically or really. . . . no change occurs in the world which does not occur as an instance of the universal and necessary connection of every element in the whole. . . . the character of experience is such that every element is connected with every other, and therefore . . . we are forced to treat any given element as having no existence except in relation to the whole." 95

${ }^{02}$ Cf. A. Seth, loc. cit.

${ }^{93}$ We find Hegel criticizing "the thought that never gets further" than "the universality of ideas," "the stage of formalism," "mere generality," "the genus, or kind," a universal which is "a mere sum of features common to several things, confronted by a particular which enjoys an existence of its own," the universal or general principle which is "indeterminate and vague, and therefore not on its own account connected with the particulars or the detalls," so that "either is external and accidental to the other," and each of the particular facts to others. He adds: "when the universal is made a mere form and co-ordinated with the particular, it sinks into a particular itself. Even common sense in everyday matters is above the absurdity of setting a universal beside the particulars" (Logic, pp. I5, 21, 23, 292).

${ }^{94}$ Cf. J. E. Creighton, Phil. Rev., Vol. XXVI, p. 532, "speculative idealism must interpret the mind and reality in terms of the concrete universal. For the individual alone is real:" "Its logic and ideal of truth must be that of the concrete universal; so much is determined by the very form of experience" (p. 529). "A rational view of experience is committed to the doctrine of identity in difference" (p. 536).

${ }^{25} \mathrm{Op}$. cit., pp. I59ff., 264, 272ff. Cf. "The Rationalism, or Rationalistic. Idealism, of Edward Caird certainly does not 'tend to emphasize universals and to make wholes prior to parts," "as did perhaps the pre-Critical Rationalism of Wolff and of Spinoza, or the post-Kantian idealisms such as that 
The term 'individuality' has also been used to bring out the idea that the organic unity or concrete universal is a selforganizing, self-differentiating whole of less inclusive wholes. ${ }^{96}$ To meet the conditions of intelligibility, reality must be a whole which maintains its unity by being ever in the act of differentiating itself into an inexhaustible variety of stuffs, structures, and functions, and into lesser wholes of varying degrees of completeness, which are partially independent of the whole, and each of which has its own peculiar significance to contribute to the meaning of the whole. Thus reality must be conceived of as comprehending an inexhaustible wealth of content, nicety of determination, and splendor of contrast, i. e., antitheses which seem at first irreconcilable, but which subsequently turn out to be inherently capable of entering into a synthesis, and even absolutely essential to the existence of each other and the whole. It would seem that the unity of reality can be maintained only through the incessant tension of these seeming contradictions, hence, through incessant change, and only through constant striving, as it were, of everything incomplete to be like the complete whole, hence, through incessant growth and progress; and it would appear that the conceptions of growth, progress, and freedom ultimately have meaning only with reference to such a whole as a source, standard, and guarantor. ${ }^{97}$

Other Objective Idealists seek to express the idea conveyed by the terms Organic Unity, Concrete Universal, and Individuality, by characterizing reality as a 'system of internal relations.' 98

of Schelling. "It does not start from the 'universal' and proceed to determine the particular by it. . . . To isolate the 'universal,' giving it an independent position, is to destroy it; for the 'universal' has no reality except as the order or system or unity of the particulars; to isolate the 'particular,' on the other hand, is to give it an apparent independence which destroys its connection with other particulars and with the whole," and thus "removes the very foundation without which there can be no system of experience whatever."

${ }^{*}$ Cf. Hegel, op. cit., pp. 29Iff., and Bosanquet, The Principle of Individuality and Value, Ch. 2, especially pp. 40, 68.

${ }^{\pi}$ Cf. ibid, pp. 69, 96f., 36I-70, and E. Caird, Hegel, pp. 127ff., I79ff., I92ff. Note that this rules out as final 'monisms of stuff,' such as Berkeleyanism and Panpsychism; see above, p. 8.

${ }^{98}$ Thus, according to Green (Prolegomena to Ethics, p. 33), any statement of the simplest facts involves the fact of "relation," which, in turn, 
In such a system relationships are organic, essential, and constitutive. Relations are always within a whole. The part cannot be, or be what it is, without the whole; and the whole cannot be, or, be what it is, without the parts. Each derives its meaning only from its relationships to the other. The whole is something more than the sum-total of its parts, but it could not be the something more without its parts. That is, there can be no abstract whole, and no transcendent particularized whole, any more than there can be a whole which is a mere collection of universalized particulars.99 A whole or a universal, abstracted from its parts or particulars, becomes indistinguishable from nothingness. But it is just as true that a part or particular, abstracted from the whole or universal, becomes indistinguishable from nothingness. A unity or a relation with nothing to unite or relate is a selfcontradiction. But so is any real or term (short of the whole) which is not a member of a unity or relation. ${ }^{100}$ A real or term is nothing apart from its relationships to other parts and its memberships in various wholes. ${ }^{101}$ It is just these relationships and memberships which give it meaning, or which enter into and constitute its nature. Its nature is altered whenever it enters or leaves a relationship or whole. So intimately bound up with each other are the parts of a system of internal relations that whatever change occurs in any part necessitates a corresponding change

involves "the existence of many in one" or "an affirmation of the unity of the manifold."

${ }^{90}$ Cf. Green (loc. cit.), "single things are nothing except as determined by relations which are the negation of their singleness, but they do not therefore cease to be single things. Their common being is not something into which their several existences disappear. On the contrary, if they did not survive in their singleness, there could be no relation between themnothing but a blank featureless identity. There must, then, be something other than the manifold things themselves, which combines them without effacing their severalty."

${ }^{100}$ E.g., an 'ultimate simple' or 'atomic absolute' or a 'solid foundation.'

${ }^{101}$ Bosanquet prefers to characterize relations as 'relevant' rather than 'internal,' meaning that relations "are connected with the properties of their terms, so that any alteration of relations involves an alteration of properties, and vice versa" (Logic, Vol. II, p. 277). See footnote 90, p. 33 above. 
in every other part. "All is relevant to all." 102 Each is a necessary support and complement of all the others. Each in its own peculiar way sustains and enriches the whole. The whole is variously in each. No isolated processes or changes can take place just as no isolated parts can sustain themselves. There can be no accidents, bare conjunctions, absolute dualisms, or isolations. ${ }^{103}$ Finally, it should be noted that for the Idealistic Logic of Internal Relations, not only is the whole of reality such a system of necessary, organic, constitutive relations, but so also (to a degree) are all less inclusive wholes, such as logical, ethical, aesthetic, and social wholes, the self, the mind, the body, a solar system, or even a series of numbers.

${ }^{102} \mathrm{Cf}$. Green (loc. cit.), "abstract the many relations from the one thing, and there is nothing. They, being many, determine or constitute its definite unity. It is not the case that it first exists in its unity, and then is brought into various relations. Without the relations it would not exist at all. In like manner the one relation is a unity of the many things. They, in their manifold being, make the one relation. If these relations really exist, there is a real unity of the manifold, a real multiplicity of that which is one. But a plurality of things cannot of themselves unite in one relation, nor can a single thing of itself bring itself into a multitude of relations."

${ }^{108}$ E.g., with regard to the nature of the special relationship of subject and object, cf. J. E. Creighton (op. cit., pp. 522f.), "Instead, that is, of assuming that there is an entity called mind, and another entity having no organic relation to mind called nature, it [historical speculative idealism] assumes on the basis of experience that these realities are not sundered and opposed, but are in very being and essence related and complementary. The relation or rather system of relations that constitute the bond between what we call mind and that which is termed nature it takes not as external and accidental, as if each of these could be real outside of this system, but rather as internal, essential and constitutive. We can think of a mind apart from an objective order only through an abstraction: to be a mind at all it is necessary to be in active commerce with a world which is more than an order of ideas. . . . the external order that we call nature is something that is at least knowable by mind. That seems to be the very least that experience can assume and still remain experience. . . . It seems, then, permissible to say that 'knowability' is a genuine characteristic of things, not an accident external to them. If it is the nature of the mind to know, it is also the nature of things to be known, and we accordingly seem entitled to assert that the order that we call nature is not fully complete apart from this relation. . . . The relation to mind is a constituent moment of things, not something added on from the outside." (Cf. E. Albee, op. cit., p. 304). 


\section{CHAPTER II}

\section{THE REALISTIC CRITICISM OF IDEALISM}

\section{English Philosophy at the Appearance of Realism}

$\mathrm{T}$ HE Idealism of the post-Kantian Romanticists became known to the English speaking world through the efforts of Coleridge and Carlyle. ${ }^{1}$ In 1865 appeared the first book on Hegelian Idealism, James Hutchison Stirling's The Secret of Hegel. ${ }^{2}$ Although Stirling was not uninfluenced by the Romanticists, the significance of the movement he initiated lay in the contention that the truth of Hegelian Idealism could be had merely by developing the principles of Kant without passing through the stages of thought represented by Fichte and Schelling. With the development of Objective Idealism by T. H. Green and Edward Ciard, there was still stronger insistence that the true interpretation of Kant is Hegel and that the logical foundation of the speculative philosophy is to be found in Kant. Stirling, Green, and Edward Caird were soon joined by an able group of thinkers, including Andrew Seth, in his earlier thought, Lord Haldane, John Caird, William Wallace, F. H. Bradley, and Bernard Bosanquet. At the time of the appearance of the new Realism, the united efforts of these men and of those with similar convictions had made Objective Idealism an important factor in the development of English thought. ${ }^{3}$

Yet within the ranks of the Idealists themselves, in a broad sense of the term Idealistic, a number of revolts against the specu-

${ }^{1}$ Cf. James Seth, English Philosophers and Schools of Philosophy, pp. 319-23; J. Watson, Phil. Rev., Vol. XVIII, "The Idealism of Edward Caird," Article I.

'For Stirling's influence, see J. Seth, op. cit., pp. $342 \mathrm{f}$.

- For writings of Green, E. Caird, Bradley, and Bosanquet, see above, pp. $7 \mathrm{f}$., footnotes. Cf. also: J. Caird, Introduction to the Philosophy of Religion (1880); A. Seth, From Kant to Hegel (1882); A. Seth and R. B. Haldane, Essays in Philosophical Criticism (1883); W. Wallace, Kant (1882), The Logic of Hiegel (tr. 1892), Philosophy of Mind (tr. 1894), Prolegomena to the Study of Hegel's Philosophy (1894). 
lative philosophy had come into evidence. ${ }^{*}$ Moreover, the influence of evolutionism was of course still strong; while the point of view of traditional English empiricism was represented by so able a thinker as Shadworth Hodgson. ${ }^{5}$ Even the older Idealism was not without a certain influence, ${ }^{6}$ and the older common-sense Realism was still alive. ${ }^{7}$ Finally, the voice of the Pragmatic reaction against Idealism was just beginning to make itself heard as a demand that more emphasis be put upon man's life of activity, volition, feeling, and sense, and on his rôle as a free, creative, moral personality.

Of these anti-idealistic reactions, J. Seth remarks: "The common feature of these reactions, over and above their common hostility to idealism, is an effort to approximate philosophy to science. They all alike are mainly concerned with questions of the theory of knowledge, of logic or methodology, rather than with properly metaphysical questions; and in all of these alike we may see the effect, somewhat paralysing, of the great scientific movement of the latter half of the nineteenth century upon the philosophic mind of the English-speaking race." 8

\section{The Realistic Criticism of Idealism}

Among the anti-idealistic reactions the new Realism soon distinguished itself by the vigor of its protest against Idealism, and at times, apparently, against almost all philosophical achievement in the past. It was noted above that as early as I895 Robert Adamson had expressed his conviction that the future course of philosophy must be "from idealism to realism, from rationalism to empiricism and naturalism," because, as he thinks, Fdealism does not keep close enough to experience, particularly to the facts of science. ${ }^{9}$ In 1899, G. E. Moore announced, in

4Cf. A. Seth, Scottish Philosophy (I885), Hegelianism and Personality (1887), Man's Place in the Cosmos (1897); G. H. Howison, The Limits of Evolution (IgOI) ; cf. also protests by R. B. Haldane, J. Ward, H. Sidgwick, G. T. Ladd, and Wm. James. (See J. Seth, op. cit., p. 360.)

${ }^{\circ}$ Cf. ibid., pp. 237, 305ff., 36r.

- Cf. ibid., pp. 332ff., on Ferrier and others.

${ }^{7}$ Cf. ibid., pp. 239, 308-17, on Martineau and others.

- Ibid., p. 359.

'Cf. "Inaugural Address in the University of Glasgow" (I895), Development of Modern Philosophy, Vol. II, pp. gff. Adamson was previously 
an article published in Mind, that his theory "renounces the supposed unity of conception guaranteed by Idealism even in the Kantian form, and still more the boasted reduction of all differences to the harmony of 'Absolute Spirit,' which marks the Hegelian development." ${ }^{10}$ In a paper read before the Aristotelian Society in I90I, Moore says: "It appears to me that if what I shall say be true, most of those theories about the nature of the world, which are of the most general interest and which attract the most disciples for the various schools of philosophy, must be either false or purely chimerical . . For my own part I am convinced that the characteristic doctrines of most philosophers, no less where they agree than where they differ, are chiefly due to their failure to trace the consequences of admitted principles." 11 Again, in his article entitled "The Refutation of Idealism," in Mind (1903), Moore says: "The only importance I can claim for the subject I shall investigate is that it seems to me to be a matter upon which not Idealists only, but all philosophers and psychologists also, have been in error, and from their erroneous view of which they have inferred (validly or invalidly) their most striking and interesting conclusions. And that it has even this importance I cannot hope to prove. If it has this importance, it will indeed follow that all the most striking results of philosophy-Sensationalism, Agnosticism and Idealism alike-have, for all that has hitherto been urged in their favour, no more foundation than the supposition that a chimera lives in the moon. It will follow that, unless new reasons never urged hitherto can be found, all the most important philosophic doctrines have as little claim to assent as the most superstitious beliefs of the lowest savages." ${ }^{12}$

a "convinced adherent of idealism;" cf. J. Seth, op. cit., p. 36r. Cf. Russell, Problems, p. 227 ; Scientific Method, especially Ch. I; Mysticism and Logic, pp. Igf., 85, 96, 99; Alexander, Basis of Realism, pp. 4, 29.

${ }^{10}$ N. S., Vol. 8, p. 183.

${ }^{11}$ Proc. Arist. Soc., Vol. I, p. 103.

${ }^{12}$ N. S., Vol. 12, pp. 435 f.; cf. p. 453 . Broad does not think that this article refutes Idealism, and he does not suppose that Moore now thinks so. But, according to Broad, the work that really matters which has been done on the subject of "The External World" in the last few years, starts in England with this article of Moore's. The article pointed out, Broad says, the scandalously ambiguous way in which the term 'sensation' had been 
It is evident from the passages just cited that Moore's quarrel is at times not merely with Idealists but with "all philosophers and psychologists." Bertrand Russell, in his recent writings, appears to go even further, and to impeach the intellectual honesty, as well as the logic, of most philosophers. For example, we read in his Scientific Method in Philosophy that not only "the problems and the method of philosophy have, I believe, been misconceived by all schools"; but also "in philosophy, hitherto, ethical neutrality has been seldom sought and hardly ever achieved. Men have remembered their wishes, and have judged philosophies in relation to their wishes." 13 "The desire to know philosophical truth is very rare-in its purity, it is not often found even among philosophers." 14 In his Mysticism and Logic, Russell offers a psychological explanation of the origin of what he calls the "mystical logic," i. e., "an elaborate logic beginning with Parmenides, and culminating in Hegel and his followers." Russell says: "Belief in a reality quite different from what appears to the senses arises with irresistible force in certain moods, which are the source of most mysticism, and of most metaphysics. . . .

"The logic of mysticism shows, as is natural, the defects which are inherent in anything malicious. The impulse to logic, not felt while the mystic mood is dominant, reasserts itself as the mood fades, but with a desire to retain the vanishing insight, or at least to prove that it was insight, and that what seems

used; and led to the distinction between sensation (an act of direct acquaintance) and sensum (Mind, N. S., Vol. 30, I921, p. 388). Russell, apparently as the result of this influence of American Pragmatists and Realists (see The Analysis of Mind, p. I43), has recently repudiated his former adherence to the distinction. The 'subject' ('self,' 'soul,' 'ego; etc.) must be dispensed with as a "perfectly gratuitous assumption." "But when we do this, the possibility of distinguishing the sensation from the sense-datum vanishes. ... . The mental act "seems unnecessary and fictitious," and "mythical." But since the sensation may still be regarded as physical and non-cognitive, the distinction of sensation (as act) and sensum is not essential to the refutation of Idealism (ibid., pp. 17-22, 141-3, 192, 195).

${ }^{18}$ Pp. 3, 27-8.

"Ibid., p. 237. 
to contradict it is illusion. ${ }^{15}$ The logic which thus arises is not quite disinterested or candid, and is inspired by a certain hatred of the daily world to which it is to be applied. ... If our logic is to find the common world intelligible, it must not be hostile, but must be inspired by a genuine acceptance such as is not usually to be found among metaphysicians." 16

The point which these passages should make plain is that Moore and Russell appear to regard the work of philosophy in the past, particularly Idealistic philososphy, as possessing little worth because of: (I) a defective logical method; and (2), Russell would add, a lack of the amount of the disinterestedness requisite to yield scientific results. The Realistic criticisms of Idealism will be considered in the order in which they are set forth just below, with a view to determine whether they are valid criticisms of the Objective Idealism characterized above. For if it should turn out that they are valid criticisms of certain types of Idealism but not of the type such as that which we have characterized as Objective Idealism, it will be evident that the critical or negative phase of Realism is scarcely as complete as some of its exponents appear to suppose. ${ }^{17}$ The Realist contends, apparently: (I) that Idealism does not keep close enough to experience, daily life, and science; (2) that the Idealistic principle of transformative degrees of reality is inconsistent with the preservation of the identity or individuality of that which is transformed; (3) that Idealism fails to distinguish between the mental act and the object, starts with the premiss that esse

${ }^{15}$ Hence, "most philosophers" have been "less anxious to understand the world of science and daily life than to convict it of unreality in the interests of a supersensible 'real' world," have been rendered incapable of giving an account of that world, have failed to discover "the errors of their logic," and have accepted complacently doctrines inconsistent with "all the common and scientific facts which seem best established."

${ }^{18}$ Mysticism and Logic, pp. 19-20. Cf. The Analysis of Mind, p. 21, "No doubt they [Idealists] are prompted to this view [that in knowledge we are in direct contact with objects] in the first place by bias, namely, by the desire to think that they know of the existence of a world outside themselves." The alternative view is "a dreary view, and they therefore seek ways of escaping from it." Cf. p. 262.

${ }^{17}$ Cf. Moore's "Refutation of Idealism" (Mind, N. S., Vol. 12) ; and Russell's "refutation of the monistic theory," Essays, p. I60. Cf. footnote I2, p. 40 above. 
is percipi, holds that reality is mental or psychical throughout, holds that finite minds manufacture truth, values, universals, and the categories, and sets out from an epistemological inquiry; (4) that the standpoint of Idealism is that of the Aristotelian formal logic or that of eighteenth century rationalism; (5) that the Idealistic theory of truth leads to an abstract monism, cannot explain in what sense one judgment is said to be true and another false, when both are equally partial, and is compelled to appeal to a notion of truth which it cannot consistently admit; (6) that the axiom of internal relations leads to a denial of relations and of diversity, hence to an abstract monism; (7) that wholes and universals as conceived by the Idealist are undifferentiated; (8) that Idealists have not been sufficiently disinterested.

(I) In view of the fact that the speculative philosophy has so of ten insisted that its point of departure is experience, and that its standpoint throughout is that of experience, it may appear strange that Idealism is charged with a failure to maintain contact with experience, with daily life, and with science. ${ }^{18}$ It will be seen, however, that this is a natural criticism for one to make who proceeds on the assumption that the prima facie appearances of reality can be taken as solid and final, in isolation from other experiences and from the results of reflection, and that no earlier stage of thought is to be modified by subsequent stages. Realism, as will be shown in more detail below, accepts this 'solid foundation' logic, and rejects the theory that every advance in the direction of complete truth includes and transforms all previous stages. ${ }^{19}$ The Realist thinks of complete truth as consisting of the crude facts or hard data with which investigation begins, supplemented by other facts and by the results of inference, regarded as outside of the facts which formed the starting point and as leaving the latter unmodified. Consequently, the discrepancy between the Idealist's final account of reality and reality as it appears on some lower stage seems to the Realist to afford sufficient justification for accusing the Idealist of getting away from the facts (wilfully, or as the result of a defective method

\footnotetext{
${ }^{18}$ See above, pp. 23f., 29, 32-8. Cf. also Bosanquet's Logic, 2 vol. ed., as essentially an elucidation of the meaning of the sciences and his "Gifford Lectures" as essentially an elucidation of the meaning of life.

${ }^{19}$ See pp. 90-100 below.
} 
or of erroneous reasoning) and of substituting for the world of experience some "supersensible real world." It is to be observed, however, that, whatever may be said of other philosophies, it is of the very essence of Objective Idealism always to maintain contact with immediate experiences, and with the mediating experiences of science. The prima facie appearances of reality, the so-called facts, as well as scientific results, are not ultimate as given, yet they are nevertheless indispensable to complete truth. Every stage of experience entitled to be called more complete must include them, but it must also transform or re-interpret them by making more explicit and intelligible their natures, functions, relations, and respective significance. ${ }^{20}$ Thus the degree of transformation which initial experiences undergo is not arbitrary, but is determined by the capacity of such re-interpretation to illuminate experiences which were before relatively empty and isolated, that is, to reveal their unique significance and to bring them into intelligible connections within a coherent whole of meaning.

(2) The Realist's objections to the principle of transformation seem to be based upon the assumption that anything has a certain individuality or nature, which no relationship with other things and no memberships in more comprehensive wholes have had any part in constituting, and which is not altered by new relationships or participations in new wholes. But this is tantamount to presupposing the finality of the Laws of Formal Logic, or that A has a distinct, self-existent nature, which is fixed or eternally self-identical, so that A cannot be both what it was at any given time and also something other than what it was without losing its individuality or identity. ${ }^{21}$ Must we

${ }^{2}$ Cf. Hegel (op. cit., p. I6), "The relation of speculative science to the other sciences may be stated in the following terms. It does not in the least neglect the empirical facts contained in the several sciences, but recognizes and adopts them: it appreciates and applies towards its own structure the universal element in these sciences, their laws and classifications: but besides all this, into the categories of science it introduces, and gives currency to, other categories, . . . Speculative Logic contains all previous Logic and Metaphysics; it preserves the same forms of thought, the same laws and objects,--while at the same time remodelling and expanding them with wider categories."

${ }^{21}$ See quotation from Russell's Principles of Mathematics (pp. 448f.), p. I4I below. Russell here refers to Moore's "Nature of Judgment," Mind, N. S., Vol. 8. Cf. Alexander, Basis of Realism, pp. 2f., 33f., "in 
not then conclude that it is the fetters imposed by taking as final the Laws of Formal Logic (and perhaps also the results of mere ar:alysis) which prevent the Realist from recognizing that identity and individuality do not necessarily exclude difference and change, hence, that the principle of transformation is not incompatible with the preservation of identity or individuality? It is to be observed that the Idealist is so far from holding that transformation destroys the identity or individuality of that which is transformed that he seems rather to maintain the exact opposite. $\mathrm{He}$ contends that a term preserves its identity only through difference, change, growth, and that individuality accrues to anything just in proportion as it enters into relations with other things and becomes a member of larger wholes, which elicit its potentialities, mould it, and impart to it a new significance.

(3) The Realist seems to suppose that Idealism fails to distinguish between the mental act and the object experienced, hence sets out from the proposition that esse is percipi or percipere and concludes that reality is mental or psychical throughout. Thus Moore, in his article entitled "The Refutation of Idealism," says: "that wherever you can truly predicate esse you can truly predicate percipi, in some sense or other, is, I take it, a necessary step in all arguments, properly to be called Idealistic, and, what is more, in all arguments hitherto offered for the Idealistic conclusion. If esse is percipi, this is at once equivalent to saying that whatever is is experienced; and this, again, is equivalent, in a sense, to saying that whatever is is something mental . . I I believe that every argument ever used to show that reality is spiritual has inferred this (validly or invalidly) from 'esse is percipere' as one of its premisses; and that this again has never been pretended to be proved except by use of the premiss that esse is

order to prove that entrance into the whole transforms the part, it must be shown that the relation is one which destroys the individuality of that which enters into the relation. But experience seems to show that at any rate not all relations have this consequence." Cf. Space, Time, and Deity, Vol. I, pp. 249-57, 345-7; II, pp. 369-71. In so far as Alexander recognizes that in some instances transformation occurs, or that in all instances some qualities and relations of a thing are altered by new relationships while others are not, his position affords a kind of compromise between the old logic and the new. 
percipi." ${ }^{22}$ Now, first, it is to be observed that this criticism assumes that Idealism starts with a 'premiss,' i. e., from a 'solid foundation,' and 'deduces' the rest of its conclusions from this initial dogma or datum. In other words it fails to recognize that Objective Idealism has gone beyond the 'solid foundation' and 'demonstrational' logic to the hypothetical, organic logic. ${ }^{23}$ In the second place, this criticism fails to distinguish between the standpoint of existence and that of meaning, and does not take account of the fact that Objective Idealism has gone beyond the former to the latter. In the third place, it should be recalled that Objective Idealists themselves, beginning with Kant's "Refutation of Idealism," have criticized the 'mentalism' or 'psychism' which assumes that mind can know only itself or what is in itself, and that "all reality must be reduced to a single form or mode of existence." ${ }^{24}$ As opposed to these psychological idealisms which maintain themselves on the level of existence (whether as an aggregate of particular conscious states and minds or as a single undifferentiated absolute 'stuff'), Objective Idealism has adopted-not as an initial dogma or datum, but as a tentative outcome of an arduous process of experimental thought-the standpoint of meaning or the concrete universal. This standpoint involves the recognition of a genuine externality, an 'other' which is not reducible to self or mind, although organically related to the more inclusive differentiation, mind, within a single, coherent significant whole. For Objective Idealism this Significant Whole is the source of truth, value, the categories and universals, which are therefore all objective and not manufactured and imposed upon a reluctant 'other' by the finite mind. From what has been said above, it hardly needs to be added that Objective Idealism contends that mind and externality are inseparable and in imme-

${ }_{22}$ Mind, N. S., Vol. 12, pp. 436ff. Cf. Russell, Analysis of Mind, "Those who maintain that mind is the reality and matter an evil dream are called "idealists" (p. Io). "Speaking quite roughly and approximately, we may say that idealism tends to suppress the object. . . Idealism . . . says that nothing can be known except thoughts, and all the reality that we know is mental. . . ." Russell adds however that "modern idealism" maintains "that in knowledge we are in direct contact with objects, which may be, and usually are, outside our own minds" (pp. 19-2I).

${ }^{23}$ See above pp. $29 \mathrm{ff}$.

${ }^{24}$ See p. 8 above. 
diate contact with one another from the first, so that Objective Idealism cannot be fairly charged with setting out from an epistemological instead of a logical or metaphysical enquiry. ${ }^{25}$

(4) The Realist sometimes seems to assume that the Idealistic logic is scarcely distinguishable from Aristotelian formal logic or from the logic of eighteenth century Rationalism. As was pointed out above, Moore assumes that Idealism deduces its conclusions from premisses, such as esse is percipi. Idealists, he believes, hold this doctrine because they think that it is "an analytic truth in this restricted sense that it is proved by the law of contradiction alone." 26 Russell also takes it for granted that the Idealist holds that a deductive relation obtains between the various facts or objects in reality. He says, for example: "if we knew ourselves, according to this doctrine, we should know everything"; "from any one portion the whole can be inferred"; "any one truth is logically inferable from any other." 27 Again, he says: "Hegel believed that, by means of a priori reasoning, it could be shown that the world must have various important and interesting characteristics"; "the most important respect in which Hegel uncritically assumes the traditional logic" is his belief "that all propositions are of the subject-predicate form." 28

But the Objective Idealist, as we have seen, has given up the 'solid foundation' and 'demonstrational' logic for the hypothetical, organic logic; he holds that every differentiation of reality is to

${ }^{25}$ See pp. 8, 26-32 above. Cf. J. E. Creighton, Phil. Rev., Vol. XXVI, p. 522: "This historical speculative idealism, as occupying the standpoint of experience, has never separated the mind from the external order of nature. It knows no egocentric predicament, because it recognizes no ego 'alone with its states,' standing apart from the order of nature and from a society of other minds. It thus dismisses as unmeaning those problems which are sometimes called 'epistemological,' as to how the mind as such can know reality as such. Without any epistemological grace before meat it falls to work to philosophize, assuming, naively, if you please, that the mind by its very nature is already in touch with reality."

${ }^{28}$ Mind, N. S., Vol. 12, p. 441.

${ }^{27}$ Scientific Method, p. 9; Analysis of Mind, pp. 20, 267f. E.g., "the fact that Caesar conquered Gaul, if adequately considered, would enable us to discover what the weather will be to-morrow."

${ }^{28}$ Scientific Method, pp. 3, 8, 19, 38f., 45. Cf. Analysis of Mind, p. 268, "The attempt to deduce the world of pure thought is attractive. . . ."; "the world is constructed by means of logic. . . ." 
some degree unique and that this unique aspect of anything cannot be reached by processes of inference. He holds too that truths are at once analytic and synthetic, and that the criterion of truth is not the law of contradiction by itself, but various complementary characteristics of the whole. ${ }^{29}$ How the Objective Idealist regards a priori philosophizing may be gathered from the following statement made by Bosanquet: "Does it enable us to think all the facts together?' was what speculation now began to ask about any thesis suggested to it. It is constantly accused of a priori philosophizing. But in fact for such a method the characteristic meanings of a priori and its opposite are destroyed. These are $a$ priori in proportion as the whole before you makes them inevitable and in no other sense." ${ }^{30}$ The distinction of a priori and its opposite (e. g., empirical) becomes a distinction of degree. Furthermore, the Idealist can hardly be said to reduce all judgments to subject-predicate form in the sense of regarding all judgments as predicating some adjective or quality of the finite reality referred to by the grammatical subject. What his standpoint involves is that all judgments refer to or affirm something of reality. "The essence of Judgment," Bosanquet says, "is the reference of an ideal content to Reality." ${ }^{11}$ Russell's criticisms of this position all seem to miscarry because of wrong assumptions as to what Idealism holds. For example, when he says that the "monistic theory holds that every relational proposition $a R b$ is to be resolved into a proposition concerning the whole which $a$ and $b$ compose-a proposition which we may denote by $(a b) r$," it is plain that he is taking the subject to be not Reality but a whole which is a mere sum of formal subject and predicate. ${ }^{32}$ Again we find him assuming that the subject for Idealism is a whole which is exclusive of its parts, as when he says: "Hence when we say ' $a$ is part of $b$ ' we really mean, if the monistic theory be correct, to assert something of the whole composed of $a$ and $b$, which is not to be confounded with $b$." ${ }^{33}$ Sometimes he is criticizing the position that "the only true whole, the Absolute, has no parts at

See p. 30 above.

so Phil. Rev., Vol. XXVI, p. 9. Cf. Implication and Linear Inference, pp. 5, I2ff., 19, 29, 60, 71, 94, 127, 146ff., 160.

${ }^{31}$ Cf. Bosanquet, Logic, Vol. II, pp. I, 344, and Vol. I, pp. 3-16.

2 Principles, pp. $224 \mathrm{ff}$., cf. pp. $448 \mathrm{f}$.

s Ibid., pp. 225, cf. pp. 222ff., Essays, pp. 152ff. 
all," a position which Objective Idealism, of course, does not take. ${ }^{34}$ Moreover, Russell's criticisms seem to take for granted the ultimate validity of the laws of formal logic, fail to distinguish between a judgment and its external or propositional form, assume that Idealism must have a 'logical prius,' and confuse the reference of the ideal content of a judgment to Reality with the reference of a formal predicate to Reality.

(5) The Realist has set forth the following objections to the monistic theory of truth: "(I) If no partial truth is quite true, this must apply to the partial truths which embody the monistic philosophy. But if these are not quite true, any deductions we may make from them may depend upon their false aspect rather than their true one, and may therefore be erroneous. (2) It is a consequence of the monistic theory that the parts of a whole are not really its parts. Hence there can not be any genuine whole on this theory, since nothing can be really a whole unless it really has parts. (3) The theory is unable to explain in what sense one partial judgment is said to be true and another false, though both are equally partial. (4) In order to prove that there can be only one coherent whole, the theory is compelled to appeal to 'experience,' which must consist in knowing particular truths, and thus requires a notion of truth that the monistic theory cannot admit." ${ }^{35}$ Now, it would seem that the first of these objections, if it is an objection to any theory, is an objection to all, and does not apply in any special sense to Idealism. Does the Realist contend that he or any one else has attained to the complete truth about anything, i. e., the fullest and most determinate meaning that anything can have under any conditions; that he sees it in exactly the same light, comprehends it exactly as he would, if he were omniscient? And if he does not, there is the same element of risk involved in deducing from his theories as from the Idealistic philosophy. We suspect indeed, though it is hardly conceivable, that the Realist at times does claim to have, of certain data of immediacy, the same kind of complete and infallible experience which one who is omniscient would have. ${ }^{38}$ Either such a claim or absolute skepticism would appear to be the neces-

It Ibid., p. 226.

Essays, pp. $159 f$.

* See pp. 92-8 below. 
sary consequence of his theory of external relations, and his consequent rejection of the principle of transformation. But whatever are the claims made by the Realist, it is certain that the Objective Idealist maintains that because of the limitations imposed by our finiteness, complete truth (i. e., the fullest and most determinate meaning attainable under any conditions) is for us unattainable. Hence, every theory, including Idealism, is merely more or less true. Idealism is believed to be truer than rival theories because it seems to exhibit to a greater degree the characteristics of completeness or wholeness; namely, inclusiveness, coherence, conceivability, stability, ability to illuminate, to reveal intelligible connections, to organize, to assign each differentiation a distinctive meaning, etc. It is to be observed that such a theory cannot be identified with a skepticism, or with a theory that truth is completely unknowable, unless the Whole is taken as an end term in a series exclusive of the events leading up to it. For Objective Idealism, however, the whole is inclusive of and variously present in each differentiation. Still less can this theory be made to mean what Russell attempts to deduce from it when he says: "Thus we, so far as we are real, do really know all truth; but only idealists know that they know all truth." ${ }^{37}$

According to the second objection, it is a consequence of the Idealistic contention, viz., that all theories including Idealism are merely more or less true, that "the parts of a whole are not really its parts." It is, however, hardly permissible to infer from the assertion that Reality "is a whole of parts all of which are not quite real," the assertion that Reality "is not quite really a whole of parts," and from this again the conclusion that "the parts of a whole are not really its parts." ${ }^{38}$ In short, Russell seems continually to tend to slip back from the level of degrees of truth and reality, i. e., the level of meaning, on which the Idealist is reasoning, and on which Russell's own argument appears to start, to the level of existence or, perhaps in Russell's terminology, being. On this latter level anything is either quite real (i. e., 'is') or totally not real (i. e., 'is not'), so that whatever is 'not quite real' is not real at all; and every proposition is either wholly true or wholly false, truth being (I) correspondence with a supposed

${ }^{27}$ Essays, p. 153.

${ }^{88}$ Ibid., pp. 153f., 160. 
'given' or with external 'fact,' or (2) a quality which attaches to a proposition in complete isolation. ${ }^{39}$ An inference which is just as little permissible as the one that has just been considered is the following, which is put forward in connection with this same objection: "If it is not quite true that $\mathrm{W}$ has parts, it cannot be quite true that $\mathrm{W}$ is a whole. In short, the diversity which modern monism tries to synthesize with identity vanishes, leaving reality wholly without structure or complexity of any kind." 40 The Idealist may admit that "it cannot be quite true that $\mathrm{W}$ is a whole," in the sense that no finite being can grasp the complete meaning of the statement ' $W$ is a whole.' But from this the irference drawn in the passage just cited does not seem to follow. One further inference should be mentioned. Russell says: "In a 'significant whole,' each part, since it involves the whole and every other part, is just as complex as the whole . . Since, moreover, the whole is constitutive of the nature of each part, just as much as each part is of the whole, we may say that the whole is a part of each part. In these circumstances it becomes perfectly arbitrary to say that $a$ is a part of $\mathrm{W}$ rather than that $\mathrm{W}$ is a part of $a \ldots$ the distinction of whole and part evaporates, and with it the entire notion of a 'significant whole." "41 However, from the facts that part and part, and part and whole are mutually indispensable and constitutive, it does not follow that part and whole are equally complex and may be identified. Russell's error here seems to consist in conceiving of the whole as if it were merely a part exactly like one of its own parts and in identifying the whole-part relationship with the part-part relationship. Moreover, even granting equal complexity in whole and part, the two could still be distinguished by differences in stability, concreteness, and in ability to explain and organize.

With reference to the objection that Idealism cannot explain in what sense one partial judgment is said to be true and another

${ }^{39}$ See pp. 7If., 92f. below, for Russell's recent more or less thoroughgoing repudiation of (2) in Analysis of Mind; and see Space, Time, and Deity, Vol. II, p. 252, for Alexander's recent repudiation of (I) in favor of a 'coherence' theory.

${ }^{\infty}$ Ibid., pp. 153f.

"Loc. cit. 
false, though both are equally ${ }^{42}$ partial, attention is called to the various characteristics of wholeness mentioned above, ${ }^{43}$ such as stability, conceivability, and ability to explain. These characteristics may be used as mutually complementary and supplementary criteria of truth, and would seem to be sufficient to determine the relative degree of truth to be assigned different partial truths. One of these, coherence, the Realist recognizes; but he holds that this criterion either presupposes another, which Idealism cannot consistently admit, or involves a vicious circle. It seems to the Realist, who takes as final the 'solid foundation' and 'demonstrational' logic, that a proposition that is pronounced true because it satisfies the criterion of coherence, is so pronounced because it is consistent with some other proposition which is known to be true. But the latter must have been known to be true in some other way or else because it is consistent with a third proposition known to be true. The same alternatives present themselves in the case of this third and in the case of every subsequent proposition considered, until either a solid foundation is reached, say in a self-evident proposition, or a proposition already considered is encountered a second time. To encounter a proposition a second time is to become involved in a vicious circle. Now, in a sense, the Idealist can admit a circle, i. e., in a whole of truth each member must sustain or reenforce every other member. But, he must add, a mutual confirmation of parts is so far from deserving the epithet vicious that it may be regarded as a good criterion of the truth of the system. The circle which the Idealist, of course, cannot admit, and which alone is vicious, is a circle of relatively isolated propositions (i. e., propositions that do not mutually imply one another within a significant whole), which, though externally related, are nevertheless supposed to be connected in such a way that one may be deduced or inferred from another. According to the Idealist, inference can take place only within a significant whole, and the notion of coherence leads to a vicious circle only when it is inadequately interpreted, interpreted to mean for instance a deductive relation between selfexistent propositions.

${ }^{42}$ Assuming this to be possible; if not possible, the test of inclusiveness can also be employed.

${ }^{43}$ See p. 30 above. 
The Realist's final objection to the Idealistic theory of truth seems to be that there can be more than one perfectly coherent system of propositions and that only an appeal to something external to these systems, as for instance 'particular experiences,' can decide which one is a description of the real world, and can prove that there can be only one coherent whole. ${ }^{44}$ It would seem, however, that reference to other characteristics of Truth, such as inclusiveness, ${ }^{45}$ would enable one to estimate the relative validity of two systems of judgments each of which possessed, apparently, a like degree of coherence. Experience, experimentation, and mediation are all of course employed in the process of determining just what whole is the most inclusive, stable, coherent, etc.; but the true judgment or system is true, not because it is given immediately or mediately, for the false is also 'given,' but because and in so far as it satisfies the conditions of wholeness. Any appeal to a mere 'given,' whether datum or dogma, regarded as expressing infallible truth in its own right apart from reference to anything else or to any system, and capable of deciding between rival systems and of guaranteeing the truth of all else, must be considered an arbitrary and irrational procedure. Furthermore, it can hardly be said that the Idealist appeals to particular truths of experience in order to prove that there can be only one coherent whole. Rather, he attempts to show that the affirmation of this meets the requirements of truth mentioned above, while its denial involves one in unintelligibilities, such as the conceptions of contingency and bare conjunction,' and ultimately renders all rationality and experience impossible.

(6) The Realists attack the "axiom of internal relations," which is regarded as "the fundamental assumption of the whole monistic theory." After criticizing the Idealistic theory of truth, Russell says concerning this axiom: "if we can show that this doctrine is groundless and untenable, we shall thereby complete the refutation of the monistic theory." It would seem, however, that Russell's argument is based upon a very one-sided interpretation of the doctrine in question. According to Russell, this doctrine "may be expressed thus: 'Every relation is

${ }^{*}$ Cf. Russell, Essays, p. 160; Analysis of Mind, p. 268.

${ }^{4}$ See above p. 30. 
grounded in the natures of the related terms.' Let us call this the axiom of internal relations. If this axiom holds, the fact that two objects have a certain relation implies complexity in each of the two objects, i. e., it implies something in the 'natures' of the two objects, in virtue of which they have the relation in question." 46 But this, it is to be observed, is at best only a part of the meaning of the theory. ${ }^{47}$ It is just as true to say that the theory means that the natures of the related terms are constituted by their relations. ${ }^{48}$ Russell's inadequate interpretation leads him to make a number of assumptions and inferences as to the meaning of the theory which appear to be distinctly erroneous. For example, he says: "According to the opposite view, which is the one that I advocate, there are such facts as that one object has a certain relation to another, and such facts cannot in general be reduced to, or inferred from, a fact about the one object only together with a fact about the other object only." 49 The Objective Idealist, however, does not contend that facts about the relations of objects can be inferred from facts about their natures. ${ }^{50}$ Neither does he maintain, as Russell seems to imply, that from a complete knowledge of the nature of one object a knowledge of the nature of other objects and of the nature of the universe as a whole can be inferred. ${ }^{51}$ For such a conception is based upon two assumptions which Objective Idealism cannot admit, namely, (I) that the nature of one object can be completely known without a complete knowledge of all other objects and reality as a whole, and (2) that the unique can be inferred. Again, the Objective Idealist does not reduce relations to qualities, adjectives, or predicates of the related terms; nor does he reduce every proposition to a subject-predicate form, in any sense other than to regard the whole judgment as referring an

${ }^{46}$ Essays, pp. I6of.

47 "At best," it is said, because, if Russell's statement implies that an object may have a nature prior to any relations or contains a complexity of mutually external elements, this "axiom" can hardly be called even a part of the meaning of the theory of internal relations.

${ }^{48}$ See above, pp. $35 \mathrm{ff}$.

4Dssays, p. 161.

${ }^{50}$ Bosanquet, Logic, Vol. II, pp. $277 \mathrm{ff}$.

${ }^{11}$ Essay's, pp. 161, 165. 
ideal content to reality. ${ }^{52}$ Russell's arguments, designed to show that the theory of internal relations is untenable because it leads to the position that there are no relations, no diversity, only one thing and one proposition, i. e., because it leads to a rigid monism and is incompatible with the conception of identity in difference, all seem to be based upon such misunderstandings of the Idealistic position as those just considered. Indeed, one is forced to conclude that all the Realistic attacks upon the theory of internal relations miscarry, because based upon misconceptions of the meaning of that theory or the meaning of Objective Idealism.

(7) The Realist appears at times to suppose that when the Idealist characterizes reality as a Unity or Whole, he is conceiving of reality as an undifferentiated unity or whole. For example, Alexander writes of "the two opposed systems of absolutism, for which only the complete is real, and of pluralism, which allows to the parts a relative but independent reality." "For Idealism there is only one self-existent, the whole. Realism inquires whether the finites do not retain their self-existence, though that self-existence be relative. Can even the whole be self-existent independently of its parts? And if it can, what has become of the parts?" 53 Similarly, Moore speaks of the "concrete" or "self-differentiating" "universal" as a powerful "instrument for persuading to the denial of numerical difference between individuals." ${ }_{54}$ Again, according to Russell, "the admission of many terms destroys monism." ${ }_{55}$ "It is a consequence of the monistic theory that the parts of a whole are not really its parts. Hence there cannot be any genuine whole on this theory, since nothing can be really a whole unless it really has parts." "In short, the diversity which modern monism tries to synthesise with identity vanishes, leaving reality wholly without structure or complexity of any kind." It is contended further that "if the axiom of internal relations is true, it follows that there is no diversity"; that "there are no relations and that there are not many things, but only one thing," "and only one proposition."

${ }^{52}$ Cf. ibid., pp. 163ff., Principles, pp. 22Iff., 445ff.; Bosanquet, Logic, Vol. II, pp. I, 279, 314, Vol. I, pp. 3-16.

Alexander, Basis of Realism, pp. 3, 33.

${ }^{54}$ Proc. Arist. Soc., Vol. I, p. 125.

${ }^{*}$ Principles, p. 44. 
"In short, the whole conception of 'identity in difference' is incompatible with the axiom of internal relations." 56

As was pointed out above, ${ }^{57}$ Russell's attempts to show that the Idealist's theories of truth and relations lead to an undifferentiated whole are based on misconceptions and faulty inferences; and after the exposition of the fundamental principles of Objective Idealism such as that of the concrete universal, offered at the end of Chapter I above, it hardly needs to be said that any attempt to identify Objective Idealism with an abstract monism is based upon a misunderstanding. Indeed, the Objective Idealists themselves have repeatedly criticized the standpoint of abstract monism. Owing perhaps to his assumption that the laws of formal logic, the products of analysis, and the standpoint of existence must be regarded as ultimate, the Realist seems unable to give any important or precise meaning to the notions of organic unity, concrete universal, and individual. ${ }^{58} \mathrm{He}$ is therefore inclined to classify philosophies into two kinds only, as Alexander does in the passage just cited: monists or absolutists and pluralists. Thus by a false disjunction, he rules out Objective Idealism at the start.

(8) In view of the fact that Kant and Hegel and their followers have repeatedly criticized philosophies which regard mystical or irrational experiences as ultimate, and have emphasized the employment of reason, the hard labor of the notion, and the arduousness of the task of 'possessing reality,' it would hardly seem that Objective Idealists can be fairly charged with lack of disinterestedness. ${ }^{59}$ The criticism of the Realists can perhaps be explained as follows. Objective Idealists and Realists alike oppose the faith philosophies that take refuge in an unmediated immediacy of feeling. Both pass on, as far as emotions and wishes are concerned, ${ }^{60}$ to the stage of mediation or of the reflective understanding. On this second stage, that of scientific observation and intellectualism, on which it is next to impossible

${ }^{56}$ Essays, pp. ${ }^{154-68 .}$

${ }^{67}$ See pp. 49 ff.

${ }^{68}$ See quotations, Ch. III, Sec. 3 below.

${ }^{59} \mathrm{Cf}$. Bosanquet, The Principle of Individuality and Value, Ch. I.

${ }^{\infty}$ For possible exceptions in the case of the Realists, see below, pp. 92, 98. Realism apparently clings to the infallibility of the immediacy of sense and insight, though perhaps again with exceptions. 
not to be hostile to all feeling (because one has not yet risen to a point of view from which the unity of the two stages may be discerned), Realism appears to stop; while Objective Idealism moves on to a third stage of mediated immediacy which is a synthesis of the other two stages. Not understanding this third stage, apparently, Realists make the mistake of supposing that the Objective Idealist is still on the first stage of uncriticized immediacy, and consequently class him with the faith and feeling philosophies and other enemies of reason.

That Realism stops on the second stage, that of scientific observation and ratiocination, may be inferred from Russell's continual demand that philosophy become scientific. The point of view of science and philosophy, it is implied, should be that of the impartial outsider. Of such an external spectator, science and philosophy demand an impersonal disinterestedness, a receptivity or submission to fact. The "whole subjective apparatus" of hopes, loves, desires, except the desire to know, is irrelevant. What is called for is a cautious, piece-meal investigation and impartial contemplation freed from all "preoccupation with the self." The scientist and philosopher are merely to receive, analyze, classify, generalize, define, infer, ratiocinate, and in general conform to an impersonal, unmeaning realm of natural fact, given as an alien external reality which 'is as it is.' ${ }^{61}$ Now it would seem that this "liberation from self" involves an abstracting from all meaning, i. e., assumes that reality "is as it is' when unmeaning. It leaves us therefore on the level of existence, contemplating reality merely as object. It thus involves an abstraction from the distinctively human, from reality at its maximum, and leads to an ultimate dualism between logic and the non-intellectual aspects of man's nature or between philosophy and life. Philosophy, we are told, can give no knowledge of life, or of the destiny of the individual or universe. Formal logic is the essence of philosophy; philosophy deals with logical forms. Indeed, the general, a priori content of philosophy

${ }^{61}$ Cf. Russell, Mysticism and Logic, pp. 18, 25-34, 106-9. Cf. Analysis of Mind, "Moral considerations are the worst enemies of the scientific spirit and we must dismiss them from our minds if we wish to arrive at truth" (p. 32). 
would seem to cut it off sharply not only from life, but also from science as science is generally understood. ${ }^{62}$

Finding this level of mediation, like the first, irrational and inadequate, Objective Idealism proceeds to the third stage, that of mediated immediacy. This is also a stage of reason; but, in contrast to the standpoint of the reflective understanding at which Realism remained, it includes the stage of immediate feeling as a moment of enriching difference. It also includes the stage of the scientific intellect and has in common with the latter the attitude of disinterestedness. It does not, however, interpret this attitude in such a way as to necessitate an abstraction from meaning or an absolute dualism between logic and life. Its standpoint is that of concretion which demands that we see reality whole, without separations and abstractions; that we interpret it in terms of what it is at its maximum; and that we keep the significant experiences in the center. This position is not accepted as an initial dogma or 'datum of feeling,' but is the tentative outcome of an arduous process of experimental thought, and is put forward, scientifically, as an hypothesis to be tested by its capacity to systematize experiences and render them intelligible. This method, Idealism maintains, far from ignoring the lower, more abstract levels of experience, gives to the latter a fuller meaning and helps to reveal their proper place and function. As long as this third stage of reason be not understood, Objective Idealism, with its identification of reality, value, and perfection, will, naturally enough, continue to be criticized from the intellectualistic standpoint of Realism as unscientific, mystical, and biassed; while, at the same time, faith and feeling philosophies will be censuring it as unduly rationalistic or intellectualistic.

As regards the realistic criticisms of Idealism, it seems necessary to conclude that not one is a valid criticism of Objective Idealism. In so far as they were intended to be such, they fail because they are based upon misconceptions of the meaning of Objective Idealism or because they involve faulty inferences. On the one hand, therefore, it is to be observed that the negative or critical phase of Realism is far from complete: that the chief aim of this phase, "the refutation of idealism" or "the refutation of the monistic theory," has not been achieved. On the other hand, one

${ }^{\circledR 2}$ See pp. I34f. below. 
must not permit this fact to obscure the real value of these criticisms as protests against other types of Idealism. In opposition to abstract monisms and intellectualisms, Realism rightly refuses to lose sight of the particular and rightly insists on the necessity of maintaining contact with science and daily life. As against psychological or existential idealisms, such as Berkeleyanism and Panpsychism, Realism well contends that philosophy must recognize a genuine externality qualitatively different from minds and mental states. Again, the protest of Realism against the apparent lack of disinterestedness on the part of philosophies of feeling and faith, must elicit the approval of every lover of reason. Moreover, Objective Idealists themselves have profited by the realistic criticism. One of their number has admitted that "a good many idealists have given some ground for the misunderstanding by failing to take and maintain from the beginning a standpoint that is objective and genuinely speculative." ${ }^{63}$ As a result of the protests of the Realists, Objective Idealists have been led to define their position more carefully and to distinguish it more sharply from other types of Idealism.

os J. E. Creighton, op. cit., p. 52r. 


\section{CHAPTER III}

\section{THE REALISTIC METHOD}

\section{Intellectualistic Tendencies}

$\triangle$ STUDENT of Realism can hardly fail to note the conA siderable extent to which the Realist sees the problems of philosophy from the standpoints of the formal logician and the mathematician and attempts to solve these problems by means of the methods and principles of abstract logic and mathematics. In Moore's early philosophy, for example, we seem to have an attempt to make the unit of formal logic, the concept, the unit of reality, and to show how everything else is constructed out of these ultimate formal units. Moore says: “. . . in the end, the concept turns out to be the only substantive or subject, . . . From our description of a judgment, there must, then, disappear all reference either to our mind or to the world. Neither of these can furnish 'ground' for anything, save in so far as they are complex judgments. The nature of the judgment is more ultimate than either, and less ultimate only than the nature of its constituents-the nature of the concept or logical idea." Things and ideas are composed of nothing but concepts, Moore adds. Time is a concept. Likewise, "an existent is seen to be nothing but a concept or a complex of concepts standing in a unique relation to the concept of existence." Such a complex of concepts is a "proposition (a true existential proposition) ... to be understood, not as anything subjective-an assertion or affirmation of something-but the combination of concepts affirmed." Inference or "the relation of premisses to conclusion" is also an "objective relation," and perception is "the cognition of an existential proposition." "It seems necessary then," says Moore, "to regard the world as formed of concepts," which are "immutably what they are," and "stand in infinite relations to one another equally immutable," which may or may not be in "relation to a thinker," and to whose nature it is indifferent "whether 
anyone thinks them or not." A proposition "must be either true or false," and "if it is true, its contradictory is as fully impossible as the contradictory of $2+2=4$." 1

It is to be observed that Moore seems not only to make the unit of formal logic the unit of reality, but also seems to conceive of concepts and their combinations in strict accord with the three fundamental presuppositions of formal logic: the laws of Identity, Contradiction, and Excluded Middle. These laws, if regarded as final, dictate that concepts and their combinations must be eternally self-identical ; must each have a nature distinct from that of every other, prior to all relationships, which these relationships are powerless to alter; and must be either true or false. Indeed, with regard to his final court of appeal, Moore himself says: "I have appealed throughout to the rules of logic; nor, if any one rejects these, should I have much to fear from his arguments. An appeal to the facts is useless. For, in order that a fact may be made the basis of an argument, it must first be put in the form of a proposition, and, moreover, this proposition must be supposed true; and then there must recur the dilemma, whether rules of logic are to be accepted or rejected. And these rules once accepted, would seem themselves to offer a confirmation of our theory. For all true inference must be inference from a true proposition; and that the conclusion follows from the premise must again be a true proposition; so that here also it would appear that the nature of a true proposition is the ultimate datum." But propositions may be analyzed into concepts, so that the "identity of the concept, in several different things," is really the starting-point; "two things are then seen to be differentiated by the different relations in which their common concepts stand to other concepts." ${ }_{2}^{2}$ Thus, universals are made abstract and are particularized; particulars do not appear to be mentioned; individuals are resolved into a complex or combination of externally related abstract universals.

It was from this abstract logic and rigid world-view of Moore that Russell derived the fundamental principles of his philosophy, as the following quotation will make clear. "On fundamental questions of philosophy, my position, in all its chief features, is derived from Mr. G. E. Moore. I have accepted from him the

${ }^{1}$ Mind, N. S., Vol. 8, pp. 179-93.

'Ibid., p. 182. 
non-existential nature of propositions (except such as happen to assert existence) and their independence of any knowing mind; also the pluralism which regards the world, both that of existents and that of entities, as composed of an infinite number of mutually independent entities, with relations which are ultimate, and not reducible to adjectives of their terms or of the whole which these compose. Before learning these views from him, I found myself completely unable to construct any philosophy of arithmetic, whereas their acceptance brought about an immediate liberation from a large number of difficulties which I believe to be otherwise insuperable. The doctrines just mentioned are, in my opinion, quite indispensable to any even tolerably satisfactory philosophy of mathematics. ... Formally, my premises are simply assumed; but the fact that they allow mathematics to be true, which most current philosophies do not, is surely a powerful argument in their favour." 3

It will be seen from this quotation that Russell purposively selected as the basis of his philosophy the assumptions which seemed most to further the work of organization and construction in mathematics. Perhaps a long and too exclusive preoccupation with mathematics serves in some measure to explain his selection of those assumptions that "allow mathematics to be true" as the basis of his philosophy and his tendency to view the universe through the eyes of the mathematician as well as through those of the formal logician. ${ }^{4}$ However this may be, mathematical conceptions and methods play an important rôle in Russell's thought. Space, time, matter, motion, and phenomena receive a mathematical interpretation. 'Continuity' and 'infinite' are defined mathematically as properties of discrete series or classes. Their nature now belongs to mathematics, not philosophy, we are told. ${ }^{5}$ Persons become 'classes' of psychical existents, or 'series' of perspectives or 'series' of momentary men, and history becomes a 'series' of mutually exclusive biographies. ${ }^{6}$ Numerical identity

${ }^{3}$ Principles, p. viii.

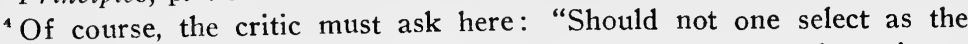
basis of his philosophy such assumptions as allow not only mathematics to be true, but all other departments of experience as well?"

'Introduction to Mathematical Philosophy, Preface.

${ }^{6}$ Principles, pp. 523f.; Mysticism and Logic, pp. I29ff., 167. 
and diversity are regarded as all-important for the meaning of unity, plurality, and individuality. ${ }^{7}$ Everything actual and possible, it is asserted, must conform to the laws of arithmetic as well as to those of formal logic. ${ }^{8}$ We read, moreover: "the first serious advance in real logic since the time of the Greeks was made independently by Peano and Frege--both mathematicians. They both arrived at their logical results by an analysis of mathematics ... the philosophical importance of the advance which they made is impossible to exaggerate." 9 Furthermore, mathematical knowledge frequently appears to be considered the ideal of knowledge, ${ }^{10}$ and it would seem that 'scientific method in philosophy' might much more appropriately be called 'mathematical method in philosophy' in view of Russell's description of this method, his indebtedness to Whitehead, Peano, and other mathematicians for suggestions and principles, and his statement that of this method "the first complete example is to be found in the writings of Frege." 11 The introduction of such a method into philosophy and the mathematical solution of certain puzzles involved in mathematically defined concepts, such as 'infinity' and 'continuity,' are believed to have most important consequences for philosophy. In short, conceptions and methods which mathematics may justifiably use for its own purposes are taken by the Realists as final, as universally applicable, as valid in any reference without modification or reinterpretation.

Russell makes little or no distinction between logic and mathematics. He writes, "But for the desire to adhere to usage, we might identify mathematics and logic, and define either as the

${ }^{7}$ Cf. "Whatever. . . can be counted as one, I call a term. . . I shall use as synonymous with it the words unit, individual, and entity." Principles, pp. 43f., cf. pp. 67, 76, 345f., and Part V; Moore, Proc. Arist. Soc., Vol. I, pp. $127 \mathrm{f}$.

${ }^{8}$ Problems, p. 135 .

'Scientific Method, pp. 4 of.

10 "I hold the paradoxical opinion," says the Russell of the Principles (p. 338), "that what can be mathematically demonstrated is true." See, however, footnote 94, p. 90 below. Cf. Moore, Mind, N. S., Vol 8, pp. 179, 182.

${ }^{11}$ Scientific Method, p. v. Cf. Prefaces to Principles, Mysticism and Logic (also pp. I17, 157), Nunn's Aims and Achievements (also p. 142), and Broad's Perception, Physics, and Reality, pp. ix, xii. Cf. Alexander, Space, Time, and Deity, Vol. I, pp. 36, 44, 58, 82. 
class of propositions containing only variables and logical constants." But "respect for tradition" leads him to the following "very arbitrary" distinction. "Logic consists of the premisses of mathematics, together with all other propositions which are concerned exclusively with logical constants and with variables but do not fulfil the above definition of mathematics. Mathematics consists of all the consequences of the above premisses which assert formal implications containing variables, together with such of the premisses themselves as have these marks." ${ }^{12}$ Thus Logic becomes identified with Formal Logic, and the expression 'Formal or Symbolic Logic' we find Russell using in a wider sense to denote that from which "all mathematics follows" and in a narrower sense as a "branch of mathematics." As to the motive for employing symbols, Russell says, "In the beginnings everything is self-evident; and it is very hard to see whether one self-evident proposition follows from another or not. Obviousness is always the enemy to correctness. Hence we invent some new and difficult symbolism, in which nothing seems obvious. Then we set up certain rules for operating on the symbols, and the whole thing becomes mechanical. In this way we find out what must be taken as premiss and what can be demonstrated or defined." 13 Now, it would seem that Symbolic Logic, like any equational logic, in equating terms or substituting one term for another, must abstract from the differences or uniqueness of whatever is equated or substituted. Consequently, it would seem to be of little value unless it is possible to make due allowance for the abstract character of its various steps and its conclusions. Equational logic, like all formal logic, appears to assume that the moment of difference is only externally related to the moment of identity, so that no invalid or inadequate results will ensue if the difference is left out of account altogether, i. e., if the operations concern only abstract universals. ${ }^{14}$ We find Russell, however,

${ }^{12}$ Principles, p. 9; cf. p. 106, and Mathematical Philosophy, p. 194. The definition referred to is: "Pure Mathematics is the class of all propositions of the form ' $p$ implies $q$,' where $p$ and $q$ are propositions containing one or more variables, the same in the two propositions, and neither $p$ nor $q$ contains any constants except logical constants" (p. 3).

${ }^{13}$ Mysticism and Logic, p. 77.

${ }^{14}$ Cf. Mathematical Philosophy, p. 20I, "Such words or symbols express what are called 'logical constants" " or "forms" or "that which is in common 
acclaiming "symbolic logic" and "rigid formalism" as "the most remarkable result of modern methods in mathematics." 15 Symbolic logic, he tells us, is "absolutely essential to every philosophical logician." " It Its philosophical importance "is impossible to exaggerate." It has "introduced the same kind of advance into philosophy as Galileo introduced into physics, making it possible at last to see what kinds of problems may be capable of solution, and what kinds must be abandoned as beyond human powers. And where a solution appears possible, the new logic provides a method which enables us to obtain results that . . . must command the assent of all who are competent to form an opinion." 17

Realism, it is true, complains of the narrowness of the Aristotelian formal logic, of the inadequacy of syllogistic deduction, and of the error of reducing all judgments to the subject-predicate propositional form. It maintains that it has enlarged upon the Aristotelian point of view in various ways and that it has expanded it sufficiently to embrace inductive as well as deductive logic. Nevertheless, the following considerations suggest that Realistic logic is scarcely less formal and intellectualistic than the Aristotelian logic which it claims to have superseded. The Realist: (I) identifies logic with formal, symbolic, or mathematical logic, and its subject-matter with forms; (2) takes as final and universally valid the laws of Identity, Contradiction, and Excluded Middle; (3) recognizes an a priori knowledge whose certainty is independent of experience; (4) makes induction (or inductive science) a species of deduction or a subsumption of merely probable generalizations under wider generalizations; (5) identifies definition with what might be called genus-species definition; (6) identifies judgment with a static relation of reference, or a proposition, or even a form of words; (7) identifies meaning with a sign or representative of something other than itself to which it may be said to point or refer; and (8) embraces a correspondence theory of truth.

among a number of propositions, any one of which can result from any other by substitution of terms. . .."

${ }^{16}$ Mysticism and Logic, p. 95.

"Principles, p. Io.

${ }^{17}$ Scientific Method, p. 59. 
(I) Russell's identification of Logic with formal, symbolic, or mathematical logic has been noted above. Logic is said to be the study of various types of deduction, syllogistic and asyllogistic, or of the general rules by which inference is made. "In all inference," he says, "form alone is essential. . . ." "In logic . . . we deal throughout with completely general and purely formal implications. ..." The object-matter of Logic is "propositions qua propositions," i. e., the form, not the subject-matter of propositions. Pure forms or "that which is common among a number of propositions" are "the only possible constituents of logical propositions." 18

(2) The three basal presuppositions of formal logic, the laws of Identity, Contradiction, and Excluded Middle, are regarded as final and universally valid by the Realist. Moore's appeal to the rules of logic, apparently the rules of formal logic, has been noted above. Russell adds that the three laws just mentioned are fundamental and self-evident logical principles, and that they are laws of things as well as laws of thought. What is important, he says, "is not the fact that we think in accordance with these laws, but the fact that things behave in accordance with them; in other words, the fact that when we think in accordance with them we think truly." 19

(3) Logical knowledge, according to Russell, is general knowledge; "it is wholly independent of the accidental facts of the existent world," or "of the existence of the universe," "and can be known theoretically without any experience of particular things or their qualities and relations." "Thus, while admitting that all knowledge is elicited and caused by experience, we shall nevertheless hold that some knowledge is a priori, in the sense that the experience which makes us think of it does not suffice to prove it, but merely so directs our attention that we see its truth without requiring any proof from experience." In other words, for the Realist, there is a kind of knowledge which is not derivable from experience alone, and the certainty of which is wholly independent of experience. Such knowledge tells us nothing about actual particular instances. No number of instances make it any more

\footnotetext{
${ }^{18}$ Mathematical Philosophy, Ch. 18; Principles, pp. 9, 106; Scientific Method, pp. 42-5, 56 f.

${ }^{10}$ Problems, pp. 113, 136; Principles, pp. 18, 445.
} 
certain. It does not imply the existence of any such instances. In fact, in mathematics and formal logic, we can know a general a priori proposition in cases where we do not know a single instance of it, and even where from the very nature of the case no instance can be given. ${ }^{20}$

(4) That Realism has succeeded in expanding the standpoint of the Aristotelian formal logic sufficiently to include genuine induction is doubtful. According to Russell, all inference is deductive, although not all deduction is syllogistic. He characterizes induction as "disguised deduction or a mere method of making plausible guesses." ${ }^{21}$ In the final form of a perfected science, we are told, everything ought to be deductive; if induction remains at all it will only be as "one of the principles according to which deductions are effected." "The ultimate result of the introduction of the inductive method seems not the creation of a new kind of non-deductive reasoning, but rather the widening of the scope of deduction by pointing out a way of deducing which is certainly not syllogistic. . . ." 22 Non-syllogistic deduction or "asyllogistic inference," would seem to be the tracing out of the formal or the material implications between propositions according to the rules of symbolic logic.

Science, according to Broad, is the progressive subsumption of empirical generalizations under wider generalizations. The 'why' of science is answered by a general law according to which phenomena occur. Scientific explanation involves two factors: general laws and a specific set of entities subject to those laws. ${ }^{23}$ In a somewhat similar vein, Russell maintains that Science does not find in causation any 'operating' causes, any necessity, any invariable sequence, or any connection between causes and effects which we can "feel." It offers "causal laws as merely observed uniformities of sequence"; "cause" in practice, means "nearly in-

${ }^{20}$ Problems, pp. I16-21, I31, I62; Scientific Method, p. 57; Mathematical Philosophy, Ch. I8. Cf. "If there were no universe, all general propositions would be true." "Logical propositions are such as can be known a priori, without study of the actual world." "It is a principle in all formal reasoning to generalize to the utmost. ..."

${ }^{21}$ Principles, p. II.

${ }^{2}$ Scientific Method, p. 34.

${ }^{2}$ Cf. Broad, Proc. Arist. Soc., Vol. I9, p. 88; cf. Russell, Problems, pp. 101-6, 120f., I31, 167, Scientific Method, pp. 218, 222. 
variable antecedent." "To ask why such-and-such a kind of sequence occurs is either to ask a meaningless question, or to demand some more general kind of sequence which includes the one in question. The widest empirical laws of sequence known at any time can only be 'explained' in the sense of being subsumed by later discoveries under wider laws; but these wider laws, until they in turn are subsumed, will remain brute facts, resting solely upon observation, not upon some supposed inherent rationality." "The laws that we actually know empirically ... are not to be regarded as universal or necessary." "All that we can know empirically is approximate and liable to exceptions." "Laws embodied in differential equations may possibly be exact, but cannot be known to be so." ${ }^{24}$ Thus, empirical or inductive science would seem to consist in the discovery and formulation of wider and wider generalizations and would seem to yield only probability.

(5) Like inductive explanation, definition would seem to consist, for the Realist, in large measure, in abstracting and isolating the 'general.' Such definition in terms of a common and peculiar quality of a group of particulars may be called 'genus- species' definition. It results in a 'class concept' abstracted from differences, i. e., an abstract universal. ${ }^{25}$

(6) What Idealists regard as a judgment-a single, active, significant whole-is dissected by the Realist into (a) something regarded as subject-matter for psychology only (one or more mental acts, occurrences, processes, or states); and (b) something merely formal, regarded as only, and perhaps the only, subject-matter of logic: a static relation of reference, a proposition, or "a form of words." Judgment tends to be identified with the latter or what may be called the external semblance of the judgment. Thus Russell describes a proposition as "a form of words which must be either true or false," ${ }^{26}$ and, in his latest work, "a series of words (or sometimes a single word) expressing the kind of thing that can be asserted or denied." It must be a

${ }^{24}$ Analy'sis of Mind, pp. 89-96.

${ }^{25}$ Cf. Russell, Principles, pp. 27, 54f., III, I14, 220 ; Scientific Method, pp. 187f., 201 ; Problems, pp. 76, 81, 145-55; Moore, Principia Ethica, Sec. I ; Broad, Proc. Arist. Soc., Vol. 21, p. I4I.

${ }^{26}$ Scientific Method, p. 52. 
series of words that has a "meaning" or "objective reference," and "given the meanings of the separate words, and the rules of syntax, the meaning of a proposition is determinate." The proposition is "the same thing (or very nearly the same thing)" as the content of a belief when expressed in words. The term may be extended however "so as to cover the image-contents of beliefs consisting of images." Hence, we may recognize two kinds of propositions: image-propositions (the more primitive) and wordpropositions. Propositions therefore may be identified with "the contents of actual or possible beliefs." 27

To identify judgment with a proposition or sentence, as Realism thus tends to do, is apparently to render it static and unchangeable. It becomes a combination of immutable, externally related components, e. g., words, 'references,' 'forms,' concepts, or terms. The terms, whether particulars or universals, are dead, abstract, and not of the nature of mind. ${ }^{28}$ They are not altered by new relationships or entrance into wholes. In Russell's words, "The notion that a term can be modified arises from neglect to observe the eternal self-identity of all terms and all logical concepts, which alone form the constituents of propositions." ${ }^{29}$ Judgments as wholes are also made lifeless, rigid, and externally related. As a solid foundation for knowledge, a proposition must be absolutely true and self-complete, and possess a meaning which will remain fixed for all time. In the capacity of building stones or links in knowledge, each judgment is in no way altered when it is brought into relation with other judgments or when it becomes a part of a more inclusive logical whole. ${ }^{30}$

(7) Russell's theory of meaning may have taken its cue at least in part from a supposed intimate analogy between an idea or judgment and a word or sentence. A word is a sign, symbol, or representative of something other than itself to which it may be said to refer or point. ${ }^{31}$ On evidence "merely introspective," 32

${ }^{27}$ Analysis of Mind, pp. 239-41.

${ }^{28}$ Cf. Russell, Principles, p. 448; Proc. Arist. Soc., Vol. 2, p. 112; Moore, Mind, N. S., Vol. 8, pp. 179-82, 192f.

${ }^{29}$ Principles, p. 448.

${ }^{30}$ See below, pp. 92ff., $98 \mathrm{ff}$.

s1 Analysis of Mind, pp. 191, 200, 239.

${ }^{32}$ Ibid., p. 230. Cf., however, pp. 20I-3, where images are recognized as necessary to account for "the entirely different response produced by a narrative and by a description of present facts." 
the existence of images may be admitted. Like words, they are also signs; but as their name suggests, they are actually copies or pictures of something other than themselves to which they may be said to refer or point, e. g., sensations, objects, occurrences, other images with the same prototype, ${ }^{33}$ or a number of similar prototypes (which together generate a "generalized image" that may function as a general or universal idea). ${ }^{34}$ It is primarily this static relation of reference with which meaning is identified, although the term appears to be used at times by Russell to denote not the relation of reference but the object referred to, or the content of belief (i. e., what is believed). ${ }^{35}$ Meaning is conferred upon the image by a 'belief' or 'belieffeeling' that the image points to an object, i. e., a feeling that "this is real," "this occurred," "this will happen," etc. ${ }^{36}$ The image and its prototype cannot be experienced together, hence, cannot be compared. Therefore, in order to avoid the difficulties of traditional 'correspondence' theories, other feelings must be supposed to accompany images: the feeling of familiarity (which determines the degree of our confidence or lack of confidence in the accuracy of the image), the feeling of pastness (which-aided by quantity of context-determines the position of the time series to which the object referred to is to be assigned), and a feeling of expectedness (which-together with the ability to act in a way appropriate to the occurrence-acquaints us with

${ }^{33}$ Ibid., p. 291. Provision is thus made for a knowledge of images.

${ }^{34}$ Ibid., pp. 207-29. See below, pp. I3of.

${ }^{35}$ Ibid., Lectures 8-10, and pp. 222, 231, 244, 269-74, 288-91. But for secondary uses of the term 'meaning,' see pp. I98, 210, 239f. Since there are meaningless or non-cognitional sensations, unattached feelings, and unconscious mental phenomena, mind is not essentially consciousness, or meaning, or cognitional, or relational, or 'intentional,' i.e., not essentially related to an other. These terms are all too narrow to be used in defining mind. "Subjectivity" ("the characteristic of giving the view of the world from a certain place") and "mnemic causation" (causation in which the proximate cause includes past events) are better differentia of mind, though perhaps too broad. With reference to his earlier position, Russell says: "Until very lately I believed ... that mental phenomena have essential reference to objects, except possibly in the case of pleasure and pain" (cf. pp. I4f., 90, I29ff., 140-3, 252, 288-96, 307).

${ }^{36}$ Ibid., pp. 175-87, 288f. "Reflection" is perhaps necessary for a clear distinction between image and object. 
the resemblance of an expectation image to the sensation to which it referred, i. e., 'verifies' our expectation beliefs). Involved in more complicated mental occurrences (disjunction, implication, etc.) are still other feelings, such as disbelief-feelings and doubt. $^{37}$

(8) According to Russell, meanings of words or images are neither true nor false. ${ }^{38}$ However, just as a word has a meaning, a series of words such as constitutes a belief-content or proposition has an 'objective reference' or meaning. And just as a word or image points to an object other than itself, so the belief or proposition points to an objective or external fact. ${ }^{39}$ The meaning of a belief or proposition is derived from the meanings of its com-

"Ibid., pp. 158-63, 250, 270. It is far from obvious that the expedient adopted by Russell really removes the difficulties of a "correspondence" theory. On the one hand, a "specious present" in which earlier and later are experienced together immediately would seem to be impossible unless there is a synthesizing subject with some degree of permanence; but Russell does not recognize a subject. And, admit such a subject, and admit that immediate past and present can be compresent in one experience and compared, there seems no longer any reason to hold that a remote past and present cannot be directly presented in one experience; hence no array of inexplicable and miraculously working feelings need be evoked to render the situation intelligible. On the other hand, without a subject and a "specious present," we would seem to be eternally shut within the present moment. It then seems miraculous that we should ever have an idea of anything but the present, could know that anything else is real, could distinguish an image from a sensation, or an imagination image from other kinds, or could connect a present image with the object (by hypothesis absent, past, or future) which it 'means.' Feelings of pastness, expectedness, and familiarity presuppose the time distinctions and resemblance which they are supposed to explain. Finally, apart from the reference to "quantity" of context and to "appropriate action," the appeal is to pure immediacy (despite Russell's assertions in the Analysis of Mind regarding the unreliability of immediacy, see pp. 92ff. below). "Appropriate action" and "context" (though it is its specific character and connectedness rather than its "quantity" which would seem to be important) would appear to be more fruitful leads.

${ }^{3}$ Ibid., p. 232; yet we read of the "correctness" of an image.

${ }^{3}$ Ibid., pp. 238, 271-3, 289. The believing and the content are in the mind and present; their objective is outside of the belief and outside of the mind (except in the case of a mental fact) and rarely if ever present. Beliefs are the components of intelligence; reasoning is a transition from belief to belief; beliefs are central in the analysis of mind; and the essence of belief is objective reference (cf. pp. 23I-3, 240, 250f.). Everything 
ponents (words or images). When we know the meanings of the latter, we know the meaning of the proposition, i. e., we know as much as can be known about the objective which would make it true, although we do not know whether it is true or false. Objective references or meanings of propositions must be either true or false according as they do or do not correspond formally with their objectives. The resemblance or correspondence between true image-propositions and objectives may be simple and exact, i. e., the same relations may obtain between the components of each, and the number of the components of each may be the same. But frequently, even in the case of image-propositions, the correspondence is complex and inexact, as for example when temporal relations are involved. In the case of word-propositions the correspondence is always complex and inexact. ${ }^{40}$

The formal and mathematical tendencies of Realistic thought lead to a mechanistic view of reality. Moore, in his early thought, apparently as the result of taking as his point of departure the standpoint of formal logic regarded as absolute or final, seems to have envisaged the world as an aggregate of immutable concepts and combinations of concepts in invariable relations to one another. Particulars are apparently overlooked, while individuals are regarded as concepts or complexes of concepts. ${ }^{41}$ The relations would appear to be external relations, either causal or

here appears to be analyzed ultimately into images and sensations except relations; their status remains obscure.

${ }^{40}$ Ibid., pp. 165, 232-8, 253f., 261, 273-8. In this formal sense of truth, in which truth is divorced from understanding, it would seem that a talking machine or a picture machine could possess truth equally as well as could a mind or cognitive subject. Cf. Russell's reference to the gramophone (p. I66) and to the cinema (Mysticism and Logic, pp. I28f.). The influence of Pragmatism is perhaps discernible in Russell's statement that the 'correspondence theory' is true but inadequate, and that the supplementation needed concerns the part played in knowledge by "purpose," the "appropriateness" (for the execution of the purpose) of the responses resulting from true belief, "the causal efficacy of beliefs," and "a feeling of expectedness." This feeling, together with the appropriateness of the response, enables one to recognize a correspondence between inferred or expected happenings and later observed happenings, and the experiencing of such a correspondence constitutes the "verification" of beliefs (cf. Analy'sis of Mind, pp. 259ff., 268ff., 278).

"See pp. 6of. above. 
inferential. Being "mutually ends and means" in an organic whole is said to be merely "mutual causal dependence" or "reciprocity." 42 Two types of necessity are to be distinguished, as Moore more recently has explained at some length: ${ }^{43}$ (I) that denoted by the expressions "is necessarily," "must," "does follow," "is as a matter of fact"; and (2) that denoted by the expressions "would necessarily be," "follows from," 44 "is deducible from," "entails," "logically implies," or "formally implies." ${ }^{45}$ This second group of expressions are all equivalent and denote "that relation which holds ... between the two premisses of a syllogism in Barbara, taken as one conjunctive proposition, and the conclusion, equally whether the premisses be true or false." In a word, the abstract universality and the rigidity (causal or inferential) of Moore's world would seem to be such as to exclude freedom, development, and teleology, and perhaps anything in the nature of genuine activity.

Russell's world is also a mechanistic world, and one all parts of which are related as expressions of a mathematical formula and connected by a necessary logical relation of implication or inference. Causation is universal. In the non-mental world reigns physical causation, illustrated by gravitation; in the mental world, 'mnemic' causation, such as is found in association. "Any set of antecedents from which the event can theoretically be inferred by means of correlations might be called $a$ cause of the event." "When, given A, it is possible to infer B, but given B, it is not possible to infer $A$, we say that $B$ is dependent upon $A$ in a sense in which $\mathrm{A}$ is not dependent upon $\mathrm{B}$. . . . If the relation is a causal law, we say that $B$ is causally dependent upon A." 46 A physical causal law has the form "X now causes $\mathrm{Y}$ now";

${ }^{42}$ Principia Ethica, pp. $3 \mathrm{If}$.

${ }^{43}$ Proc. Arist. Soc., Vol. 20, pp. 47, 52ff.

4" "follows being understood in the sense in which from the proposition with regard to any term, that it is a right angle, it follows that it is an angle, and in which from the proposition with regard to any term that it is red it follows that it is coloured" (loc. cit.).

${ }^{45}$ The distinction which Moore draws between the "would necessarily be" and the "is necessarily," appears to be the eighteenth century distinction between the necessary (that which holds for all possible or conceivable worlds) and the contingent (that which holds for our actual world only), though this is not wholly clear.

* Mysticism and Logic, p. 136; Analysis of Mind, pp. 93, 302-7. 
a psychological or mnemic causal law has the form "A, B, C, . . in the past together with $\mathrm{X}$ now, causes $\mathrm{Y}$ now." 47 "It is probable, though not certain, that mnemic causation is derivative from ordinary physical causation in nervous (and other) tissue;" 48 "that past experience only affects present behaviour through modifications of physiological structure;" hence, that physiology is "theoretically reducible to physics and chemistry;" and that "chemistry reduces to physics." But "in order to obtain invariable physical laws, we have to proceed to differential equations, showing the direction of change at each moment, not the integral change after a finite interval, however short." "In a perfected science, causal laws will take the form of differential equationsor of finite-difference equations, if the theory of quanta should prove correct." 49 A scientific law thus states functional relations between events, and its constancy consists in the sameness of differential equations. As subject to such invariable general laws, the universe is a deterministic system, i. e., one in which we can infer events at any time from events at certain assigned times. The word 'deterministic' has a purely logical significance: a certain number of variables determine another variable if that other variable is a function of them. The law of universal causation may be enunciated as follows: "There are such invariable relations between different events at the same or different times that, given the state of the whole universe throughout any finite time, however short, every previous and subsequent event can theoreti-

"Ibid., p. 87. For mechanistic interpretations of various phases of mind and of knowledge, see especially pp. 85ff., 104f., r20, I 50f., 205, 227, 279-85, 30Iff. Cf. "In our sensational life we are in causal dependence upon physical laws" (p. 303).

${ }^{48}$ It is highly probable that the difference in the laws of voluntary movements and movements of what is devoid of life is not irreducible (pp. 36f.).

${ }^{4}$ Ibid., pp. 36-7, 47, 87-95, I39, I72, 303-7. "A physical law does not say 'A will be followed by B,' but tells us what acceleration a particle will have under given circumstances, i.e., it tells us how the particle's motion is changing at each moment, not where the particle will be at some future moment." "We merely have, as the embodiment of our causal law, a certain direction of change at each moment." "Hence, we are brought to differential equations as embodying causal laws." 
cally be determined as a function of the given events during that time." 50

Causal relations, then, become for Russell not mere correlations but necessary and invariable logical and mathematical relations between particular events or states, relations of a kind that makes inference possible from some to others of such events or states. "It is quite likely," Russell says, "that, if we knew more about animal bodies, we could deduce all their movements from the laws of chemistry and physics." "It seems not improbable that if we had sufficient knowledge we could infer the state of a man's mind from the state of his brain, or the state of his brain from the state of his mind." "Even the most private sensation has correlations which would theoretically enable another observer to infer it." Or again, "If we knew all atomic facts, and also knew that there were none except those we knew, we should, theoretically, be able to infer all truths of whatever form." ${ }^{51}$ In short, concrete reality appears to be dissolved in Russell's thought into an abstract logical or mathematical skeleton or schema on the one hand and externally determined particulars on the other. There is no place for freedom in such a world, ${ }^{52}$ and teleology and meaning are made merely subjective. ${ }^{53}$ Although Russell protests against philosophies that make time and change impossible as well as against philosophies that regard "time as the devouring tyrant of all that is," ${ }^{54}$ it is difficult to see how a place can be found in his world for genuine activity, change, and growth, so long as reality is conceived of as a completely calculable system of mathematical functions and equations; and change is defined as only the fact that immutable indestructible terms have different relations, equally immutable, to different instants of time without duration;

${ }^{50}$ Scientific Method, p. 221. Cf. Mysticism and Logic, pp. 101, 194ff., 200-3 for allusion to "the single and supreme law of the spatio-temporal world," a formula which, theoretically, embraces all general laws of the behavior of all particles in the universe (all functions of the times corresponding to all sets of points in space).

${ }^{51}$ Ibid., p. 136; Analysis of Mind, pp. 47, 119, 305; Scientific Method, pp. 53 ff.

${ }^{62}$ Cf. ibid., pp. 233ff.; Mysticism and Logic, pp. 122, $201-8$.

${ }^{63} \mathrm{Cf}$. ibid., p. 201. "A teleological system is one in which purposes are realized, i.e., certain desires . . . . are followed by their realization." For the subjectivity of values cf. ibid., p.v.

Ibid., Ch. I and pp. 105f.; Scientific Method, Ch. I. 
and motion is regarded as made up of simple parts which are not motions but immobilities. ${ }^{55}$

Finally it should be noted that in Russell's most recent view the externally determined particulars which obey the mathematical formulae are all of a kind, all made of the same "neutral stuff." 56 These particulars comprise sensations and their copies, images, which differ from sensations not in 'stuff' but only in correlates and causal laws. ${ }^{57}$ The physical is composed of sensations, and the mental of sensations and images; hence the physical and mental have a common ground in sensation, are of the same stuff, and differ from one another only as to correlates and causal laws; while these laws, as we have just seen, are probably ultimately (though not proximately) reducible to the same kind. ${ }^{58}$ Matter and mind become then merely different "conventional groupings of an underlying material," which is more "primitive" than either and the "common ancestor" of both, and whose causal laws are the basis of the causal laws of both physics and psychology. In a word, in Russell's view, not only are genuine growth, freedom, purpose, and objective meaning apparently lost sight of, but also the concrete differentiation of reality tends to be replaced by a monotonous sameness or abstract identity in the form of an undifferentiated "neutral stuff."

Intellectualistic tendencies are much less conspicuous in Alexander's thought than in that of Moore, Russell, and Broad.

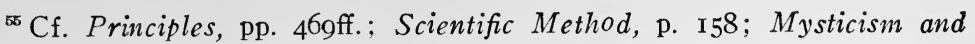
Logic, p. 84. Cf. Analysis of Mind, p. 94: "Everything in nature is apparently in a state of continuous change, so that what we call one 'event' turns out to be really a process." However, "the theory of quanta suggests that the continuity is only apparent. If so, we shall be able theoretically to reach events which are not processes."

${ }^{56}$ Neutrality is difficult to maintain: the ultimate constituent of reality in Russell's view appears to be more like the "element" of empirical psychology than like that of the physical sciences, in so far as it is ephemeral, has pleasure and discomfort as characteristics of it, and, by itself, is subject only to psychological not physical causal laws (Analysis of Mind, pp. 25, 36, 71, 103-4, 287, 305, 308).

${ }^{57}$ Ibid., pp. I09-10, I20-I, I38, I48, I 56, 287, 297-9; cf. however p. IIo: images are always private, sensations not always; sensations always give knowledge of a present object, images seldom do if ever. But they are both known in the same way.

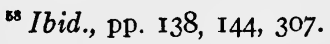


Alexander tells us that he dislikes argument and contrasts himself with Broad in this respect. ${ }^{59}$ Furthermore, he seems most at home not in the realms of formal logic and mathematics, but primarily perhaps in the realm of empirical psychology, ${ }^{60}$ and secondarily in those of physics and biology. ${ }^{61}$ "Mathematics," he holds, "is not, like metaphysics, an ultimate treatment of its subject matter." For, mathematics disregards or "idealizes away" the sensible, and "generalizes," i. e., cuts a notion "loose as it were from its attachments to the one empirical Space," and extends concepts "beyond their first illustrations." Moreover, mathematics, unlike metaphysics, is concerned only with the extension of terms, proves "propositions about any things or about some things without specification of particular things," and is not "analytical to the death," e. g., it takes as ultimates "things . . . under their generalized name of beings or entities." 62 Mathematics is therefore in part artificial and fictitious, and stands in need of correction. It gives genuine knowledge, how-

${ }^{59}$ Mind, N. S., Vol. 30, pp. 422-3. Philosophy, he says, proceeds by description and uses argument only to help one to see facts, just as a botanist uses a microscope.

${ }^{60}$ Space, Time, and Deit.y, Vol. I, pp. 8-10; II, pp. 52, 6r, 67, 80. The study of mind is "of special importance and value for philosophy," because our minds are more directly "open to our own inspection" and the workings more "manifest" than is the case with external things. Therefore in studying features shared by minds and things, and in studying the relations of various grades of existence, "our readiest approach is through the mind," or "borrowing a page from psychology." One way of procedure, and the road by which "I have come myself to consider the larger task," is "to begin by examining in detail the relation of mind to its objects, always on the empirical method of analysing that relation in our experience of it; and to draw from thence what indications are legitimate as to the general nature of things, and of their categorical features."

${ }^{21}$ Ibid., Vol. I, pp. 90, 285; II, p. 53. He interprets 'cause' as it is interpreted by science, especially physics. The theory of relativity is important because it interprets the world as a physical, not a geometrical world. Cf. for evolution in time (as opposed to an evolution of categories or thought) I, p. 227; II, p. 55; Mind, N. S., Vol. 21, pp. I9ff., 313ff.; Spinoza and Time, pp. 44, 7I.

${ }^{2}$ Space, Time, and D'eity, Vol. I, pp. 175f., 318, 343. Metaphysics is concerned with the 'intension' of terms and the relation between intension and extension, deals with our actual world, is "purely analytical" and "analytical to the death," and is mere "description" or "acquaintance," whereas mathematics uses argument and proof and attempts to "explain." 
ever, because it sets out from the one experienced Space-Time, and never completely loses its connection with the empirical. Number, dimensionality, order, relation, and all else that enters into the subject-matter of mathematics, are derivative from SpaceTime, which is more ultimate than they. Like every science, mathematics has its definitions, axioms, and postulates, but these axioms and postulates are hypothetical; and, like every science, mathematics attempts to weave certain data into a consistent system. Metaphysics or philosophy is the most comprehensive of the sciences; it asks how the various orders of fact are related to one another and to the fundamental nature of things. "If a method proper to a particular science is converted into a metaphysical method, it may be defective or false." ${ }^{63}$

Alexander is thus at variance with extreme intellectualism in differentiating to the extent to which he does between metaphysics or philosophy and mathematics (or formal logic). He also appears to be headed away from intellectualism in the emphasis which he puts upon the reality of time as duration, and of motion, change, novelty, and growth. In taking issue with Russell, who maintained that there is a sense in which time is an unimportant and superficial characteristic of reality, Alexander urges that "to realize the importance of Time as such is the gate of wisdom." For time is the very life of ultimate reality. The seventeenth century distinction of thought and extension must give place to that of duration and extension. Further, the indissoluble partnership of duration and extension, called Space-Time, which alone is ultimate, absolute, and primordial, and is the "stuff" of which everything is made, is itself "Motion." The ultimate element of Space-Time, the point-instant, is accordingly the ultimate element of Motion, and may be called a "bare event" or "pure event." Existents and things, as complexes of Space-Time, thus become complexes of motions, groupings of pure events, "eddies," "vortices," or "whirl-pools." Movement is anterior to things; it does not imply something that moves. Rest is either non-existent, or merely relative and a kind of motion. In the inseparable union

Ibid., Vol. I, pp. 2f., 90, I49-64, I79f. Mathematics requires correction in so far, for example, as it abstracts space from time, and considers space and time as mere relations between things, or as aggregates of self-existent isolated elements. 
of Space and Time, or Space-Time, Time is the moving principle, the source of motion. Because of its connection with Time, Space, which by itself is without motion, becomes the theatre of perpetual movement, and Space-Time the theatre of "incessant change." Space-Time thus comes to be through and through "historical," an "infinite becoming" which never itself began to become. "In virtue of the restlessness of Space-Time which it owes to its temporal character," Space-Time becomes also a creative principle, the source of endless variety and novelty in the form of a hierarchy of qualities, which accompany new complexes of motions, and each of which (after the first) grows out of a more simple level in the order of time. Due to the "impulse of Time," there is throughout Space-Time a "nisus" to a next higher quality, and, as a result of this nisus, an evolution takes place to a new level of complexity with its own distinctive quality and with a nisus to further novelty. ${ }^{64}$

To an extent, then, Alexander's thought is non-intellectualistic in its interpretation of (I) the nature of mathematics and metaphysics and the relationship of the two; (2) the relation of the subject-matter of mathematics to Space-Time; and (3) the importance of time, motion, change, and evolution. Nevertheless, intellectualistic tendencies are to be found in his thinking which lead to abstract universals and a mechanistic interpretation of reality; and it is not entirely clear that he has not been unduly influenced by the standpoints of mathematics and formal logic. He regards as his fundamental hypothesis the hypothesis "that the simplest being is Space-Time itself, and that material things are but modes of this one simple being finite complexes of SpaceTime or motion, dowered with the qualities which are familiar

\footnotetext{
${ }^{64}$ Ibid., Vol. I, B. I, Ch. I, II, and pp. 226, 329, 338; II, B. III, Ch. II, and B. IV; Spinoza and Time. Cf. Space is "generated in Time, or . . . by Time . . . the source of movement" (I, pp. 6If.). "Vortex has expelled Zeus and reigns in his place. . . . But $I$ hope to show in the end how Vortex reintroduces Zeus in a more considered and worthier guise and to a securer throne" ( $I$, p. 226). "Time is the moving principle that brings out that constant redistribution in the matrix which is equivalent to the birth of finite forms. . . . it is, properly speaking, Space-Time itself which is the creator and not God" (II, p. 397). The "nisus" in reality is variously described as an "effort," "striving," "impulse," "conatus," "tendency," etc.
} 
to us in sensible experience . . . bits of Space-Time . . . f from the beginning spatio-temporal and in spatio-temporal relations to one another." This hypothesis, he tells us, "is no new one but as old as the Timaeus of Plato with its construction of things out of elementary triangles, and has been revived in physics in our own day in a different form," i. e., in "the physical theory of the late Osborne Reynolds, according to which the universe is Space, and matter is comparable to a strain or a geological fault in this homogeneous medium." Further light is thrown on the origin of Alexander's system by the following quotations: "Hence Descartes could identify Space with matter, and there is nothing astonishing in the hypothesis that Space as qualified with Time is the matrix of all being." "The term point-instant is used by Mr. A. A. Robb in A Theory of Time and Space (Cambridge, I912)." "We have thus, by purely analytical or metaphysical and non-mathematical methods applied to a subject-matter presented in experience, arrived at a notion of Space-Time which at least in spirit is not different from the notion of a world in Space and Time which was formulated by mathematical methods by the late $\mathrm{H}$. Minkowski, in 1908. The underlying conception had been used or implied in the memoirs of Messrs. Lorentz and Einstein, which along with Minkowski's memoir laid the basis of the socalled theory of relativity." 65

To what extent Alexander's fundamental thesis is traceable to the newer mathematics and mathematical physics it is of course impossible to determine, but such passages as those just quoted strongly suggest that the influence of these special disciplines upon his thinking has been considerable. Mathematics is said to deal with "motion and Space, and Time," and "because it deals with the fundamental material of which all qualities represent complexities," "it is the fundamental science." "It is my belief," he says, "that the metaphysician who is to make the greatest advances will be one who, like the seventeenth century philosophers, is familiar at first hand with the notions of the fundamental

\footnotetext{
${ }^{85}$ Space, Time, and Deity, Vol. I, กp. 58, 6I, I72f. Cf. Spinoza and Time, pp. 15-7, 24, for similar allusions to Einstein, Whitehead, "the mathematicians and physicists," and to "the proposition of the mathematicians that we live in a four-dimensional world," and that "Space and Time . . . are but aspects or elements of Space-Time."
} 
and simple forms of existence which are treated in physics and mathematics." ${ }^{66}$ It is noticeable, too, that Alexander does not hesitate to avail himself of the mathematical interpretations of continuity (i. e., the existence of another term between any two terms, so that there is no "next term" to any term, which implies an infinitely divided space with no smallest part), ${ }^{67}$ and of infinity (i. e., self-representativeness, which, though not itself endlessness, implies endlessness), ${ }^{68}$ and of unity (which is equated with number I, and becomes a whole which is the same as its parts, or a limiting case of the distinction of whole into parts in which the distinction has vanished). Moreover, his interpretation of the categories in terms of properties of Space-Time (i. e., occupancy, continuity, contour, constant curvature, etc.) strikes one as essentially a geometrical interpretation. ${ }^{69}$ We read too that "the universal is related to its particulars as the equation of a curve is related to the instances of it which may be obtained by varying the so-called constants in the equation." ${ }^{70}$ The relations of things to Space-Time, their ground, is not "that of the properties of a triangle to the triangle, but rather that of the two tri-

* Space, Time, and Deity, Vol. II, pp. 53, 63, 206.

${ }^{6}$ I Ibid., Vol. I, pp. 39, 44, I46, 283. Continuity means for Alexander, however, an "uninterruptedness," an absence of isolation, or a connectedness, which the mathematical definition does not by itself imply (and perhaps excludes).

${ }^{68}$ Ibid., Vol. I, pp. 44, I47, 259. Infinity means for Alexander a selfsubsistence, self-containedness, or totality, which the mathematical definition does not imply (and perhaps excludes). Alexander sees no difficulty here, perhaps because he believes that Mathematics has effected a reconciliation of the notions of infinity and quantity (cf. Spinoza and Time, p. 26).

${ }^{60}$ Space, Time, and Deity, Vol. I, pp. 190-9, 238-49, 276, 305, 312, 316. Cf. "The self-identity of anything is its occupation of a space-time. Diversity is the occupation of another space-time." Existence is "the occupation of any space-time." "Being is the occupation of space-time which also excludes other occupancy of space-time." "Universality is . . . . the name of . . . the uniformity of Space (or what is the same thing, SpaceTime)." "Relation amongst existents follows from the continuity of SpaceTime," and "expresses the continuity"; and relations are themselves spaces and times. Substance is a "defined volume of space-time"; "the persistence of a space in its time or the occupation of a space by a duration." "Everything is in the end, in its simplest terms, a piece of Space-Time and breaks up therefore into parts, of which it is the rehole."

${ }^{70}$ Ibid., Vol. I, p. 220. 
angles which compose an oblong to the oblong." 71 Furthermore, Logic is identified with Formal Logic and with mathematics "at its limit"; it is the formal science of truth concerned with "the forms of propositions in which the connections of things are expressed," or "the formal coherence of propositions in their character of propositions." 72 The so-called Laws of Thought appear to be accepted as ultimate, i. e., as metaphysical laws, and are given a spatio-temporal interpretation and ground. ${ }^{73}$ Metaphysics, while differing from mathematics as to method in the ways which have been noted above, like mathematics seeks a 'solid foundation' among particular experiences ${ }^{74}$ (though this foundation is to be looked for primarily where the empiricist rather than the intellectualist hopes to find it). The method of metaphysics is empirical, and the word empirical "is intended to mean nothing more than the method used in the special sciences." But as to subject-matter, metaphysics, while like all sciences selective, like mathematics selects the simplest, most general and abstract characteristics of reality-the categorical, "a priori," or "pervasive" features of things. Each appears to be an empirical science of non-empirical material..$^{75}$

For Alexander, then, the problem of metaphysics is primarily this: according to the deliverances of immediate experiences, ${ }^{78}$ what do all things (regarded democratically as beside one another and equally real $)^{77}$ have in common? And perhaps here is to be

${ }^{7}$ Spinoza and Time, p. 42.

${ }^{72}$ Space, Time, and Deity, Vol. I, pp. 175-7, 297 ; II, p. 270.

${ }^{73}$ Ibid., Vol. I, pp. 205f. "The law of identity means that to occupy Space-Time is to occupy it, that a thing is itself." The Law of Contradiction "means that occupation of one piece of Space-Time is not occupation of a different one" or "that one space-time is not another." The Law of Excluded Middle "means . . . that given a special occupation of Space-Time, every occupation of Space-Time is either that or belongs to the rest of Space-Time."

74 This is the common ground on which the extremes of intellectualism and empiricism meet. For Alexander there is first the "given," the "deliverances" of immediate experience, the "indefinables" of "acquaintance"; and secondly, every science "finds the simplest principles from which to proceed to the propositions it is concerned with." See below, pp. $96 \mathrm{ff}$.

${ }^{75}$ Ibid., Vol. I, pp. 4, I75-9; II, pp. $206 f$.

${ }^{\pi}$ See pp. 96ff. below.

"Ibid., Viol. I, pp. 5-8, 338. 
found the clearest trace of intellectualism in Alexander's thinking, namely, the tendency to look for the ultimate, the fundamental, and the primordial in the simplest, most elementary, or pervasive features of reality, i. e., to identify the essentially and absolutely real with what all things have in common. For surely it is of the essence of intellectualism to lose sight of the particular and concrete and to identify reality with the general and abstract, or, in other words, with the formal and empty. Alexander's immediate experiences appear to him to report that all realities (whether physical or non-physical) possess in common, as their simplest and most elementary characters: spatiality, temporality, motion, existence, identity, diversity, universality, particularity, individuality, relation, order, substance, quantity, intensity, magnitude, number, causality, reciprocity, and being a whole of parts. ${ }^{78} \mathrm{Im}$ mediate experience, with the aid of reflective analysis (and with the aid perhaps of suggestions from the newer mathematics and mathematical physics, as well as from Plato, Descartes, and others), prompts Alexander (I) to single out space, time, and motion as simpler, more elemental, hence more fundamental and ultimate than the other pervasive properties of things; and (2) to regard the union of space and time as identical with motion; and (3) to regard this union, Space-Time or Motion, as in some sense in which the other pervasive features are not, a 'stuff' or 'material,' in fact, the one and only ultimate stuff of which not only all things but also all of the other pervasive features are made. ${ }^{79}$

${ }^{78}$ Ibid., Vol. I, B. II.

79 The notion of "stuff" or "material" or "matrix" remains obscune to the end in Alexander's thought. It is not identifiable with substance or apparently with being or existence, all of which are less ultimate than Space-Time, though Space-Time is called the "simplest being" and "this one simple being" (Vol. I, p. I72); and Space and Time are said to be "themselves entities, or rather there is one entity, Space-Time" (Vol. I, p. I68). Space-Time is the "quarry from which the stones [substances] were hewn," "not the substanqe of substances, but . . . . the stuff of substances." "Just as a roll of cloth is the stuff of which coats are made, but is not itself a coat, so Space-Time is the stuff of which all things, whether as substances or under any category, are made." Cf. "The variable and the pervasive are alike Space-Time . . . . all the categories are configurations of space-time" (Vol. I, p. 345). One cannot but wonder why "stuffness," which is apparently a feature of any space-time, is not classed among the categories. 
Immediate experience reveals in Space-Time or Motion (the absolute) properties such as the following: occupation, continuity, infinity, dimensionality, uniformity as constant curvature, contour, coexistence, duration in succession, betweenness, uniformity and irreversibility of direction. ${ }^{80}$ From these essential properties of the ultimate reality or Space-Time, the pervasive characters or categories other than spatiality, temporality, and motion may be derived. ${ }^{81}$

Now it is to be noticed that for Alexander the characteristics of anything real include all of these pervasive, categorical, a priori, or non-empirical features of reality (i. e., the aspects of ultimate reality, and what is due to the properties of ultimate reality). But they also include certain empirical, non-pervasive characteristics or qualities (i. e., characters which are neither aspects of ultimate reality nor due to its essential properties), such as materiality, the secondary qualities, life, and mind. Thus there emerges a distinction between the $a$ priori or non-empirical and the empirical or contingent which, in spite of Alexander's attempts to soften it, remains sharp to the end, and is reminiscent of the eighteenth century intellectualistic distinction between the necessary (what follows from the nature of ultimate reality) and the contingent (what does not so follow, but is accidental, and not essential to ultimate reality).

It is to be noted secondly that, for Alexander, ultimate reality is to a high degree undifferentiated, hence illustrative of what has been called in the present work an abstract universal. For ulti-

so Ibid., Vol. I, B. I, Ch. I and II.

81 "The categories are only determinations of finites or other beings within Space-Time which these parts of the whole owe to the properties of any space-time." "All the categories are derived from the nature of Space-Time in any part of it." "With each category in turn we have indicated the basis of it in Space-Time-the occupation of Space-Time, the continuity of it which lies at the bases of relation, its uniformity or the constancy of its 'curvature' and the like." "The categories are, as it were, begotten by Time on Space." They are "expressions of the nature of Space-Time itself"; "arise out of the intrinsic nature of Space-Time . . . . or . . . . any space-time"; "owe their being," "follow from," "flow from," are "implied in," or "presupposed by" the properties of SpaceTime. (Ibid., Vol. I, B. II, Ch. I, IX, X, and pp. 195, 207, 262, 284, 302, 305f., 312; Vol. II, B. III, Ch. I-III, and p. 312. See pp. IIgff. below.) 
mate reality (Space-Time) is "unqualitied," capable of existing without mind, life, secondary qualities, and materiality, and in fact did once so exist. Meaning, value, purpose, or any teleological principle are also unessential to it; and apparently it must be thought of as not necessarily involving change, becoming, a nisus, or growth, since these are not to be rated among the categories. Ultimate reality has in the first instance only mathematical or mathematico-physical properties (occupation, constant curvature, etc.), and in the second instance such features only as characterize the phases of reality studied by mathematics, mathematical physics, and formal logic (existence, identity, etc.). Thus the real comes to be identified ultimately and essentially with three of its most abstract and empty phases (space, time, and motion), with the universe in one of its lower expressions, or with what it is when it is very close to its minimum. The categories are likened to "the grey or neutral coloured canvas on which the bright colors of the universe are embroidered." The reader "needs only, in order to help himself in the abstract (that is, elementary) inquiry, to think of empirical things, divest them of their qualitative colouring, and single out the categorical foundations of what the colouring is correlated with." Furthermore, the whole is not a system of relations. None of the categories apply to reality as the whole, their source, and the whole has no characters or qualities superior to the categories. Though asserted not to be a negative conception, it would appear that little or nothing can be said of it as the whole. Space-Time, as also its fundamental features (occupancy, etc.) and the categories, cannot be defined or described; they can "in the end only be indicated and known by acquaintance," or "revealed to us direct as red or sweet are." "We attempt to describe what is only to be accepted as something given, which we may feel or apprehend; to describe, as has been said above, the indescribable." ${ }^{82}$ We have then as the whole of reality and as the essentially, absolutely and primordially real an approximation to an abstract universal, i. e., ( $\mathrm{I}$ ) a whole which is capable of existing apart from (or is independent of much of) the variety discoverable within it (qualities, value, etc.) and to which this variety stands in no essential rela-

Ibid., Vol. I, pp. 38f., I86, 192f., 324-42; II, 368, 409f., 422f. A world "anterior to qualities" is not an "illegitimate abstraction." 
tion and makes no difference; and (2) a whole which is very close to a blank, which includes little in the way of differentiation, and about which as a whole almost nothing can be said. Perhaps we can say only that it is the all-embracing and self-contained in the sense that there is nothing outside of it; that it is the bare "stuff" or material out of which everything is made; or that it is the primordial, unmeaning chaos out of which all else emerges in time, though itself without beginning or end; or that it has two and only two attributes: space and time. ${ }^{83}$ All that is found outside of the subject-matters of the three abstract disciplines, mathematics, mathematical physics, and formal logic (e. g., materiality, secondary qualities, change, growth, life, and mind), having been excluded from the Ultimate and Whole, have to be brought back by Alexander as qualities of finite "pieces" of SpaceTime. ${ }^{84}$ As such they remain inexplicable "emergents," unidentifiable with mere space-time or motion, and in no essential connection with the fundamental properties and characters of Space-Time, hence, as it were, immigrants from nowhere. ${ }^{85}$

It is to be noticed, thirdly, that Alexander's world is a mechanistic world. Causality is one of the categorical or universal

${ }^{3}$ Cf. Spinoza and Time, p. 77.

${ }^{84}$ Cf. Space, Time, and Deity, Vol. I, p. 342. "All the wealth of qualities which makes things precious to us belongs to existents which grow within it [Space-Time]."

${ }^{85}$ Cf. ibid., Vol. I, pp. 229, 328, 343; II, pp. 312, 353. "A category implies no empirical determination in the finites to which it applies." "How there comes to be particulars at all" is a problem "apparently insoluble." "Quality is the distinctive empirical element in things, as contrastred with their a priori or categorical characters and with the relations of empirical things which arise from their being complexes of Space-Time." "The empirical is the variable or contingent." "The Universe, though it can be expressed without remainder in terms of Space and Time, is not merely spatio-temporal. It exhibits materiality and life and mind." See below, pp. 117-22.

There is also a 'leveling' tendency in Alexander's thought which deserves notice because it is always in danger of forcing him to lose sight of the uniqueness of the various qualitative levels, and to define the latter in terms of what they have in common with the lower, e.g., knowing becomes 'nothing but' compresence. Similarly, mind, the body-mind relation, freedom, value, etc., tend to become identified with what is analogous to them on lower levels (cf. II, pp. 75-83, 302-35). 
fcatures of reality. "Reciprocity ... is reciprocal causality," a "transaction ... in which each partner is cause and effect in turn." Causality is the "relation of continuity between two different motions," "the motion which precedes that into which it is continued in the order of time being the cause and the other the effect." The extreme instrumentalistic, as well as the extreme intellectualistic, interpretation of causality must be rejected..$^{\mathbf{8}}$ Prediction cannot go beyond past experience and present knowledge. The future is not entirely predictable. It is completely predictable in terms of Space and Time, and each new level of life, in terms of lower levels, though not in itself.$^{87}$ In the unfolding of the characters of the universe, the new appears, i. e., qualities, which are unpredictable. Yet, although there is unpredictable novelty and uniqueness, there is thorough determinism: after the event we can always see that it was determined and can see its connections with conditions that determined it. All causality is a tergo, the past determining the present and the present the future. "Our power is an instance of causality," i. e., of continuous transition from an earlier to a later motion. Mental processes affect each other causally and may be causes or effects of non-mental processes. "The experience we have in our own persons of causality .... is but an example of the same relation as we find outside ourselves in external events." "Freedom is nothing but the form which causal action assumes when both cause and effect are enjoyed; so that freedom is determination as enjoyed or in enjoyment." This is self-determination or willing freely, namely, enjoying "the determination of one mental state by another." "Freedom in general is the experience which each thing has of the working of its own nature"; and as such (i. e., "enjoyed determination"), "is not an exceptional privilege of

${ }^{86}$ Ibid., Vol. I, pp. 279-30I. Cf. "Implication is a notion posterior to causation"; the relation of ground and consequent eviscerates the causal relation of its essential element of Time."

${ }^{87}$ E.g., the movements of the French Revolution might have been calculated beforehand in mechanical or even physiological terms, but we could not have predicted what they meant. We might predict a human future in physiological but not wholly in mental terms; from knowledge of neural (or mental) processes, it may be possible to predict the combination of ideas a man will have at a future date, but not the meaning of the ideas or the spirit of them or the objects to which they refer. 
human life," but universal. "It involves no feature save enjoyment which distinguishes it from natural or physical action." "Purpose is the idea of an end which precedes the action. But this idea (I mean the ideation of it) is itself determined by antecedents and in turn determines action." This determinism, Alexander thinks, is compatible with the reality of responsibility, the consciousness of obligation, the sense of guilt, and remorse. ${ }^{88}$

In the fourth place, it is to be observed that despite the emphasis placed by Alexander on change, becoming, novelty, and evolution, these are not regarded by him as categorical, as due to the fundamental properties of Space-Time or ultimate reality, hence, not as necessary characters of things. They are, rather, empirical characters of finite existents or things, as are the various "qualities." Indeed, even motion's title to be classed as categorical, instead of as a quality of Space-Time, is not entirely beyond dispute. In a word, when Alexander comes to select the "essential," the "prerogative," or "highest kinds of beings," which form the "warp" or the "groundwork" of reality, preference seems to be accorded the static features of reality. ${ }^{89}$ Moreover, at times Alexander appears to give even motion and development themselves a more or less static interpretation in terms of successive different rearrangements of instants with reference to immovable points. For instance, we read: "What we ordinarily call motion of a body is the occupation by that body of points which successively become present, so that at each stage the points traversed have different time-values when the line of motion is taken as a whole." "Points do not of course move in the system of points, but they change their time-coefficient." "In terms of earlier and later, $b$ having been later and $c$ earlier, $a$ becomes later and $c b$ earlier. Now this is the meaning of motion." "We have to think of lines of advance as displacements of the present in relation to past and future over positions in Space. In this way we conceive of growth in Time, or the history of the Universe as a whole, or any part of it, as a continuous redistribution of instants of Time among the points of Space. There is no new Space generated as Time goes on, but within the whole of Space or the part of it the instants of Time are differently arranged, so that points be-

${ }^{88}$ Ibid., Vol. II, pp. 290, 315-36.

${ }^{80}$ Ibid., Vol. I, pp. I84-6, 320-30, $342 f$. 
come different point-instants and instants become also different point-instants. I believe that this very abstract (I mean very simple, yet highly concrete) conception lies, in fact, very near to our common notions of a growing world." 90

Broad's stand with reference to the issue of mechanism and teleology is tersely stated in the following passage: "Teleological behaviour is in itself no sign that anything but mechanical laws in the most rigid sense are operating. Nothing could be more teleological than a watch or a motor-car. Whatever laws be operating, the behaviour of a system depends on its structure and its components as well as on general laws. On any view the question of teleology and its explanation comes back to the question: How did this system come to have the peculiar structure and components which determine in accordance with general laws that it shall behave in this teleological way? . . the ultimate question is: How do these particular material systems called organisms come to have their peculiar structure and components. So long as we explain their origin by laws, whether mechanical or otherwise, we merely referred back to earlier collocations of matter and so on, ad infinitum." 91

It seems necessary to conclude that the Realist seeks for the ideal of knowledge in formal logic and mathematics.9 ${ }^{92}$ The concepts, principles, and methods of these abstract disciplines are regarded as final, i. e., as valid in any reference without supplementation and reinterpretation. Philosophy, like these two special sciences, is regarded as having for its subject-matter only the most abstract aspects of reality ; and the method of philosophy is identified with the technical procedures of these special sciences, largely because, apparently, these procedures have been found by

${ }^{20}$ Ibid., Vol. I, pp. 61, 63. Cf. pp. 65, 204, 339. "Material bodies can move in this absolute plenum of Space-Time, because their motion means merely that the time-coefficients of their spatial outlines change." "Becoming . . . is in fact motion or Space-Time in its simplest conceptual form." "In the redistribution of dates among places, new existents are generated within the one Space-Time." Cf. Spinoza and Time, p. 17: "Religious passion is a manifestation of the nisus which the human being possesses because he is caught in the general machinery."

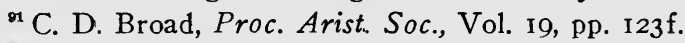

${ }^{2}$ Bearing in mind the qualifications which must be made in the case of Alexander and which have been noted above. 
mathematicians to be extremely fruitful in the abstract realm of mathematics. ${ }^{93}$ Realistic thinking frequently displays a confidence in the possibilities of 'scientific,' i. e., mathematical, method in philosophy which is distinctly reminiscent of a similar optimism and 'dogmatism' in the seventeenth century. ${ }^{94}$ The Realist's categories of interpretation are the notions employed by formal logic and mathematics with the addition of some taken over from physics, chiefly from mathematical physics. ${ }^{95}$ The universalizing of these categories leads to a static and mechanistic interpretation of reality in terms of : (I) passivity and immutability $;^{96}$ (2) either rigid mathematical and logical relations or external causal determination; (3) abstract universals; and (4) being, stuff, or substance. ${ }^{97}$ Therefore, growth, meaning, and other teleological and rational aspects of reality, in so far as recognized at all, have to be assigned a very restricted if not subjective rôle as characters of finite existents.

\footnotetext{
${ }^{23}$ For example, Cantor, Peano, Frege, Whitehead, Russell himself, Lorentz, Minkowski, and Einstein.
}

${ }^{24}$ It will be remembered that the optimism and dogmatism of the seventeenth century issued in the skepticism of the eighteenth century. Hume, for example, made it evident that if the methods and conclusions of abstract logic and mathematics are taken as the ideal of knowledge, the only certain knowledge which we have consists of propositions concerning the relations between our own ideas, chiefly mathematical ideas, while propositions concerning matters of fact, which comprise the rest of our knowledge, must be regarded as only more or less probable. (Hume of course left unexplained the possibility of mathematical ideas and relations and of the paltry amount of certain knowledge which he supposes attainable.) It is interesting to compare with Hume's standpoint the recent statements of Russell to the effect that (I) the mathematical method alone will yield objective knowledge, induction yielding only probable generalization; and yet (2) that mathematics is a subject in which we never know what we are talking about or whether what we are saying is true, and a subject which merely deduces the consequences of any set of propositions which seem humanly interesting. For further statements implying skeptical tendencies in Russell, see below, p. 99.

${ }^{25}$ Add to the categories enumerated by Alexander (see p. 83 above) the following: form, appearance, actuality, possibility, and necessity, and we have nearly all of the notions employed by the Realists in their interpretation of reality.

"Such nisus and novelty as Alexander recognizes appears as something inexplicable and "superinduced." (See below, pp. II7-22.)

"See below, Ch. III, Sec. 3. 


\section{Analysis}

In the preceding section attention was called to certain formal and mechanistic tendencies which have characterized Realistic thinking from the first. The intellectualistic processes which give rise to such tendencies seem to be always abstracting from the differences in reality, and, since not subordinated to processes of concretion, seem to substitute for concrete reality one or more abstract universals. The latter may take the form (I) of static concepts; or (2) fixed laws, formulae, and equations, perhaps related 'subsumptively' or constituting a kind of skeletonized reality; or (3) a mechanistic and largely undifferentiated and pauperized Absolute. From this point of view, particulars tend to be lost sight of, or are regarded as mere instances of universals, or are admitted to be real but inexplicable. So far only an incidental mention has been made of what appears to be another characteristic tendency of Realistic thinking, namely, the almost complete trust which it places in the process of analysis unaided by synthesis as a means of understanding reality. ${ }^{98}$ This feature of Realism will now be considered with special reference to the atomistic interpretations to which it seems to have led.

Russell maintains that "the essence of philosophy . . . . is analysis, not synthesis," 99 and that "the true function of logic," "as applied to matters of experience . . . . is analytic rather than constructive." $\mathrm{He}$ calls his method the "Logico-analytic" method. ${ }^{100}$ Moore writes: "we cannot define anything except by an analysis, which, when carried as far as it will go, refers us to something, which is simply different from anything else, and which by that ultimate difference explains the peculiarity of the whole which we are defining." 101 Alexander also characterizes the method of philosophy as "purely analytical," and "analytical to the death"; and says: "to define is to explain the nature of something in terms of other and in general simpler things, themselves existents. ${ }^{102}$ When analysis is pushed as far as it will

${ }_{28}$ 'Synthesis' in the sense of comprehending anything in its wholeness.

- Mysticism and Logic, p. I13.

Scientific Method, pp. v, 8, 65. Cf. Analysis of Mind, pp. 9, I5, 306 , for the philosophical importance of an analysis of mind and matter.

${ }^{101}$ Principia Ethica, p. Io.

${ }^{102}$ Space, Time, and Deity, Vol. I, pp. 175-7, 336. 
go, according to Russell, Moore, and Alexander, we reach indefinables or ultimate simples.

In the employment of this analytic method, philosophy, in Russell's words, "starts from what may be called 'data," or "matters of common knowledge, vague, complex, inexact." ${ }^{103}$ Analysis reveals the fact that parts of this body of common knowledge are immediately known, while the rest consists of extensions based on others' testimony and on common sense and scientific inferences. This immediate knowledge cannot be deceptive. ${ }^{104}$ It is "completely self-evident"; only inferences from it are ever erroneous. It is also perfect and (so far as it goes)

${ }^{103}$ Scientific Method, pp. 65ff.; cf. p. 211. In The Analysis of Mind, the term "data" refers, apparently to what analysis terminates in rather than what it starts with. "Data" are said to be: (I) "sensations, images and their relations" (the ultimate data of Psychology); (2) perceptions, "in which only the sensational core is ultimately and theoretically a datum," i.e., "sensations, which include within themselves certain spatial and temporal relations" (primarily data in any science other than psychology); (3) "those objects of whose existence we become certain through perception"; (4) "those propositions of which the truth is known without demonstration, so that they may be used as premises in proving other propositions"; and (5) those objects whose existence is asserted by such propositions. "Data are not those things of which our consciousness is earliest in time," or "the things of which we feel sure before scientific study begins, but the things which, when a science is well advanced, appear as affording grounds for other parts of the science, without themselves being believed on any ground except observation" or "on having been seen." Data involve belief, memory, "mnemic phenomena," judgment, trained observation, "analytic attention, knowing the sort of thing to look for, and the sort of thing that will be important," making "the kind of observation that will be scientifically illuminating," etc. Data are therefore "just as sophisticated and elaborate as the theories" based upon them (pp. 297-9).

${ }^{104}$ In The Analysis of Mind, Russell appears to waver between this position and one which asserts the fallibility of immediacy and repudiates self-evidence as an intrinsic property of beliefs. On the one hand, we read of (I) "indubitable data" or "fact," and the "certain" and "fixed" with which we start in any study; (2) of data that are "propositions the truth of which is known without demonstration, so that they may be used as premisses in proving other knowledge," data that are "grounds for other parts of the science without themselves being believed on any ground except observation" or on "having been seen"; and also (3) of feelings of familiarity, pastness, expectancy, and reality, which we must trust in order to have knowledge of anything other than the 
complete; it admits of no degrees. Russell says, for example, 'When we speak of becoming 'better acquainted,' as for instance with a person, what we must mean is, becoming acquainted with more parts of a certain whole; but the acquaintance with each part is either complete or non-existent." "I know the colour perfectly and completely ${ }^{105}$ when I see it, and no further knowledge of it itself is even theoretically possible. Thus the sense data . . . are ... things immediately known to me just as they are." In other words, the immediate object is as it is experienced as. This immediately known portion of knowledge, which is believed on its own account "without the support of any outside evidence," comprises besides knowledge of sense data, knowledge of other data and knowledge of truths. "The hardest of hard data are of two sorts: the particular facts of sense, and the general truths of logic." The solid foundation of immediacy would also seem to include: data and facts of introspection and memory, experiences of some relations and concepts (i. e., universals) and cer-

present (Pp. II, I35, I52, I55, I64, 297-9). On the other hand, we are told that sense-perception, so far as cognitive, involves non-sensory elements contributed by past experience (by memory, recognition, association, habitual correlation, interpretation, and inference), expectation, instinct, etc. These non-sensory elements are fallible, dubitable, and may be illusory, and would have been different had past experience been different. Introspection, too, is exceedingly fallible, and liable to falsification in accordance with preconceived theory. "Data" involve belief, mnemic phenomena, memory, judgment, etc., so that "it follows that no datum is theoretically indubitable, since no belief is infallible." In fact, beliefs have no intrinsic properties (e.g., self-evidence, indubitableness, or feeling of subjective certainty) by means of which those that are true and constitute knowledge can be distinguished from those that are false or uncertain, without reference to outside fact. There is no infallible or absolute criterion of truth (pp. 43, 55, 60, 8I, I22, I35-40, I58, 232, 254, 262-6, 297-8).

${ }^{106}$ Cf. Analysis of Mind, p. 306, "wholly true, even if not the whole of truth." Yet compare a still more recent passage, in Russell's Free Thought and Official Propaganda, pp. I4f., "None of our beliefs is quite true; all have at least a penumbra of vagueness and error. The methods of increasing the degrees of truth in our beliefs are well-known .... scientific knowledge at the moment is sure to require correction with the progress of discovery. . . . In science, where alone something approximating to genuine knowledge is to be found, men's attitude is tentative and full of doubt." 
tain a priori, general truths of mathematics and perhaps of ethics. All our knowledge of things and of truths, according to Russell, "rests upon acquaintance as its foundation." 108

By analysis we reduce these matters of common knowledge "to propositions which are as nearly as possible simple and precise, and we arrange them in deductive chains, in which a certain number of initial propositions form a logical guarantee for all the rest. These initial propositions are premises for the body of knowledge in question. Premises are thus quite different from data-they are simpler, more precise, and less infected with logical redundancy.... The discovery of these premises belongs to philosophy; but the work of deducing the body of common knowledge from them belongs to mathematics, if 'mathematics' is interpreted in a somewhat liberal sense." Now, in the course of this analysis, "when everything has been done that can be done by method, a stage is reached where only direct philosophic vision can carry matters further. Here only genius will avail." "All depends, in the end, upon immediate perception" or "intuition." "Philosophy is, in fact, mainly a question of insight and perception." "The discussion of indefinables-which forms the chief part of philosophical logic-is the endeavor to see clearly, and to make others see clearly, the entities concerned, in order that the mind may have that kind of acquaintance with them which it has with redness or the taste of a pineapple." "Some propositions are true and some false, just as some roses are red and some white." "It is plain that true and false propositions alike are entities of a kind, but that true propositions have a quality not belonging to false ones, a quality which, in a non-psychological sense, may be called being asserted." Moore, very early, concluded similarly that the truth or falsehood of a judgment "cannot depend on its relation to anything else whatever, reality, for instance," but "must be immediate properties of its own." 107

${ }^{108}$ Problems, pp. 73 ff.; cf. Scientific Method, pp. 68ff., I44f.; Mind, N. S., Vol. 22, p. 78. In The Analysis of Mind, universals are excluded from "data" and said to be an inferred part of the structure of the world, if real at all (p. 228).

${ }^{107}$ Russell, Scientific Method, pp. 211, 239-41; Mathematical Philosophy, p. 145; Principles, pp. v, 35, 129f.; Mind, N. S., Vol. 13, p. 523; Moore, Mind, N. S., Vol. 8, p. 192. 
Alexander's system does not appear to be so unambiguously a philosophy of immediacy as does the early thought of Moore and Russell, and chiefly because he professes a coherence theory of truth. "Truth is a coherent whole of knowledge," we read; "true propositions are those which settle down into a system with one another; errors are propositions which do not cohere with the rest and are discarded." Objects are not always what they claim or pretend to be; the prima facie cannot always be trusted; "the erroneous proposition at its face value is not real." "Error is always partial truth, and truth in its turn may contain the seeds of error." "As knowledge grows .... propositions true for the older revelation may need to be readjusted for the fuller one." "Percepts and memories are undeveloped or implicit judgments." 108 "The simplest objects of experience are full of our ideas. . . . Half the object is ideal, due to our interpretation of what we see." ${ }^{109}$ All our experience is "helped out by reflection." 110

It would seem, however, that Alexander's 'coherence' theory of truth differs in several important respects from that of the Idealists, and in particular does not exclude an ultimate appeal to immediacy. Reality, for Alexander, "is what it is" and "will be what it will," a ready-made something, independent of mind, which comes to be experienced by mind but which would have "been" and would have been in no wise different, were there no mind or experience. "There is no property of coherence in reality itself"; "system or coherence belongs not to reality as such but only in its relation to mind." Coherence means the property of not having features which differ from those of the real, together with the property of not differing from "social believings" or the

${ }^{108}$ Space, Time, and Deity, Vol. II, pp. 247-72, 204-8. It is difficult to determine whether Alexander conceives of percepts and memories as like what the coherence theory of the Idealists means by 'judgment,' or conceives of judgments as like what Realists mean by percepts and memories.

${ }^{109}$ Ibid., Vol. I, pp. 4of. Here, the significant question is: Can we, according to Alexander, analyze out of these simple objects a "given" completely unmodified by the ideal supplementation?

${ }^{110}$ Ibid., Vol. II, p. 3I. It is impossible to say just what the word "reflection" means in this passage. Elsewhere Alexander distinguishes sharply between direct experience and inference, between 'acquaintance' and 'description' or 'knowledge about,' etc. 
beliefs of the "standard mind." "True propositions cohere; or rather false propositions are incoherent with true propositions and are rejected by us." ${ }^{111}$ There are no degrees of truth: "one finite may be more complete or more highly organized than another, but the second occupies its space-time as much as the first, and is equally real; and the propositions about it equally true." 112 Propositions that embody categorical characters ("as that every event has a cause") cannot change. ${ }^{113}$ And we can say of all truths: "once true always true" within the narrow range of fact within which they were first revealed. But, "a theory may be true for one generation and false for the next." 114 Moreover, the self-contradictory is not derivatively real; it is "downright false."

Alexander's philosophy therefore appears to appeal in the first instance to a 'given' of immediate experience, and only in the second instance to coherence,- - a procedure which should not be unexpected in view of his adoption of the empirical method. As he says, he "starts from Space-Time as a given experience." "Space-Time itself and all its features are revealed to us direct as red and sweet are. We attempt to describe what is only to be accepted as something given, which we feel and apprehend," i. e., what is "known only by acquaintance." "Our description of Space-Time itself and of the features which belong to any bit of it is but a means of reaching by thought to what is deeper and more fundamental than the products of thought." "That the categories are begotten by Time or Space, or are fundamental

${ }^{111}$ Ibid., Vol. II, pp. 252-8, 272.

${ }^{113}$ Ibid., Vol. II, pp. 263-5. "Comprehensiveness" appears to mean for Alexander not inclusiveness, but wide range of applicability, so that "number," for example, would be higher than "life" or "mind" in any scale in which comprehensiveness determined rank. "Harmonious" means intimate connection of parts. "These things make the reality and its correspondent truth more perfect but do not affect its intrinsic reality or truth. It is only that there is more to reality or truth in one case than the other; a wider range or richer contents in one case than the other."

${ }^{113}$ Loc. cit. Apparently, the test of "conceivability," according to Alexander, can be employed only in the region of the categorical (p. 257).

${ }^{114}$ Loc. cit. It is difficult to see how this contention is consistent with the realistic conception of a ready-made reality, known directly, hence completely, in such part as known at all. However, if such a change can be consistently admitted, it must be a change from the wholly true to the wholly false, since there are no degrees of truth. 
features of any space-time," is "founded not on any pretence of proof or reasoning but on empirical inspection."115 "The appeal is to the bare facts"; "the facts are accepted as experience supplies them." "Facts however strange the description of them may be, must be accepted loyally and our theories accommodated to them." "It is a fact that a triangle's angles are equal to two right angles, a fact which is discovered by inspection as all facts are." Of the union of the same and the other in "existence," he says: "such union calls for no explanation; it is given with Space-Time itself." 116 "The appeal," he says again, in describing the relation of mind and object, "lies from Berkeley to experience itself. So appealed to, my experience declares the distinct existence of the object as something non-mental .... the distinct existence of my object from my mind is attested by experience itself. This is a truth which a man needs only to open his eyes to see." "When I receive a sensation from an external object, I feel myself passive to that object; I enjoy my sensing as an effect of the sensum, which is its object. This is not a mere postulate made by philosophers for theoretical purposes-that there is an external cause of my perceptions. It is a direct deliverance of experience, and Locke and Berkeley, who insist (particularly Berkeley) on our passivity to sensations in contrast with our activity in imagination, were rendering a fact of experience not a dogma." "Postulates are to be regarded in metaphysics with the deepest suspicion; and no postulate is needed for what experience, which is our only ultimate test, asserts." ${ }^{117}$

There are those, no doubt, to whom it will come as something of a surprise to read that so much as is designated in the passages just quoted is to be accounted to the 'given': Space-Time, its properties, the categories, the distinctness of the object as nonmental, the passivity of the self in sensation, the external causality of perception, etc. But in truth these passages far from adequately indicate the range and depth of the immediately given in Alexander's view. Immediate experience also reveals: ( $\mathrm{I}$ ) our own existence, as substances, as unities, and as permanent amid

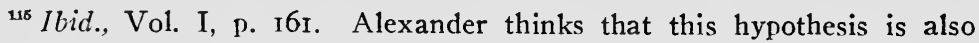
justified by its "metaphysical success" in the way of unifying data, etc.

${ }^{110}$ Ibid., Vol. I, pp. 126-7, I33, 195, 207, 291, 336f.

${ }^{118}$ Ibid., Vol. I, pp. I6, 28; II, p. 156; cf. p. 247. 
changes, in our bodies or heads, and in the same space and time with our objects; (2) the oneness of body and mind or of mental and neural processes; (3) the pastness or futurity of objects of memory and expectation; (4) the existence of universals and values; (5) the existence of minds in others and their likeness to ours; (6) the existence of deity or God. Immediate experiences are apparently of different kinds, the simplest and most pervasive of which is intuition. Space, Time, Space-Time, Motion, their properties, the categories, and the primary qualities are apprehended by intuition; the secondary qualities, materiality, and life, by sense ; universals, by thought; values, by appreciation; the mind, by acquaintance in enjoyment; other minds and God, by emotion, assurance, or faith. ${ }^{118}$

It is plain then that the analytic method of the Realists: (I) seeks a foundation for knowledge in terms of solid data; (2) is a philosophy of immediacy; (3) implies that truth can be a property of isolated entities; and (4) that absolutely certain and complete knowledge is attainable. What is sought, partly in the immediate data of sense, etc., and partly in the immediate insight which in the end replaces the process of analysis, is a logical prius which is self-evident and infallible and possesses complete truth in its own right apart from all other truths or truth as a whole. From a number of such isolated self-existents all other truths are to be deduced or inferred. The prius is to furnish the guarantee of the validity of all the rest of truth. Now, to take refuge in immediacy, and separate it absolutely from mediacy, would seem to be tantamount to the rejection of any objective criterion of truth, since there seems to be no reason why each man's immediate experiences should not be regarded as final for him, however much they may vary from those of others. In other words, a philosophy of immediacy implies relativism and subjectivism $^{119}$ and, when subjectivism becomes self-conscious,

${ }^{118}$ Ibid., Vol. I, B. I, Ch. III, IV, and p. 29; Vol. II, B. III, Ch. I; B. IV, and p. I55. Cf. "Facts about what God is felt to be, facts comparable to the green which we see in leaves or to the fragrance of mignonette" (p. 396). The religious sentiment is "like the apprehension of colour or life, except that we cannot say what the new quality is like. . . . We are only sure that it is there" (pp. $4 \mathrm{I} 6 \mathrm{f}$.).

${ }^{110}$ So far as the "standard mind" is appealed to by Alexander (rather than coherence) he escapes a complete subjectivism, but becomes involved 
skepticism. Consequently, no surprise should be occasioned by Russell's recent contentions that not only is there no infallible criterion of truth, but that the belief in the existence of anything outside of one's own experience is a "prejudice"; that "it is difficult to find any ground, except a pragmatic one, for supposing that memory is not sheer delusion"; that "the non-existence of the past," "like all skeptical hypothesis . . . . is logically tenable, but uninteresting"; and that "universal skepticism is" "theoretically" or "logically" "irrefutable" and "unassailable."

The standpoint which takes analysis as final, Logical Atomism, implies that "whatever is complex is composed of related simple things" and that the part is prior to the whole. It follows that ideas, problems, propositions, and judgments, if complex, may be dissected into simpler units. ${ }^{121}$ As was pointed out above, the single, active, significant whole which the Idealist calls judgment is dissected into (I) one or more mental acts, processes, occurrences, or states, and (2) a static relation of reference, or a "form of words" or a proposition. ${ }^{122}$ Judgment is identified with the latter, the proposition, and tends to be regarded as a more or less mechanical combination of self-existent, externally related elements, which are more ultimate than the judgments they compose. ${ }^{123}$ Meanings of propositions are derivative from the meanings of their constituents. Parts can be known before the whole

in what might be termed a "group relativism." Cf. "A theory may be true for one generation and false for the next" (ibid., Vol. II, p. 263).

${ }^{120}$ Analysis of Mind, pp. 128-33, 160-3, 228, 268-71; Scientific Method, p. 67 .

${ }^{201}$ Ibid., pp. 52-7; propositions are here classified into general, molecular, and atomic. Mysticism and Logic, p. III ; Essays, p. I69; Principles, p. 442.

${ }^{122}$ Alexander intends to employ a simpler analysis: (I) the act of judging, and (2) the object or proposition, which is part of reality itself. A proposition is an "asserted perspective" of an actual event and not different from that event. Its reference to the whole of reality distinguishes it from an idea and a supposal. Yet he speaks of "propositions about reality," an expression which suggests the more complex analysis (see Space, Time, and Deity, Vol. II, pp. 249-68).

${ }^{123}$ Moore, Mind, N. S., Vol. 8, pp. I77-93; Russell, Principles, Ch. IV, and pp. $42 \mathrm{ff}$; Analysis of Mind, Lec. XII and XIII. Since, for Alexander, the proposition is a part of reality, it contains such continuity, etc., as reality (Space-Time) does. For his divergence from "Logical Atomism," see $o p$. cit, Vol. I, pp. I46ff., I69. 
is known and undergo no transformation with the knowledge of the latter.

Thus analysis shatters the whole of knowledge. ${ }^{124}$ The ultimate simples into which it dissects knowledge may be summed, or combined mechanically into a complex, or arranged in deductive chains, but a genuine whole, once shattered, apparently cannot be regained. Therefore inference comes to be conceived as a movement from one self-existent particular to another-a movement which cannot but appear miraculous so long as the particulars in question are not regarded as interconnected members of a systematic significant whole. Implication, in like manner, becomes a relation of what might be called one-sided dependence rather than one of interdependence. The ultimate simples, moreover, are set outside the rest of knowledge, and made immutable, with the consequence that the rest of knowledge neither includes them nor transforms them nor makes them any more or less true. The process of acquiring knowledge becomes therefore merely an accumulative process, an addition of static, self-complete elements, related externally. All successful investigation is therefore "piece-meal” investigation. " 'Divide and conquer' is the maxim of success. . . ." So far as the "simples" are thought of as self-complete and self-contained, they constitute an aggregate of "tiny Absolutes." ${ }^{25}$ Why such independent atomic entities ever become related to mind at all, and why (and how it is possible that) they become related in the determinate way necessary to yield the various forms and various significant wholes of knowledge which we have, would seem to find no explanation from the Realist's standpoint, and therefore become arbitrary facts, miraculous coincidences, a 'given' to be taken on faith rather than to be justified by reason.

The logical-analytic method appears to shatter the unity of reality just as it shatters the unity of knowledge. Moore, in his early thought, as we have seen, envisaged reality as an aggregate

${ }^{124}$ With the proper qualifications in the case of Alexander. Cf. the curious statement: "The aggregate of true beliefs is knowledge, and as exhibited in their inter-relations the knowledge is science" (ibid., Vol. II, p. 253).

${ }^{125}$ Cf. Russell, Problems, pp. IIIf., I23; Scientific Method, pp. 53ff.; Mysticism and Logic, pp. I12f., I28. Cf. Bosanquet, Logic, II, p. 280. 
of concepts and their combinations in external relations to one another. ${ }^{126}$ Russell tells us that he accepts from Moore "the pluralism, which regards the world, both that of existents and that of entities, as composed of an infinite number of mutually independent entities, with relations which are ultimate, and not reducible to adjectives of their terms or of the whole which these compose." 127 Again he says: "The philosophy which I wish to advocate may be called logical atomism or absolute pluralism, because, while maintaining that there are many things, it denies that there is a whole composed of those things." Russell further contends that "we can easily conceive of things that shall have no connection whatever with each other," and "that there is no such thing as the 'universe." " 128 "The only kind of unity" to which he "can attach any precise sense-apart from the unity of the absolutely simple-is that of a whole composed of parts." ${ }^{129}$ The part is not logically dependent on the whole; only a whole is logically dependent upon the existence of anything else, namely, upon its parts. ${ }^{130}$ "Whatever is complex is composed of related simple things." 131 Complexity "results from a combination of mutually external units.",132 The world-views of Russell and Nunn seem to contain two kinds of elemental simples: (I) universals or subsistents, comprising, possibly, in addition to Moore's concepts and relations, impossible or imaginary entities; and (2) particulars or existents. ${ }^{133}$ These "mutually external" atomic absolutes, for no apparent reason and in some inexplicable way, have combined to form such wholes as experience reveals.

Mind, N. S., Vol. 8, pp. I79-82, I92f.

Principles, p. viii.

${ }^{128}$ Mysticism and Logic, pp. I00, I Iof.; cf. Alexander, Basis of Realism, p. 33 .

${ }^{129}$ Principles, p. 466.

${ }^{130}$ Scientific Method, p. 74. Cf. Moore, Proc. Arist. Soc., Vol. 20, p. 51.

${ }^{121}$ Essays, p. 169; Principles, p. 442.

${ }^{182}$ Scientific Method, p. 145.

${ }^{128}$ Russell, Proc. Arist. Soc., Vol. 12, pp. 4, 24; for the status of universals in The Analysis of Mind, see pp. I3of. below; cf. Nunn, Aims and Achievements, pp. 7 ff., 142. For Alexander, subsistence appears to be only one kind of existence (space-time occupation) although universals remain to the end characteristically different from particulars and individuals (see below, pp. 124-6, 132). 
The tendency of the process of analysis, when unaided by synthesis, to lead to atomistic interpretations may be further illustrated by Russell's description of the external world. We are first told that we must distinguish between real or mathematical space, time, matter, motion, and change on the one hand, and perceived space, time, etc., on the other. Real or mathematical space is composed of an infinite number of points, and time of an infinite number of instants. Points are without extension, and instants without duration. Things are composed of extensionless, durationless elements which occupy only a point and an instant. The ultimate formal constituent of matter in physics is such a point-instant particle. Motion is the successive occupation of successive positions at successive times. The 'infinite' is either a kind of number or a property of a discrete series or collection. Continuity is a property of a discrete series. ${ }^{134}$

When we come to perceived space, time, etc., the picture becomes more complicated. ${ }^{135}$ There seems to be a different space, time, matter, and motion, or sense world for each separate sense. These different spaces, times, and worlds have to be correlated by each individual to form his own peculiar, private space, time, and sense world. There are as many of these private worlds as there are percipients. Each private world is one aspect or view of the universe, the way the universe looks from the particular point of view of some one percipient. Since there are an infinite number of points of view not occupied by any percipient, we must suppose that there are an infinite number of unperceived worlds. Such worlds, whether perceived or unperceived, may be called "perspectives." "The reference to our perceptions .... introduces an irrelevant psychological suggestion," as does also perhaps the term appearance; hence we would do better to think of perspectives in terms of the effects of various objects upon a photographic plate. ${ }^{136}$ A perspective consists of all the effects of

${ }^{134}$ Cf. Principles, pp. 43, I44, 470; Scientific Method, pp. 129, 138, 147-58, $177 \mathrm{f}$.; Analysis of Mind, pp. 94ff. The theory of quanta suggests that continuity is only apparent and that theoretically we shall be able to reach events which are not processes.

${ }^{135}$ See ibid., Ch. V, VII, XV; Mysticism and Logic, Ch. VI-VIII; Scientific Method, Ch. III and IV.

${ }^{136} \mathrm{~A}$ perception is an appearance, or effect of an object at the place 
all objects at any one place (e. g., the place of the plate), called the "passive place," or, in terms of time, of a given particular (effect or appearance) and all particulars simultaneous with it. Many of these perspectives are capable of becoming perceived worlds as soon as some one occupies their proper points of view.

No two private worlds have a space or time or entity in common. Nevertheless, the spaces and elemental constituents ${ }^{137}$ in one private world are sufficiently similar to those in other private worlds to make possible a correlation of all private spaces into one public all-embracing space, and all private views into one common system of all views of the universe, perceived or unperceived. 'Here' means the place in the all-embracing space occupied by one's private space. The sum-total of all particulars that are (directly) either simultaneous with, or before or after, a given particular may be called the 'biography' to which that particular belongs. A biography is thus a series of perspectives. Just as a perspective need not be actually perceived by any one, so a biography need not be actually lived by any one. Just as one perspective may constitute the momentary data of one percipient, one biography may constitute the whole of the data of one percipient throughout his experience. Those biographies that are lived by no one are called 'official.' An experience or life thus becomes a series of perspectives, which, it will be remembered, are but aggregates of particulars. However, "it is not only by time-relations that the parts of one biography are collected together in the case of living beings. In this case there are the mnemic phenomena which constitute the unity of one 'experience,' and transform mere occurrences into 'experiences' .... a biography .... into a life.

where there is a brain, with sense organs and nerves forming part of the intervening medium. Perceptions are distinguished from appearances of objects in places where there is no living being by the fact that perceptions are causes and effects of mnemic phenomena, i.e., they may be remembered, associated, may influence habits and give rise to images, and are different because of our past experience. Cf. Analysis of Mind, pp. 99, 104, I31.

${ }^{137}$ These elemental constituents were originally called 'sensibilia' when thought of as not necessarily data for any mind, and 'sense-data' when actually data for some mind. Since the repudiation of the distinction between mental act and object, they have come to be called simply 'sensations'. 
It is they that give the continuity of a 'person' or a 'mind.' " 138 "There is not one universal time, except by an elaborate construction; there are only local times, each of which may be taken to be the time within one biography." The history of the world is divided into a number of mutually exclusive biographies. Time relations within a biography are perceived; but those between biographies are "merely logical, being designed to afford convenient ways of stating the correlations between different biographies." There is no direct means of correlating the times of different biographies. Biographies may be correlated roughly however into a single, common, all-embracing time.

Any particular is a member of two sets of particulars: (I) a perspective (the effects of all things at a given place), and (2) the physical object, thing or piece of matter (the effects of one thing at different places). The latter may be collected together by their relations to each other: "by their similarity primarily," by their continuity and inherent laws of correlation, "and, more correctly, by the fact that they are related to each other approximately according to the laws of perspective,"139 and the laws of the medium concerned (e. g., the laws of the reflection and diffraction of light). When we have a sensation we know at least one appearance of a given object; of all or most of the remaining effects we know only the correlates and abstract properties. Each appearance has a fixed place, but is often ephemeral and gives way to another appearance. This may be brought about by a change in the physical object itself, in which case all or almost all of its effects change, or by a change in the intervening medium, i. e., in particulars not a part of the series which is the physical object, in which case only a few of its appearances change. The momentary state of a 'thing' is an assemblage of particulars in different perspectives, and not all simultaneous in the one constructed time, but spreading out from the place where the thing is

${ }^{138}$ Analysis of Mind, p. I29. Cf. "We might, in fact, define one chain of experience, or one biography, as a series of occurrences linked by mnemic
causation" (p. 83).

130 "The laws of perspective" are all the intrinsic laws of changes of appearances not due to the intervening medium, i.e., the laws according to which the particulars of one thing differ when no irregularities are caused
by a medium. 
(the "active place") with velocities (of light, sound, etc.) depending on the nature of the particulars. The temporal grouping of appearances belonging to a given thing at a given moment is in part conventional. A thing is thus a series of aspects (sensibilia or sensations) taken severally. A common sense thing is the system of all its views or the series of all its aspects in all perceived and unperceived worlds. The matter of a given thing is the limit of its appearances as their distance from the thing (or "active place") diminishes. A piece of matter is "the limiting set of appearances," i. e., "that system of appearances which the object would present if the laws of perspective were alone operative and the medium exercised no distorting effect." It "is not a single existing thing but a system of existing things." A physical object is a "system of correlated particulars in different places." Physical things are those series of appearances whose matter obeys the laws of physics. Physics is concerned with a particular only so far as it is a member of the set of particulars which would be called the effects of one thing in different places at one time (the momentary thing), such a set being determined by the laws of perspective, and a series of such sets (the permanent thing) by the laws of dynamics. So far as a particular is a member of a series of particulars at one place at different times (determined by the laws of dynamics) or a set of such series (determined by the laws of perspective) it becomes an element in a perspective, a biography, an experience, or a person, and therefore subject matter for psychology. In other words, physics is concerned with radiations from an "active place"; psychology with concentrations on a "passive place," which is a center of privacy and subjectivity.

When we attempt to discover what, precisely, according to the Realist, is the relation of the perceived world to the world of mathematical-physics and common-sense things, we seem to encounter two very different conceptions. The first is that this relation is one of partial correspondence of a perceived world to a real physical world, on which the perceived world is perhaps causally dependent. The existence of the real world may be inferred from the world of appearance, but its nature is to an extent unknowable. The second is that the perceived world alone is real, while the world of physics and common-sense things is a construction or a "symbolic fiction." The first conception seems 
to be the result of setting out from an epistemological enquiry, of taking an isolated world of independent immediates as the point of departure, and of taking for granted an ultimate dualism between mind and matter. For example, in his Problems of Philosophy, Russell begins with the question: "Is there any knowledge in the world which is so certain that no reasonable man could doubt it?" He adds: "In the search for certainty, it is natural to begin with our present experiences," "our personal sensible acquaintance." "All this, which is psychological, we are not calling in question. In fact, whatever else may be doubtful, some at least of our immediate experiences seem absolutely certain." "By inventing the method of doubt, and by showing that subjective things are the most certain, Descartes performed a great service to philosophy." "Thus the world from which our reconstruction is to begin is very fragmentary. The best we can say for it is that it is slightly more extensive than the world at which Descartes arrived by a similar process." It is "a world with the kind of properties that psychologists find in the world of sense." Since no two persons perceive anything from exactly the same point of view, no two have the same sense-data, and sense-data "cannot be supposed to reveal directly any definite property" of a real world. At most, they are only signs of something that may be regarded as causing them. "What the senses immediately tell us is not the truth about the object as it is apart from us, but only the truth about certain sense-data which, so far as we can see, depend upon the relations between us and the object." Sense-data, though the "sole basis for our knowledge of the external world," "depend for their existence upon physiological conditions in ourselves, and . . . cease to exist when we shut our eyes" or otherwise destroy these conditions. The beliefs that "sensible objects in general persist when we are not perceiving them"; that there are physical objects, a real space and time, and other minds; that there is a permanent self (i. e., that " $I$ am seeing a brown colour," rather than "a brown colour is being seen") are all derivative.

Starting thus from the subjective and psychological, from an oasis of immediacy, the problem is in Russell's words: "Can the existence of anything other than our own hard data be inferred from the existence of those data?" In other words, the problem 
is the seventeenth and eighteenth century problem of arguing one's way out of the circle of one's immediate experiences to a genuine objective reality, physical objects, other minds, etc. Russell admits that the problem is insoluble: ". . . we can never prove the existence of things other than ourselves and our experiences." However, he finds that "it is rational to believe" that "what we directly see and feel is merely 'appearance,' which we believe to be a sign of some 'reality' behind," "something independent of us and our perceptions." We may infer that there is a real space, time, matter, etc., but apart from the inference that the relations of objects in this real world in some way correspond to the relations of appearances in the perceived world, we can know nothing of the nature of 'reality.' There is no reason to believe that the properties of this real world resemble those of sense-data, since the latter are "physiologically subjective." "We can know the properties of the relations required to preserve the correspondence with sense-data, but we cannot know the nature of the terms between which the relations hold." Thus, it would seem that this trend of Realistic thought reproduces many of the epistemological puzzles of pre-Kantian philosophies, along with a theory of representative perception, the conception of unknowable realities, and a correspondence theory of truth. ${ }^{140}$

In the Problems of Philosophy, which sets forth this correspondence conception of the relation of the perceived world to the worlds of physics and common sense, Russell tells us that "as regards the relations of sense-data to physical objects," he has "derived valuable assistance from unpublished writings of Mr. G. E. Moore." ${ }^{141}$ Russell's rejection of this standpoint, which regards sense-data as "mere subjective phantasms," for that which regards "sensibilia" as the "ultimate constituents of the physical

${ }^{1 * 0}$ For this first conception of the relation of the "perceived" to the "real" world, see Problems, Ch. I-III ; Scientific Method, pp. 64, 67, 72-4, 122; Mysticism and Logic, pp. I34, 149.

${ }^{141}$ Cf., however, Moore's apparent concurrence with Russell's phenomenalistic interpretations (Proc. Arist. Soc., Vol. I9, pp. 28f.) and such early statements as the following: "There is, therefore, no question of how we are to 'get outside the circle of our own ideas and sensations'. Merely to have a sensation is already to be outside that circle. It is to know something which is as truly and really not a part of my experience, as anything which I can ever know," Mind, N. S., Vol. I2 (1903), p. 45I. 
world" may have been due to the influence of the writings of Alexander, Nunn, and Whitehead. Russell tells us, for example: "My main position, which is realistic, is, I hope and believe, not remote from that of Professor Alexander, by whose writings on this subject I have profited greatly. It is also in close accord with that of Dr. Nunn." "It is said, not wholly without plausibility, that these different shapes and different colours cannot co-exist simultaneously in the same place, and cannot therefore both be constituents of the physical world. This argument I must confess appeared to me until recently to be irrefutable. The contrary opinion has, however, been ably maintained by Dr. T. P. Nunn in an article entitled: 'Are Secondary Qualities Independent of Perception?" " ${ }_{142}$ Nunn thus apparently facilitated the shift in point of view which is well described in the following passage: "Instead of supposing, as we naturally do when we start from an uncritical acceptance of the apparent dicta of physics, that matter is what is 'really real' in the physical world, and that the immediate objects of sense are mere phantasms, we must regard matter as a logical construction, of which the constituents will be just such evanescent particulars as may, when an observer happens to be present, become data of sense to that observer." For the application of the method of construction to physics, Russell appears to be largely indebted to Dr. Whitehead, to whom we are also told, "are due almost all the differences between the views advocated" in Scientific Method in Philosophy "and those suggested in The Problems of Philosophy." Russell says: "I myself cannot claim originality in the application of this method tn physics, since I owe the suggestion and the stimulus for its application entirely to my friend and collaborator Dr. Whitehead, who is engaged in applying it to the more mathematical portions of the region intermediate between sense-data and the points, instants and particles of physics." 143

${ }^{142}$ For the more important articles by Alexander and Nunn, see Alexander's Basis of Realism, p. 3.

${ }_{143}$ Mysticism and Logic, pp. 125, I37, 153; Scientific Method, p. vi; cf. Analysis of Mind, pp. 300 . For physics to predict, and to assume or prove the legitimacy of the inference from appearances to matter (and thus be an empirical, verifiable science), it must deal with what psychology calls sensations. 
According to the trend of Realistic thought which regards the world of physics and common-sense things as a logical construction and adopts, apparently, a direct or presentative theory of perception, the empirical successes of mathematics and physics as a means of prediction and of solving practical problems are sufficient to establish the validity of these sciences in some sense or other. Many have supposed that these triumphs of science imply the metaphysical validity of the hypothetical imperceptibles of the sciences, such as points, instants, particles, and matter. But this transcendent machinery of science is never an immediate datum of sense. Observation and experiment never carry us beyond "certain patches of colour, sounds, tastes, smells, etc., with certain spatio-temporal relations." The supposed contents of the physical world can be verified only through correlation with sense-data. But since we actually find but one term of this correlation, namely, sense-data, the correlation itself by which physics was to be verified is "utterly and forever unverifiable." The problem then is this: "Physics exhibits sense-data as functions of physical objects, but verification is only possible if physical objects can be exhibited as functions of sense-data." We must, therefore, if possible, define the objects of physics as functions of sense-data. In fact, "just in so far as physics leads to expectations, this must be possible since we can only expect what can be experienced. And in so far as the physical state of affairs is inferred from sense-data, it must be capable of expression as a function of sense-data." Given the world of sense, by means of purely logical construction and manipulation we make it amenable to mathematical and physical treatment by defining series or classes of sense-data, so that they have all the essential properties and functions of the hypothetical imperceptibles of mathematical-physics and satisfy all the definitions and laws of the latter. Thus in every formula or law it is apparently theoretically possible to substitute some group of sense-data for the artificially simplified hypothetical or formal entities of mathematical-physics without interfering with the validity of the formula or law. All propositions of physics are therefore translatable into propositions about sense objects. Hence, to say that the mathematical-physical account of phenomena is correct is to 
say that something definable in terms of sense-data satisfies mathematical-physical formulas.

The method by which the construction proceeds is as follows: "Given a set of propositions nominally dealing with the supposed inferred entities, we observe the properties which are required of the supposed entities in order to make these propositions true. By dint of a little logical ingenuity, we then construct some logical function of less hypothetical entities which has the requisite properties. This constructed function we substitute for the supposed inferred entities, and thereby obtain a new and less doubtful interpretation of the body of propositions in question." "The supreme maxim in scientific philosophising" is this: "Wherever possible, logical constructions are to be substituted for inferred entities." "Logical constructions or symbolic fictions" are "classes or series of particulars, collected together on account of some property which makes it convenient to be able to speak of them as wholes." 144

When the work of analysis, construction, and substitution which is demanded by this method has been completed, there is no longer any necessity of assuming the independent metaphysical reality of the imperceptible entities of physics, or indeed of common sense; and Occam's razor counsels their rejection. ${ }^{145}$ In other words, mathematical and physical ultimates, such as points, instants, and particles, and the energy, matter, and 'things' of natural science, become functions of sense elements, classes or series of sensedata (or sensations). Likewise, absolute space, absolute time, the common-sense thing, and the person become classes or series of particulars-"logical constructions, symbolic fictions enabling us to express compendiously very complicated assemblages of facts." A thing is therefore merely a series of aspects, or the collection of all those correlated particulars which would normally be regarded as its appearances or effects in different places. It "ought to be regarded as no more 'real' or 'substantial' than, for example, the rôle of the trombone." An "unknown cause"

${ }_{14}$ Mysticism and Logic, pp. 129, I55f., I59ff.

${ }^{145}$ Scientific Method, pp. 65, 89, 97, IIIf., I22, I30, I4off., I46f. Cf., however, "For purposes of science, it is justified practically by the simplification which it introduces into the laws cf physics." "But there is no very good ground for supposing that a simple law is more likely to be true than a complicated law..." (Analysis of Mind, pp. 132f.). 
(a 'real' thing behind the different sensations) or "an unknown assumed existent called a piece of matter" "would be a mere unnecessary metaphysical thing in itself." Thus tables, chairs, stars: "each of these is to be regarded, not as one single persistent entity, but as a series of entities succeeding each other in time, each lasting for a very brief period. . .." "The sun itself and the eyes and nerves and brain must be regarded as assemblages of momentary particulars." The number of such particulars is infinite. ${ }^{148}$

${ }^{146}$ Mysticism and Logic, pp. 128ff., 137, 165, 173; Scientific Method, pp. I05ff., I12, I43ff.; Analysis of Mind, pp. 97-108, 125-6, 134. Cf. Nunn, Proc. Arist. Soc., Vol. 10, pp. 146, 200; Vol. 12, pp. 42ff. A number of difficulties seem to be inherent in this view of the external world as it stands at present: (I) Russell appears to be saying that an object is its effects, thus presupposing the very notion of an object (as the cause of such effects) which his new conception is supposed to supersede. What he means is perhaps that an object is to be identified with those particulars (colors, etc.) which others (but not Russell) call its effects. He continually falls back however into the causal interpretation which involves the difficulty in question. (2) If things, medium, and body are each an infinite collection of particulars, it is difficult to see what can be the meaning of such phrases as "the place where the thing is," "intervening," and "the place where the brain is," etc., even if considerations of "relativity" are not allowed to complicate the problem as apparently they must ultimately for Russell. (3) To admit a "distorting" medium (light, sense organ, nervous system, etc., to say nothing of mind) as a result of the changes in which, we experience, not the physical object (the "regular" appearances, or those it would present in accordance with the laws of perspective were there no distorting medium), but only "irregular" appearances due to the interference of such a medium, is apparently to reinstate the old dualism between the unknown "real" object and its experienced appearances, the very dualism which the direct or presentative theory of perception of New Realism is supposed to have left behind. We read for example: "Every regular appearance" "is due to the star alone, and is actually part of the star"; but, "the irregular appearances of the star are not, strictly speaking, members of the system which is the star ${ }^{*}$; their sources are the object and the medium. "When the distorting influence of the medium is sufficiently great, the resulting particular can no longer be regarded as an appearance of an object, but must be treated on its own account." It may not be traceable to one object, but may be a blend of two or more. "This case is normal in perception." "We see as one what the microscope or telescope reveals to be many different objects." Hence arises the old problem of the resemblance between the physical object and 
It would seem then that the method of analysis in Russell's hands has led to a phenomenalistic, atomistic interpretation of reality which (apart from the abstract universals considered in the preceding section $)^{\mathbf{1 4 7}}$ banishes all permanence as well as all unity and leaves in the place of concrete reality an aggregate of abstract particulars. In Russell's words: "The stuff of the world, so far as we have experience of it, consists, on the view that I am advocating, of innumerable transient particulars such as occur in seeing, hearing, etc., together with images more or less resembling these. . . I If physics is true, there are, besides the particulars that we experience, others probably equally (or almost equally) transient, which make up that part of the material world that does not come into the sort of contact with a living body that is required to turn it into a sensation." The assumption that there is a "constant entity" which "has" qualities is a "piece of gratuitous metaphysics." What we really know is that one appearance (color, sound, etc.) follows another according to statable laws, i. e., that changes of sense-data can be correlated. The

the perceived object. We read that "it is not necessary that it [the irregular appearance] should bear any resemblance to the regular appearances as regards its intrinsic qualities. All that is necessary is that it should be derivable from the regular appearances by the laws which express the distorting influence of the medium. When it is so derivable, the particular in question may be regarded as caused by the regular appearances, and therefore by the object itself, together with the modifications resulting from the medium." If it is caused by several objects together with the medium, it is a confused appearance, and, if in the brain, a confused perception of these objects. "All actual perception is confused to a greater or less extent." "Except in cases of perfect regularity in apearances (of which we can have no experience), the actual appearances of a piece of matter are not members of that ideal system of regular appearances which is defined as being the matter in question" (The Analysis of Mind, pp. 134-6, 300-3). Apparently we have reinstated here the dualism of appearance and reality together with representative perception with its difficulties regarding correspondence. It might be added that Broad and Alexander, so far as they recognize distorting media, appear to become involved in the same type of difficulty and one which jeopardizes the direct or presentative theory of perception for which they stand. (For Broad's latest statement, see Mind, N. S., Vil. 30, pp. 395-409, Scientific Thought, Part II. For Alexander, see Space, Time, and Deity, Vol. II, pp. I83-208.)

${ }^{147}$ Logical and mathematical "constants," the "sameness of differential equations," etc. 
object of sense has only momentary reality. "The cinema is a better metaphysician than common sense, physics, or philosophy." In a word, for Russell reality becomes a world of mutually exclusive sense-data, if not indeed a helter-skelter, haphazard world. Moreover, no sense-datum is ever a datum to two people at once. Indeed, we find Russell saying: "It would give me the greatest satisfaction to ... establish physics upon a solipsistic basis." "A complete application of the method which substitutes constructions for inferences would exhibit matter wholly in terms of sense-data, and even, we may add, of the sense-data of a single person." The belief in the existence of anything outside one's own personal biography or experience is "a prejudice, not a wellgrounded theory. With this proviso, I propose to continue yielding to the prejudice." ${ }^{148}$

Even the person is not to escape the dissection of the process of analysis. "We might regard the mind," says Russell, "as an assemblage of particulars, namely, what would be called 'states of mind,' which would belong together in virtue of some specific common quality." A person is a class of psychical existents, or a series of perspectives, and is to be regarded "not as one single persistent entity, but as a series of entities succeeding each other in time, each lasting for a very brief period. . . ." "The real man ... is really a series of momentary men, each different one from the other, and bound together, not by a numerical identity, but by continuity "and certain intrinsic causal laws." 149 The reality of a "mind," "self," "subject," "person," "ego," "agent," "man," and "single observer," regarded as single, simple, permanent or identical from birth to death, is repudiated as "a perfectly gratuitous assumption." There is no way of proving that there are not such realities, it is admitted, but "there is also not the slightest reason to suppose that it is the case." "The functions that they appear to perform can always be performed by classes or series or other logical constructions consisting of less dubious entities." Moreover, as "empirically known," such

${ }^{145}$ Cf. Scientific Method, pp. 77, 83, Io6f., II2, I43; Mysticism and Logic, pp. I29, I38f., I54-8; Analysis of Mind, pp. I19, I32f., I43f.

${ }^{149}$ Presumably "continuity" is to be interpreted mathematically here as a property of a discrete series and a "causal law" as merely a statement of a correlation. 
realities consist of series of gradually changing appearances together with various occurrences having certain kinds of causal connection with them. They therefore appear to be "logical fictions" like mathematcal points and instants. What actually exists and is called a mind, etc., is only a series of particulars bound together by causal laws. These particulars or "ultimate brief existents that go to make up the collections we call things or persons .... such as the visual sensation which occupied the center of my field of vision at noon on January I, I919," are "ultimate simples," or "the ultimate indivisible constituents of the world." "Sensations (including images) supply all the 'stuff' of the mind," and "everything else can be analysized into groups of sensations related in various ways, or characteristics of sensations or of groups of sensations." 150

Thus the method relied upon by Russell in the construction of his phenomenalistic, solipsistic world-view involves, besides analysis, the following processes: abstract definition, substitution, and simplification in accordance with Occam's razor. Analysis dissects each object of study into an infinite number of supposedly mutually exclusive, self-existent 'entities,' i. e., atomic 'reals' and external relations. All unity is shattered $:^{151}$ discontinuities supersede continuity of development, and concrete meaning is dissolved into isolated existents and subsistents. In defining classes by reference to common properties abstracted from differences, and in substituting the fictions or symbols thus constructed for the original entities, Russell's method abstracts still further from the vitality and uniqueness of the differentiations of concrete reality. Finally the employment of Occam's razor results in a progressive rejection of the more complex and concrete for the simpler and more abstract. The outcome of the introduction of 'scientific' method in philosophy is therefore the replacing of concrete reality with an aggregate of externally related symbols or abstractions which bears a suspiciously close resemblance to an aggregate of numbers.

Alexander's thought shows tendencies away from an atomistic

${ }^{150}$ Principles, p. 417; Mysticism and Logic, pp. 129-32, 167; Analysis of Mind, pp. 18, 69ff., I13f., I41-4, 192-5.

${ }^{151}$ Except the "sameness of differential equations" and the abstract unity or eternal self-identity of the "simple." 
interpretation of reality and mind which are not evident in Moore and Russell. Unlike the other Realists (with the exception of Russell in his latest stand), Alexander is concerned to trace everything to a single and primeval ultimate stuff or material. This elemental stuff, he finds, possesses two attributes, space and time, which are organically related in an indissoluble unity, SpaceTime or Motion. Also, he insists, within this stuff there is no interruptedness or isolation, but continuity throughout. ${ }^{152}$ There is nothing which is not related to something else. Relation, order, and reciprocity (as reciprocal causation) are essential features of every space-time, hence of every existent and thing. Moreover, things are substantial, unified, and permanent; connected wholes of qualities (or syntheses of motions, features, and acts) with "plans" of the movements which take place within them. Minds are things. The mind is a unity and its experiences are differentiations of that unity. It is characterized by permanence amid change. It is the organization or synthesis of its processes or acts, between which there is a "substantial coherence." Within it are smaller substantial groups of cohering activities. "The mental element is essential to the neural process which it is said to accompany .... and is not accidental to it, nor it in turn indifferent to the mental feature." 153

On the other hand, certain of Alexander's assumptions seem to prevent him from conceiving of reality as a genuine whole. "There is no property of coherence in reality itself," he tells us; "system or coherence belongs not to reality as such." ${ }^{154}$ Reality or Space-Time is not a universal, or an individual, or a whole of parts, or a system of relations. ${ }^{155}$ Reality is self-contained, but apparently only in the sense that there is nothing not contained

${ }^{162}$ Alexander rejects Logical Atomism, Associationism, and other interpretations which imply self-existent, elemental units of reality and mind.

${ }^{168}$ Ibid., Vol. I, pp. 269-78; II, B. III, Ch. I, and pp. I5If. Cf. "The fact of mental unity is beyond dispute" (II, p. 24) ; "The agglutinative conception of mind is replaced by the organic one" (p. 13).

${ }^{164}$ Ibid., Vol. II, pp. 258, 272. Yet, we read: "The One is the system of the Many in which they are conserved not the vortex in which they are engulfed" ( $I$, p. 347).

${ }^{155}$ None of the categories apply to it, ibid., Vol. I, pp. 337-41. 
in it. ${ }^{156}$ It is infinite, but apparently only in the sense of being self-representative in such a way as to involve endlessmess. ${ }^{157}$ Reality had no beginning and will have no end, and "the only eternity is infinite time." 158 Alexander thinks that the newer mathematics has reconciled the notions of infinity and quantity. ${ }^{159}$ But to those who hold that no such reconciliation has been effected, this very endlessness of reality will appear to preclude its being a whole, a unity, or an individual, since to think of an actual infinite as a whole requires the self-contradictory and impossible conception of a summed unsummable or a complete which is ever incomplete. Likewise, if continuity is to mean for Alexander actual infinite division of Space-Time, and a state of affairs in which there is no next term to a given term, the uninterruptedness which he is concerned to emphasize would seem to have vanished, because any given motion considered as a term would be interrupted to all eternity from passing into another owing to the actually infinite number of terms between the two through which it must pass. ${ }^{160}$ Again, it would seem that what for Alexander is the ultimate analytic unit of reality, namely, the pointinstant or pure event, can be actual only at the price of stopping arbitrarily, and inconsistently with the notion of infinite actual division, or at the cost of finite division and discontinuity. According to Alexander, however, the point-instant, while conceptual or ideal, is actual and real, and is free from the objections which have been urged against the 'infinitessimal.' Though not isolated or unrelated, it is absolute in the sense that "it is what it is" and "in its own right.". ${ }^{61}$ Furthermore, it turns out that unity of substance or a thing "means belonging to one contour of space-time," that "spatio-temporal volume or contour is that which unifies all its qualities into a connected whole," that "the

${ }^{150}$ Loc. cit.

${ }^{157}$ Ibid., Vol. I, pp. 44, I47, 259; II, pp. 337, 362.

${ }^{168}$ Ibid., Vol. I, pp. 348, 343; II, pp. 36I, 4IO.

${ }^{158}$ Spinoza and Time, p. 26.

${ }^{180}$ Space, Time, and Deity, Vol. I, pp. 39, 44, I46, 283.

${ }^{101}$ Ibid., Vol. I, pp. $85-6,272,325$. It may be that the notion of a point-instant involves another difficulty, namely, that of understanding how there can be a point-instant if every point occurs at more than one instant and every instant occupies more than one point, as the conception of continuity would appear to demand (cf. Vol. I, pp. 44-82; II, p. 42)'. 
sensible quality .... is itself a substance or thing within the thing whose quality it is, . . a continuum of sensations or scnsibles." ${ }^{162}$ And even this spatio-temporal inclusion and continuity, which to many will appear to be only a minimum or a mere semblance of unity scarcely distinguishable from mere juxtaposition, is apparently possessed only by 'contemplated' things; in 'enjoyment' there are discontinuities in the form of gaps not filled up on the conscious level. To secure the unity of mind, Alexander appeals not to meaning or to anything, so to speak, above mind (though including it), but to what is below mind (the neural, etc., and ultimately space-time), with a portion of which, he contends, we must identify mind if we are to save its continuity and unity. ${ }^{163}$ Such an identification, however, appears to purchase unity at the cost of the mind's novelty and uniqueness.

It is to be noted further that although Space-Time is beginningless, there is a first term to the series of degrees or levels of complexity, namely, the point-instant or pure event; and that there is also a first term to the discontinuous series of qualities or emergents. ${ }^{164}$ Such a first term seems to bear a close analogy to the notion of a first cause and perhaps is open to similar objections. $^{165}$ We are asked, in brief, to accept some such story of the creation as the following. Originally, there was only Space-Time or Motion, unqualitied, i. e., isolated or detached from all the wealth of differentiation which it now exhibits. ${ }^{166}$ At that time it either contained no complex arrangements of points and instants or else not arrangements sufficiently complex to give birth to qualities. After having been in this condition

${ }^{102}$ Ibid., Vol. II, pp. 23-5, 29, 76-7.

${ }^{183}$ Loc. cit. The inseparable connection between the neural and the mental becomes thus an identity; and at best it obtains between the conscious and only a portion of the neural, the portion with the required degree of complexity. The relation between the mental level and the neural as a whole is for Alexander a relation of what might be called one-sided dependence (cf. pp. 39, 62-70).

${ }^{164}$ That is, discontinuous in itself, but possessing continuity indirectly, according to Alexander, through its relation to or identification with the spatio-temporal.

${ }^{165}$ E.g., with regard to its arbitrariness, and its inconsistency with the principle of the series.

${ }^{168}$ Ibid., Vol. I, p. 38 ; II, B. III, Ch. II and pp. 4-8. 
from all eternity, for no assignable reason something novel occurred: ${ }^{167}$ arrangements of points and instants became so complex that they (to all appearances, miraculously) changed into something not merely of the nature of point-instants or motion, namely, into something which contained besides these an 'emergent' or quality. ${ }^{168}$ This quality was new and inexplicable: of no known 'stuff,' with no discoverable continuity with preceding Time, and, so to speak, an immigrant from nowhere. Thereafter, an infinite number of such immigrants will appear, one at a time as complexity increases, the latest of which to date is mind. ${ }^{\mathbf{1 6 9}}$ Each is absolutely independent of all that succeed it, but each (save the first) is absolutely dependent on all that precede it. ${ }^{\mathbf{1 7 0}}$ In the arbitrary, hence irrational, first term of the unending series, it would seem, the principle of the series is contradicted and continuity and coherence are dethroned by isolation and confusion. It is here, when we reach this 'prius' or 'solid foundation' (as Alexander himself recognizes) that attempts to rationalize by means of analogy break down. ${ }^{171}$

It remains to be noted that Alexander's assumptions of ( 1 ) the ultimacy of Space-Time as an actual mathematical infinite, and (2) the actuality of a first term in an unending series of complexities and qualities, separate 'stuff' and the 'categorical' from 'quality' and the 'empirical' to such an extent that he never seems to be able to bring them again into organic relation with one

${ }^{167}$ It avails nought to attribute this activity to the restlessness of Time or of Space-Time, for if such a conception can be given any determinate meaning, it remains unexplained why this restlessness which had "been" for an infinite time had not before caused complexities to arise.

${ }^{108}$ It is difficult to understand what a complex or redistribution of points and instants can consist of when every point is related to every instant and every instant to every point (cf. ibid.. Vol. I, pp. 64, 8I ; II, p. 42).

${ }^{169}$ This description of the development of Space-Time appears to presuppose a second "time" in which the points and instants (of the Space and Time of Space-Time) take on ever new successive arrangements, i.e., instants appear to be a second set of points.

${ }^{170}$ It is beyond the purpose of the present work to consider the more specific difficulties which Alexander's view shares with evolutionary naturalism.

${ }^{171}$ In another context Alexander has himself described this primitive state of things as "chaos" (cf. ibid., Vol. II, p. 55; Spinoza and Time, p. 77). 
another. 'Stuff' consists of Space-Time or Motion, which, as primordial, was unqualitied, or largely undifferentiated. As such, it was self-subsistent and contained nothing which necessarily entailed the subsequent appearances of anything different from mere Space-Time or Motion. The 'categorical' includes Space, Time, Space-Time or Motion, their fundamental properties, and such phases of reality as are derivative from or essentially and accountably connected with these properties. 'Qualities' or 'emergents' are not mere space-time or motion but contain an element of genuine novelty, which is not necessarily or accountably related to the ultimate 'stuff,' and the presence and nature of which, therefore, become mere inexplicables to be accepted as a 'given' but not understood. Likewise, the 'empirical' comprises the 'contingent,' what is due to circumstance rather than to the fundamental properties and features of Space-Time. ${ }^{172}$

Alexander tries to prevent these contrasts from becoming absolute dualisms. He thinks that indications of an intimate connection between the primitive stuff and the emergent qualities are to be found in the following facts: (I) the fact that motion may be regarded indifferently as Space-Time stuff or as the quality of that stuff ; ${ }^{173}$ (2) the fact that each level of quality is expressible without residue in terms of the next lower level, hence ultimately in terms of Space-Time ;174 (3) the fact that the processes of each level are identical with a part of the processes of the next lower level, hence ultimately with a part of SpaceTime $;{ }^{175}$ (4) the fact that each of the qualities other than mind, as also time, performs on its level a function analogous to that

${ }^{172}$ For references and citations, see above, p. 84, footnote 8I.

${ }^{173}$ The difficulty here is that of determining whether this fact indicates that motion is the 'meeting place' of stuff and quality, or indicates lack of clearness in our conceptions. The latter is suspected.

${ }^{174}$ The danger here is that of confusing (I) the quality as such, with (2) the process which 'carries' it, or (3) with the process together with the quality. In so far as there is to be any novelty and uniqueness, it would seem that (I) at least must not be completely expressible.

${ }^{175}$ The danger here is the same as that noted in the note above. The distinctive quality itself can be so identified only at the price of losing novelty. And even if mind and body can be regarded as the same thing experienced in two different ways (a conception which identity theories have difficulty in making intelligible), it would still remain true that the other qualities are distinguishable from one another by contemplation alone. 
of mind, ${ }^{176}$ so that something analogous to mind and to the mindbody relationship has been present from the beginning; $(5)$ the fact that the quálities may therefore be regarded as having emerged from Time, and as different complexities of Time or special successive forms of Time $;^{177}$ and (6) the fact that SpaceTime and the point-instant may be regarded as having an experience out of which enjoyment and contemplation both arise. ${ }^{178}$ Closely similar facts, he believes, reveal an intrinsic solidarity between the categorical and the empirical: (I) the difficulty or impossibility of determining whether certain characters are categorical or empirical; (2) the essential identity of stuff between the categorical and the empirical (as existents or things); $;^{179}$ (3) the fact that motion or spatio-temporality may be regarded indifferently as categorical or an empirical quality of Space-Time ; (4) the fact that the point-instant is empirical and yet the ultimate constituent of Space-Time which is categorical; (5) the fact that primary qualities are empirical and yet specific determinations of the categories; (6) hence, the fact that the empirical is the modification of the categorical, "a multiform determination

${ }^{176}$ All that the point of analogy seems to amount to is that in SpaceTime, Space is filled with an extensive present, and a past and a future, which is what we enjoy in our minds, and that each instant is continuous with the past and future, just as the mind is. Moreover, in many important respects the analogy admittedly breaks down.

${ }^{177}$ The analogy considered in the note above is hardly sufficient to ground this interpretation. Besides, it is difficult to understand just what can be a complexity of Time which is not a complexity of Space-Time. The notion of a complexity of Time seems to imply a separation of Time from Space which is inconsistent with their organic connection, and also seems to make a 'stuff' out of Time. Furthermore, it remains unexplained why a complexity of time should be something so radically different from time itself as color, life, and meaning are (especially if the complexes of space and motion are not different from space and motion), and also why Time presumably after an eternity of simplified existence should become complex and qualitied at all.

${ }^{178}$ This conception is too obscure for its value to be determinable.

${ }^{170}$ The identity of stuff would seem to be only between the categorical on the one hand and the spatio-temporality and primary qualities of things on the other (if even here), and not between the categorical and the secondary or other qualities. The empirical is the qualitied, and primary qualities are strictly not qualities at all. 
under various circumstances of categorical characters"; $; 180$ and (7) the fact that both categorical and empirical are empirical in a wider sense of the term, i. e., are experienced. ${ }^{181}$

It would seem then that Alexander's efforts to prevent the distinction of the categorical and the empirical and that of stuff and quality from becoming absolute dualisms involving isolations are unsuccessful. The empirical and the emergents or qualities remain to the end contingent, unessential, and separable, with the characters of something accidental or superinduced as it were, hence something isolated from the ultimate and absolute, and inexplicable. The outcome, then, of making space and time more ultimate than meaning and of interpreting them as mathematical infinites (involving endlessness) is to make it impossible for reality to be thought of as a genuine whole. Organic unity and concrete universality are apparently not to be had so long as the principle of unity is sought for in identity of material or stuff instead of in a teleological principle or meaning. Such unity as is attainable on Alexander's assumptions is a relatively undifferentiated unity of a 'stuff,' i. e., of unqualitied Space-Time or motion. Such variety as can be recognized must play the rôle of inexplicable, detached 'emergents.' In a word, so far as unity is attained, variety is lost and so far as variety is attained, unity is lost. This situation is the issue of analyzing reality into a number of characters and then identifying the absolute, essential, and ultimate with such of these characters as appear to be simplest.

It seems clear then that the Realist regards the products of analysis unaided by synthesis as final, i. e., as absolutely true, without supplementation and completion which would involve modification and transfiguration. In other words, a process and procedure which are legitimate and indeed indispensable in a special science are regarded as ultimate and universally applicable, and are identified with the method of philosophy. The result of the introduction of 'scientific' method, thus understood, into philosophy is a more or less thoroughgoing atomistic interpreta-

${ }^{180}$ This again would seem to be true only of motions and primary qualities which strictly are not empirical at all.

${ }^{181}$ Space, Time, and Deity, Vol. I, B. II, Ch. IX, X and pp. 4, I44, I85f.; II, B. III, Ch. I-III and pp. 312, 345, 362, 428. 
tion of knowledge, the self, and reality. Continuity and unity give way to dualisms, separations, and isolations. Wholeness and self-containedness make way for endlessness and 'ultimate simples,' or 'solid foundations,' i. e., 'tiny absolutes,' which, if not self-existent, are at least real in their own right. Such simples or solid foundations are inexplicable 'givens' to be accepted on faith, as it were, without being understood. The part for this point of view is prior to the whole; the whole is a mere sum-total or mechanical combination of parts. Parts are mutually exclusive and externally related to some or all other parts. Concrete meaning is dissolved into entities (existents and subsistents), and becomes subordinate to 'material' or 'stuff.' Novelty and identity are each attained only at the expense of the other. Any tendency or nisus away from the undifferentiated 'simple' becomes inexplicable, and the emergents which appear must appear to be "accidental" and "superinduced." The problem of philosophy becomes one of attempting to show how knowledge and reality are built out of and derived from one or more simples or indefinables. One trend of Realistic thinking, setting out from an epistemological enquiry, would seem to involve the conception of transcendent or unknowable entities, along with a theory of representative perception and a correspondence theory of truth. Another trend, taking its point of departure, apparently, from empirical psychology, and motivated in part (i.e., in Russell's case) by the necessity of accounting for the verifiability of physics, comes to regard ephemeral appearances (together perhaps with their copies, images) as the sole (or almost the sole) reality, and thus approximates phenomenalism and solipsism. ${ }^{182}$

\section{Universals and Wholes}

A large number of the atomic entities which analysis substitutes for concrete reality are for the Realist, as was noted in the preceding section, 'evanescent' or 'momentary' particulars;

${ }^{182}$ It is interesting to note that Russell's recent views have been compared to Berkeley's idealism and Hume's phenomenalism by Realists and that the similarity, in some important respects, to Hume has been remarked by Russell himself. (Cf. Broad, Proc. Arist. Soc., Vol. 15, pp. 239f.; H. A. Prichard, Mind, N. S., Vol. 24, pp. I45ff.; Analysis of Mind, pp. 145-6, 155, I58, 208-9. ') 
but in so far as these particulars are made self-existent and absolute, they become universalized, as it were. On the other hand, such universals as are recognized by the Realist become particularized in so far as they are regarded as mutually external and as exclusive of particulars. From the 'either-or' standpoint of the formal Law of Excluded Middle, which the Realist considers ultimate, it would indeed seem to follow that anything must possess either identity (in accordance with the Law of Identity) or difference (in accordance with the Law of Contradiction), but not identity in difference. Moreover, processes such as abstract lefinition, generalization, and substitution, when not subordinated to processes of concretion, would seem to prevent one from comprehending anything in its concreteness or individuality, because they have the tendency to lead away from differences to an undifferentiated identity or abstract universal. On the other hand, the process of analysis, when not supplemented and re-interpreted by synthesis, would seem to prevent one from grasping anything in its genuine universality or wholeness, because it reveals only isolated or abstract particulars. Since Realism does not embrace processes of synthesis and concretion, it is to be expected that it should envisage universals and particulars as alike undifferentiated and inert, and as self-existent, exclusive of one another, and externally related. And, so far as it binds itself to the laws of formal logic, it is not to be wondered at that Realism seems unable to attach any precise or important meaning to the notions of organic unity, concrete universal, or individual.

Alexander, ${ }^{183}$ it is true, asserts that universals cannot be divorced from particulars and can exist only so far as realized in particulars. Strictly speaking, he adds, there is no such thing as a particular or a universal: "all things are individuals," i. e., particulars as determined by their universals. He attempts at some length to differentiate his position from extreme forms of historical realism and nominalism. Universals, he maintains, are not imposed upon particulars from without (e. g., by mind, or by some supra-particular world); are not prototypes exactly copied by particulars, or limits towards which particulars are in progression. They are not inventions of mind or creatures of

${ }^{100}$ Space, Time, and Deity, Vol. I, pp. 208-38; Mind, N. S., Vol. 21 and 22. 
abstract thought. Hence, they are neither of the nature of bare repetition nor bare potentiality. Nor are universals derivations from particulars by a process of omitting variation. They cannot therefore be identified with abstract or general ideas or generalizations, with the common features of things, with class concepts, or with qualities that adhere in things. Universals are not predicated or something which is 'asserted' or 'obtains' of particulars. Nor are they classes. They are not the changeless, eternal universals of the ancient world, and cannot be said to be petrified and dead. On the other hand, Alexander is no less concerned to differentiate his standpoint from that of Objective Idealism. He contends that universals are not 'concrete universals,' in the sense in which Idealism employs that term. Universals are not universes, systems, worlds, organized individuals, or organic or individual wholes. Instances of the latter exist, to be sure, and are empirically discoverable (as for example, a species or a society-though this is not beyond dispute); but they are not properly to be called universals.

In contradistinction, as he thinks, from both older Realisms and Nominalisms as well as from Objective Idealisms, Alexander characterizes universals as plans or laws ${ }^{184}$ of the construction of things or of the relations of things. They are patterns or forms of the configuration of particulars, and are of the nature of equations, formulae, schema, outlines, diagrams. They may be regarded as habits or dispositions of response. There may be plans of plans and plans of combinations of plans or 'key plans' ${ }^{18.5}$ With one exception, ${ }^{186}$ plans are not simple, but complex, although "the internal complexity or systematic character of a plan is not its universality." 187 Universality is admission of repetition without distortion, or capacity of repeated response according to the same plan. It is repetition which makes possible both the universal and knowledge of it; hence, there must be the possibility

184 E.g., the law of a series or a 'law of nature.'

${ }^{185}$ E.g., the categories, the most comprehensive plans of all.

${ }^{180}$ The limiting case of 'bare existence' or point-instants where there is simplicity (though even here an instant is intrinsically, not merely empirically or as a matter of fact, repeated in space, and a point in time) point-instants being the bare conceptual elements of Space-Time (ibid., Vol. I, p. 228).

${ }^{187}$ Loc. cit. 
of more than one instance of a universal. The individuals or particulars under a universal must be of the same kind. Universality is "conceptual identity" ${ }^{188}$ between particulars, or identity of kind-generic identity or sameness.

Now the emphasis which Alexander puts on the schematic, repetitive, and generic character of universals would seem to suggest that he has not entirely avoided a number of the inadequacies which he criticizes in others. In the first place, it is difficult to see how the universal as Alexander describes it can be reached by any other process than abstraction from variation, and indeed we find Alexander himself comparing a universal to a map which omits details. ${ }^{189}$ Secondly, universals when thus abstractly conceived would seem to be changeless and dead, so to speak. But despite the fact that only particulars are said to move and act, Alexander protests that universals are very much alive. They are constitutive plans. All action conforms to universals, the character of all acts depends on them and it is in virtue of them that particulars can work their effects. In the third place, the universal, as conceived by Alexander, does not seem to overlap and include its particulars. It is not a whole or system of its particulars, but a plan "distinct from the execution."190 It appears therefore to be outside or beside particulars, as if it were itself another particular, and to be standing in need of something else to unite it with its particulars. Yet this is the very type of 'third man' situation which Alexander himself criticizes. ${ }^{191}$

Meanwhile, the difficulties just referred to are aggravated and another difficulty created by Alexander's realistic concern to make universals objective together with his tendency to identify objectivity with the Spatio-Temporal. Universals are concepts, the compresent objects of conceiving. They are however independent of mind; they owe to thought only their compresence with thinking and the fact that they are thought of or known. They are part and parcel of the constitution of things. They

${ }^{18 s}$ Ibid., Vol. I, p. 247. Acknowledged to be Moore's phrase. Examples of generic universals are 'dog', 'tree', 'justice'.

${ }^{180}$ Cf. Mind, N. S., Vol. 22, p. 45, and Vol. 21, p. 310. Also Space, Time, and Deity, Vol. I, pp. 236, 3I3f. For further examples, see pp. 83-6 above.

${ }^{100}$ Cf. ibid., p. 338 .

${ }^{191}$ Ibid., p. 218. 
may be categorical, or empirical and qualitied. As qualitied, they are physical, biological, mental, human, etc., according to the level of their particulars. But in their simplest terms universals are essentially spatio-temporal forms or shapes, patterns of configuration of Space-Time or Motion. As patterns of response and direction, they may be called habits of Space-Time. Universality arises from the uniformity of Space-Time or constant 'curvature' of Space and is the name for this uniformity. Or, it may be said to be the name for the constancy of an existent in Space-Time, i.e., for its freedom from distortion. Universals are thus of the same order and stuff as their particulars. They are more important and significant though not more real than their particulars. They belong to no neutral realm of logical entities. However, there is a sense in which they may be said to 'subsist,' namely in the sense that they are nowhere and nowhen, but anywhere and anywhen, and are free from limitation to a particular time or space. ${ }^{192}$ But subsistence is only a form of spatio-temporal existence.

Having refused to make universals 'wholes' or 'universes' (i. e., concrete), and thus forcing them to find a place in reality outside of their particulars, as it were, Alexander thus attempts to restore their intimate union and render unnecessary any 'third man' by conceiving universals as of the same 'stuff' as particulars, i.e., as spatio-temporal. ${ }^{193}$ And herein lies the new difficulty. Even granting that universality can be identified with 'uniformity' or 'constant curvature' and 'habit' (which is far from obvious), universals seem to be of a different stuff from particulars, for they do not appear to be space-and-time 'occupying,' and admittedly do not move or act, and are anywhere and anywhen. Like the often referred to 'continuity' of Space, Time, and Space-Time, and the reciprocal relations between Space and Time, universals do not seem to belong to the spatio-temporal world, but rather to be something, to an extent, apart from particulars, something

${ }^{192}$ Cf. ibid., Vol. I, p. 224 : "We may make the matter easier for imagination by saying that any space contains actually all geometrical patterns as soon as the time comes to draw them"; "universals . . . are the formulae according to which Time brings forth particulars in a Space that can receive this plan"; "time which is the life of Space brings to birth particulars in their image."

${ }^{103}$ Cf. ibid., Vol. I, p. 221 . 
over and above the space-time world, hence, something ultimately unexplained. ${ }^{194}$ And how much more does this seem to be the case when the transition is made (if indeed it can be made) from universals as 'uniformity', 'constant curvature', and habits to universals as equations, formulae, laws, plans, or a plan of a person's life!

Alexander admits the existence of organic wholes (e.g., a species or a society) which are more than mere wholes of parts; but he holds that we are not entitled, on the strength of such special and perhaps disputable cases, to identify a universal with an organized individual. The doctrine of the 'concrete universal', which does this, errs in making a universal a substance or singular existent; "mistakes universality for system"; and "combines into one two distinct notions": (I) "the union of different features into a plan or law which is realized with modifications in different individual instances, the combination of many predicates," and (2) "the union into a system of different individuals in or by or under such a plan." According to Alexander, although elements may receive a new value from entry into an organic whole, "the new character which they thus receive does not necessarily alter their intrinsic nature." 195

Moore seems to hold that universals do not necessarily imply particulars and that they may 'subsist' or 'be' without particulars. ${ }^{196}$ The term 'universal', in its most proper sense, means 'characteristic', 'property', 'predicate', or 'attribute' and such a universal does not contain its particulars. On the other hand, when it is a question of the relation of parts to wholes, it is the part which appears to be independent. A part can exist without the whole but not the whole without the part. ${ }^{197}$ Moreover, parts have a value by themselves or in their own right: they are good, bad, or indifferent. And the "part of a valuable whole retains

${ }^{194}$ Just as 'qualities' appear to remain in the end inexplicables, in the opposite direction, as it were, from Alexander's Space-Time world.

${ }^{195}$ Ibid., Vol. I, pp. I80, 197, 234-7, 316, 323, 328; II, p. 323. Cf. "an individual is a particular of a certain sort"; there may be persistence without change (e.g., of a quality or a uniform motion); "to omit is not necessarily to distort"; unity is posterior to multiplicity, and is a whole in which there is no distinction of whole and parts, the number $\mathrm{I}$.

${ }^{198}$ Cf. Proc. Arist. Soc., Vol. I, pp. 104-25.

${ }^{197}$ Cf. op. cit., Vol. 20, pp. 133, 5I ; Mind, N. S., Vol. 8, pp. 179-93. 
exactly the same value when it is, as when it is not, a part of that whole. If it had value under other circumstances, its value is not any greater, when it is part of a far more valuable whole; and if it had no value by itself, it has none still, however great may be that of the whole of which it now forms a part." However, the value of such a whole bears no regular proportion to the sum of the values of its parts; it may be, for example, immensely greater. This kind of a whole may be called an 'organic whole' or 'organic unity' and this peculiar relation of parts to whole an 'organic relation'. These are terms which "as at present used . . . . have no distinct sense and, on the contrary, both imply and propagate errors of confusion." ${ }^{198}$ The relation of being "mutually means and ends to one another," which obtains between the parts of an organic whole, is merely "mutual causal dependence" or "reciprocity", and the relation cannot obtain between whole and part. ${ }^{199}$ "This doctrine, therefore, that a part can have 'no meaning or significance apart from its whole' must be utterly rejected." The term 'organic' then is to be used merely "to denote the fact that a whole has an intrinsic value different in amount from the sum of the values of its parts. . . . It will not imply... . that the parts are inconceivable except as parts of that whole, or that, when they form parts of such a whole, they have a value different from that which they would have if they did not." 200

Russell tells us that there are universals and particulars, not universals in particulars. For Realism, "Identity in difference' disappears: there is identity and there is difference." Universals are abstract or general ideas (qualities and relations), and are of "an essentially different character from sense-data." 201 They are the common nature, or essence, or form of particulars, and are immutable and indestructible. Particulars are either physical or mental existents; universals are neither physical nor mental and do not exist. Universals subsist or have a bare, neutral, timeless, and spaceless, and otherwise only negatively definable

${ }^{108}$ Ibid., pp. 30-4. And involves the self-contradiction that a whole is part of its part.

${ }^{109}$ Loc. cit. The reason given is that a part cannot be the cause of itself (included in the whole).

${ }^{200}$ Ibid., p. 36.

${ }^{201}$ Problems, pp. 76, 8ז. 
being. Of organic unities, Russell says: "We are sometimes told that things are organic unities, composed of many parts expressing the whole and expressed in the whole. This notion is apt to replace the older notion of substance, not, I think, to the advantage of precise thinking. The only kind of unity to which I can attach any precise sense-apart from the unity of the absolutely simple-is that of a whole composed of parts. But this form of unity cannot be what is called organic; for if the parts express the whole or the other parts, they must be complex, and therefore themselves contain parts; if the parts have been analyzed as far as possible, they must be simple terms, incapable of expressing anything except themselves. . . Thus the notion of an organic whole in the above sense must be attributed to defective analysis, and cannot be used to explain things." "We are told, by those who advocate this opinion, that the whole contains diversity within itself, that it synthesizes differences, and that it performs other similar feats. For my part, I am unable to attach any precise significance to these phrases." "What a term is, it is, and no change can be conceived in it which would not destroy its identity and make it another term. Another mark which belongs to terms is numerical identity with themselves and numerical diversity from all other terms. Numerical identity and diversity are the source of unity and plurality. . . ."202 "Whatever may be an object of thought, or may occur in any true or false proposition, or can be counted as one, I call a term. . . . I shall use as synonymous with it the words unit, individual, and entity."

Thus, for the Realist, ${ }^{203}$ an individual becomes simply what can be counted as one. A whole tends to become merely an aggregate or sum-total, a mechanical combination, or a comparatively undifferentiated 'simple' reached by a process of analysis which has apparently been halted arbitrarily in its endless task of dissecting, i. e., in each case an existential rather than a significant whole. Universals become concepts, predicates, abstract

${ }^{202}$ Principles, pp. 466, 225, 44, 43; Proc. Arist. Soc., Vol. I, pp. II2ff.; Scientific Method, pp. 39f., 201 ; Problems, pp. 142-61 ; Essays, pp. 169, 184; cf. Analysis of Mind, p. I80, "Hegelian continuity and identity-in-diversity, and a host of other notions which are thought to be profound because they are obscure and confused," result from confounding an image and its prototype, i.e., from regarding as identical what are closely similar.

${ }^{200}$ With the qualifications in the case of Alexander noted above. 
ideas, or general terms (i. e., common elements of groups of particulars reached by a process of abstraction). They tend to be regarded either as prototypes of particulars only numerically distinguishable from particulars, or as of such a different nature that their relationship to particulars in an individual or concrete universal becomes unintelligible. Hence they come to be thought of as self-subsistent, i. e., as not only independent of each other and of mind, but even independent of embodiment in particulars, and capable of 'being' apart from particulars. The chasm between universals and particulars becomes, therefore, absolute. Universals do not express themselves in and through a wealth of differentiation or uniqueness; they do not organize or animate particulars, or give them meaning and make them intelligible. In fact, universals cease to have an assignable function or nature and tend to become mere names, while particulars too, so far as universals are thought of as exclusive of them or external to them, are left unqualified and unrelated, and become self-existent indefinables. We are thus confronted with the irrational conceptions of thingsin-themselves, unities with nothing to unite, wholes without parts, parts which are not parts of any whole, universals with no particulars, and relations which do not relate. In short, wholes and parts, universals and particulars, tend to lose their distinctive characteristics and to become merely so many numerable items of inventory.

A word should be added, however, concerning certain nominalistic tendencies in Russell's recent thought, necessitated by his new theory of the nature of mind. So long as all mental content is regarded as having an "essential reference to an object, it is then natural to suppose that there is some peculiar kind of mental content of which the object is a universal, as opposed to a particular"; that a particular is perceived or imagined while a universal is conceived. "But this whole manner of viewing our dealings with universals has to be abandoned when the relation of a mental occurrence to its 'object' is regarded as merely indirect and causal, which is the view that we have adopted," says Russell. "I think," he adds, "a logical argument could be produced to show that universals are part of the structure of the 
world, but they are an inferred part, not a part of our data."204 "Whether there is a universal, called 'whiteness,' or whether white things are to be defined as those having a certain kind of similarity to a standard thing, say freshly fallen snow, is a question which. . . . I believe to be strictly insoluble." ${ }^{205}$ In any case "the mental content is, of course, always particular." "A universal never appears before the mind as a single object in the sort of way in which something perceived appears." Moreover, there is no imageless thought or 'idea.' One may however have a vague image which reproduces a number of related similar prototypes without copying any single one of them exactly, and which is therefore a kind of compromise that can be likened to a composite photograph. Such an image, "produced by the superposition, or, in Semon's phrase, homophony, of a number of similar perceptions", may be called a 'generalized image' or a 'generic image'; and as it comes to have the effects which all the objects of the class which it means have in common, it may thus come to function as a general idea. ${ }^{206}$ The image ceases to be merely vague and becomes general or universal, when both the generalized image and particular images of some of its prototypes are present, when the latter are recognized as different and as instances of the generalized picture, and are compared and contrasted with it, and when there is an accompanying belief that no one individual is represented. ${ }^{207}$ "Generality and particularity are a matter of degree." 208

It is to be noted that the destruction of a genuine whole or universal by such abstract processes as analysis and genus-species

${ }^{204}$ Analysis of Mind, p. $227 \mathrm{f}$. Since the mental world is composed only of sensations and images, and the non-mental world only of sensations, it is difficult to see how "universals" can be admitted, or what "inference" and the "inferred part" of the world can mean.

${ }^{200}$ Ibid., pp. 192, 196; of course, kinds of universals other than qualities (e.g., relations) may be recognized, though qualities are not.

${ }^{200}$ Ibid., pp. 207-29.

${ }^{207}$ Since no active subject is to be admitted, this discriminating, comparing, and recognizing is, presumably, to be analyzed away into sensations and images and belief-feelings (which are complexes of sensations).

${ }^{208}$ Ibid., p. 209. Universals, in Russell's thought, make possible a priori knowledge, which "deals exclusively" with them. Hence, if universals are to be analyzed away nominalistically, radical changes in Russell's theory of knowledge must be made (cf. Problems, p. I62). 
definition involves the replacing of the standpoint of meaning with that of existence. These processes resolve a significant whole into existents and subsistents. Hence, to be 'real' means to exist or subsist, to be actual or factual, i.e., to 'be'. ${ }^{209}$ Since all entities equally 'are', all are to be regarded as equally real. All are on the same plane with one another, coördinate and mutually exclusive. Since reality is identified with its emptiest category, being, there seems to be no reason for ranking differentiations of reality as more or less real, i.e., to assume degrees or levels of reality. Since all categories are mutually exclusive and equally pervasive, ${ }^{210}$ and there is no genuine whole,

${ }^{200}$ Cf. Moore, Proc. Arist. Soc., Vol. I8, pp. IoIff., Vol. 6, pp. 68, 82, 96, 104, I2I; Alexander, Space, Time, and Deity, Vol. I: Things "have being, are entities." "The most general description of thing is entity . . . of their behaviour... relation" (pp. I75f.). "Being is the occupation of space-time which also excludes other occupancy of space-time" (p. 195). "There are no beings (occupants of space-times) which are not existents" (p. 199). "There is no category then of being other than that of determinate being or the existent" (p. 200)'. "The existent is nothing but motion (that is Space-Time)" (p. 204). "My mind exists at this moment because it occupies a certain portion of Space-Time, and that bare occupation is existence" (p. I90, cf. p. 323). Being "is not something simpler of which existence is a specialisation" (p. 20I). Existence is not "something added to some more formal reality, call it being, call it subsistence, call it what corresponds to the 'is' of propositions" (p. 202). "The universal . . . may be said to have that reality of existence which is called subsistence. For it is free from limitation to one particular space and time. But subsistence must not be understood to imply a neutral being which is distinct from the world of spatio-temporal existence" (p. 222). "What corresponds to the copula is thus not being but reality, and reality is at least existence or determinate being; it may be and is much more, but at any rate, it is not less and wider than existence" (p. 20I). It is not clear to what the words "much more" in the preceding quotation refer, (perhàps to categorical determinations other than that of existence, or more particularly to relations). At any rate, there is no reason to think that Alexander has in mind primarily "meaning" or "significance," which, according to him, are not to be found in reality until minds appear, i.e., are not inherent, necessary, pervasive characters of reality. Reality, so far as whole (SpaceTime or Motion) and elemental (point-instants or pure events) and primordial is without meaning, signnficance or value (cf. Vol. II, Ch. IX).

${ }^{210}$ For Alexander all categories are equally pervasive so far as things are concerned, but may be ränked as more or less inclusive with reference to each other, "motion" being the most inclusive (ibid., Vol. I, pp. 20I, 322-4). 
there appears to be no standard by reference to which one may determine respective degrees of reality, of truth, or of significance. Moreover, the formal law of Excluded Middle, which Realism accepts as final, seems to demand that everything be wholly real or wholly unreal, every experience wholly true or wholly false. ${ }^{211}$ So, too, all types of judgment and inference, and all methods, categories, and points of view, which are valid at all, would seem to be, for the Realist, wholly and universally, hence equally valid. Therefore, each is as adequate as any other for the determination of the ultimate nature of reality. The relatively abstract and hypothetical characterizations of reality constructed by formal logic, or by mathematical-physics, are thus as true descriptions of ultimate reality as are the concrete characterizations of the special humanistic disciplines and of philosophy. ${ }^{212}$ In Alexander's words, "Realism is the democratic spirit in metaphysics." It is to be noticed however that Alexander recognizes degrees of importance, development, and perfection in reality. ${ }^{213}$ But it is doubtful whether this contention is consistent with the Realistic position, for if it is denied that Reality is a significant whole, it seems impossible that there could be any rational (i.e., not arbitrarily selected) standard by reference to which one could distinguish degrees of importance, development, and perfection as opposed to mere difference or change. The democratic spirit of the new Realism would seem to find a truer expression in the implications of the following statement made by Russell: "A process which led from the amoeba to man appeared to the philosophers to be obviously a progress-though whether the amoeba would agree with this opinion is not known." 214 Moreover, even if Alexander can consistently admit degrees of importance and perfection, he will be unable to admit degrees of reality. For in identifying reality exclusively or primordially

${ }^{\text {I1 }}$ Cf. Scientific Method, p. I44: "it is a mistake to speak as if acquaintance had degrees: there is merely acquaintance and non-acquaintance."

${ }^{212}$ With the qualifications in the case of Alexander noted above, pp. $77 \mathrm{f}$.

${ }^{210}$ Cf. Basis of Realism, pp. 2ff.; Space, Time, and Deity, Vol. I, pp. 5-I I, 17, 29; II, pp. 252, 264: "In respect of being or reality all existences are on an equal footing." Cf. footnote 85 , p. 86 above on 'leveling.'

21 Scientific Method, p. 12; cf. Mysticism and Logic, p. 24. 
with existence or being, ${ }^{215}$ the Realist has thereby divorced it from meaning and perfection. Hence, value and ideality, if they are to be recognized at all, must be regarded as characters of, or as dependent upon, the presence of certain classes of finite or particular existences, i.e., must be regarded as, to this extent, subjective. In other words, for the consistent Realist, meaning is an accidental character of reality, confined, as far as we know, to a few insignificant beings on a petty' planet; hence it is of little or no metaphysical importance. Being or factuality, on the other hand, is an objective, universal and necessary aspect of reality, and consequently demands our utmost attention.

Thus, the divorce of existence and meaning leads to a separation of philosophy and logic from life, and even from science. Philosophy, says Russell, "does not offer, or attempt to offer, a solution of the problem of human destiny, or of the destiny of the universe." "All the questions which have what is called a human interest-such, for example, as the question of a future lifebelong, at least in theory, to special sciences, and are capable, at least in theory, of being decided by empirical evidence." "Philosophy is a study apart from the other sciences: its results cannot be established by the other sciences, and conversely must not be such as some other science might conceivably contradict." Philosophy and logic deal only with logical forms, with the general, a priori aspect of reality, with what is common to all possible worlds, i.e., with universals. Science deals with the content of these forms, and with the special features of the actual world which serve to differentiate it from other possible worlds. ${ }^{216}$

Contemporary English Realism, then, with Ancient Realism and modern science, recognizes the reality of universals (i.e., of something more permanent and pervasive than particulars); but as a result of its intellectualistic assumptions, it tends to conceive of universals as abstract, i.e., as identity without difference (plurality and variety). As such, universals appear to be incapable of synthesizing and preserving the significance of particulars (except at the cost of depriving them of their

${ }^{215} \mathrm{Cf}$. for Alexander, footnote 209, p. 132 above.

${ }^{216}$ Cf. Russell, Scientific Method, pp. 15-30, 43-59, 185ff., 236f. For qualifications in the case of Alexander, for science, see above, pp. $77 \mathrm{f}$; for religious problems, Space, Time, and Deity, Vol. II, pp. 34I-43I. 
uniqueness by reducing them to repetitious instances of universals), or of explaining the working relationship that obtains between the moments of identity and difference in concrete reality or the 'individual'. In consistency with its analytic, atomistic assumptions, Realism can recognize no other whole than an aggregate, or a mechanical combination, the parts of which are self-existent, and their connections (as well as the difference between the value of the whole and that of the sum-total of the parts, which Moore and Alexander recognize) unexplained. In the absence of a concrete universal and a genuine whole, reality becomes identified with 'being' (and is no longer a matter of degree), i.e., is divorced from significance (as philosophy is from life and even from science), so that the conceptions of development, progress, and perfection no longer have any but an arbitrary meaning.

\section{Relations}

The Realist, as we have seen, attempts to show that the doctrine of internal relations is groundless and untenable. The laws of formal logic which he accepts as ultimate would seem to involve the conception of entities that possess natures which are prior to and not constituted by their relations and which remain eternally self-identical, i.e., unaffected by their relations. The process of analysis, which, with one exception, he regards as absolutely adequate by itself for the attainment of ultimate truth, appears to resolve reality into an infinite number of mutually external simples. The Realist's search for a solid foundation or prius in every field of study implies the conception of absolutely independent or externally related entities. The dualisms, the acceptance of mathematical definitions of continuity and infinity as final, the recognition at times of transcendent unknowable realities-all these appear to involve a theory of external relations. In short, there is hardly a fundamental principle of Realism which does not, apparently, presuppose or involve the theory of external relations.

Of the theories of the nature of relations advanced by the Realists under consideration, the view set forth by Alexander is perhaps the least extreme. ${ }^{217}$ According to Alexander there is

${ }^{217}$ See Space, Time, and Deity, Vol. I, pp. 238-62; Mind, N. S., Vol. 2I, pp. 306ff., 314ff.; Basis of Realism, pp. 2f., 30, 34 ; Proc. Arist. Soc., Vol. ro, p. 34 . 
no unrelatedness. Parts of Space-Time are in organic connection with one another. Time makes space continuous and space performs a similar office for time. "Thus spatial relation is of the very being of any two spaces, for it is their connecting situation into which they are compelled by their time." The same may be said of the temporal relation with reference to any two times and space. The terms and their relations are distinguishable elements in one and the same empirical fact which is spatio-temporal. We never find relations without terms or terms without relations. Terms are always related in Space-Time by all the relations that arise out of the categories, i.e., the pervasive and necessary features of all things. Except by abstraction, we never have terms and relations, but terms or things in relation. A relation must relate; it must bring the terms into one continuous whole or integral situation, and bind them into one continuous tissue. A relation is the whole situation into which its terms enter in virtue of that relation, or the concrete system of circumstances which brings the terms into connection. A relation is thus a 'transaction'. Relations are not qualities; nor do they inhere in terms. They are not subjective, but objective, and are not the work of the mind. Things before they become terms in a relation are not necessarily the same as when they have entered it. There are instances in which the characters of terms are altered upon entering into a relation.

Now, so far, nothing has been said to which the champion of internal relations could offer very strenuous objections. But Alexander brings to his study of relations two preconceived theories: (I) that Space-Time is an absolute, a metaphysical prius, a stuff from which alone everything is made and has come; and (2) that there is an absolute distinction between the categorical or necessary and the empirical or accidental. ${ }^{218}$ These two theories appear both to presuppose and to lead to a theory of the externality of relations.

Alexander tells us that there is no unrelatedness because of the continuity of Space-Time, and that it is this continuity (a 'primordial' and 'given', apparently not itself a relation) which relations depend on and express. All relations, as all terms, ultimately or in their simplest expression (though not all in their

${ }^{218}$ See pp. 84, IIgff. above. 
immediate character or quality) are spatio-temporal. They exist as spatio-temporal occupations or facts which may turn into things. They are themselves spaces and times, and are thus homogeneous with their terms since both are made out of the same stuff. They are motions with directions or 'sense'. They may be particulars or universals, external or mental, 'contemplated' or 'enjoyed'. As universals, relations are known by thought, but are also perceived and belong to the same sensible reality as their terms. Relations hold primarily between particulars or individual things, and only indirectly between universals, and not at all, perhaps, between a universal and its particulars. ${ }^{219}$ "The relations and the things they relate are equally elements in the one reality and so far are separable realities."220 "Relation from the nature of the case, as being the situation which unites things, is outside each of them spatially (or rather spatio-temporally)." ${ }^{221}$ In a word, the identification of relation as such with spaces and times between other spaces and times would appear to lead in the end to a leveling of terms and relations to the status of being "equally elements in the one reality"; and also would appear to lead to the envisaging of relations as outside and beside the terms related, as if they did not include their terms or as if the terms were not themselves parts of the wholes or unities which the relations are said to be, i. e., as if, after all, despite Alexander's assertions to the contrary, relations do not relate but require other relations ad infinitum to unite them with their terms.

According to Alexander a thing has two kinds of characters: (I) categorical characters (derivative from the properties of Space-Time, hence common and necessary to all things as also derivative from Space-Time), and (2) empirical characters (not derivative from the nature of Space-Time and not pervasive). The latter are again of two kinds: (a) essential characters and (b) accidental or unessential characters. These characters are

210 Elsewhere Alexander speaks of the relation of a universal to its particulars: cf. ibid., Vol. I, pp. 220f., 234f., 324.

${ }^{200}$ Ibid., Vol. I, p. 249. Italics not Alexander's.

Ibid., Vol. I, p. 250. Italics not Alexander's. Alexander makes this statement in an attempt to contrast 'relation' and 'inherence' (which "means to be included spatially in a thing"), but it appears to have a significance that goes beyond this contrast. 
expressed by relations which may be similarly classified, or, those expressing ( $\mathrm{I}$ ) and (a) may be grouped together as 'intrinsic' relations and contrasted with those expressing (b) which are 'extrinsic', i.e., dependent upon circumstances (e.g., marriage or paternity). Now these 'extrinsic' relations would seem to be external in the sense in which that term has been used in the present work. They are accidental, unessential, not organically connected with the natures of the terms they relate. They seem to be something secondary which happen to terms, i. e., which by chance get annexed to ready-made, self-identical natures that are not even recognized as adapted to receive them. This being the case, the whole transaction becomes to all appearances inexplicable and of the nature of a miracle. We are told further that when a term enters a relation, its empirical determinations may be altered, ${ }^{222}$ whether or not alteration takes place being determinable apparently only by empirical observation. But its categorical nature, which "is what it is" and "is perfectly and absolutely real or true," ${ }^{223}$ is unalterable and appears to constitute an eternal self-identity. Now, so far as relations encounter terms or characters of terms to which they make no difference and to which they are not organically related (directly or indirectly), they are relations which must be called external. ${ }^{224}$ And to admit, as Alexander seems to do, that ultimately there are external as

22 I.e., its 'accidental' qualities and 'extrinsic' relations, and, it would seem, in extreme cases, its empirical 'essential' characters, as well as its 'empirical variations' of Space-Time and the categories. Cf. ibid., Vol. I, pp. 252-54.

${ }^{223}$ Ibid., Vol. I, p. 254. Cf. II, pp. 323, 369ff. "Finites, though partial, are real in their own right and are not affected by their being only parts of the whole"; "they are what they are." (They are transformed however in the next higher quality.) The new character which elements receive from entry into an organic whole "does not necessarily alter their intrinsic nature. Interpenetration, if so understood, would make a colour red different in itself because it may mean blood, or a point defined as the intersection of two straight lines different in itself because it is also the focus of an ellipse." For other statements implying external relations, see p. I27 above.

${ }^{224}$ How far Alexander accepts Stout's theory, which he states on pp. 255f., Vol. I, it is difficult to say. He rejects the implication that there can be relation independent of relatedness, or qualities outside of all relation. On the other hand, he seems to hold that reciprocal identical dependence of qualities and relations would be a self-contradiction. And it is not clear 
well as internal relations is tantamount to maintaining that the universe is not an organic whole or system of internal relations, and makes incomprehensible such internal relations as observation may suppose it has discovered.

For Moore, ${ }^{225}$ all relations are internal in the sense that "no relational fact is completely analyzable," and that every relational fact constitutes a unity which cannot be identified with any set of constituents (e.g., terms and or together-with their relation). A relation must relate and must relate in a particular way. Moreover, some relations are internal in the sense that they cause terms to undergo changes; for example, relationship to a flame melts wax. More strictly, in these cases, it is not a relation (e.g., fatherhood), but a relational property (e.g., fatherhood of B) derived from it, which modifies the term, so that such cases are irrelevant to the question whether relations are internal or external. Also, in some relations, such as the knowledge relation, there are terms that do not change. The absence of a relational property from a term does not entail qualitative difference; the relational property may be purely external to it. A term (e.g., Edward VII) could have existed without a particular relational property (e.g., being the father of George V), the fact of its having this property being a "mere matter of fact." ${ }^{228}$ The relational property entails some quality in a term without which the term could not have had that relational property, but no quality in the term entails the relational property. A part can exist without the whole, though not the whole without the part. "We may admit, indeed, that when a

whether, in order to avoid this supposed contradiction, he takes the position that "while relations depend on the qualities for their very being, qualities depend on their relations only for the fact that they are related, not for the qualities themselves"; that the terms "must be there" to be related; that relations imply qualities in a way in which qualities do not imply relations; or that qualities may be independent of relations. Such a stand would again imply the theory of external relations.

${ }^{220}$ See Proc. Arist. Soc., Vol. 20, pp. 40-62.

${ }^{226}$ Cf. ibid., p. 51. "The most important thing that can be meant by saying that some relations are purely external," is "that in the case of many relational properties which things have, the fact that they have them is a mere matter of fact: that the things in question might have existed without having them." Involved here, apparently, is the eighteenth century distinction between what is necessary for all conceivable or possible worlds and what as a "mere matter of fact" is found in this particular world. 
particular thing is a part of a whole, it does possess a predicate which it would not otherwise possess-namely that it is a part of the whole. But what cannot be admitted is that this predicate alters the nature or enters into the definition of the thing which has it." ${ }^{227}$ Moore's theory then implies that some relations are external, and not only implies but asserts "that some relational properties certainly are not internal." "And in defense of this proposition," he says, "I do not know that I have anything to say but that it seems to me evident in many cases that a term which has a certain relational property might quite well not have had it ; that, for instance, from the mere proposition that this is this, it by no means follows that this has to other things all the relations which it in fact has." ${ }^{228}$

Broad seems to hold that there are no bare 'and' relations or absolute isolations. In a wide sense everything is related, but things are related merely externally. Relations make no difference to their terms. Nothing more is true of terms in relation than in isolation except the fact that they stand in relation. ${ }^{229}$

According to Russell, the doctrine that relations are external is the fundamental doctrine of the realistic position. This doctrine means, first, that "relatedness does not imply any corresponding complexity in the relata," and, secondly, that "any given entity is a constituent of many different complexes." ${ }^{230}$ It is difficult to see that the second of these supposed differentia really distinguishes the theory of external relations from that of internal relations. The first, however, does distinguish the two theories in so far as it implies that relations have no part in constituting the natures of the terms related; that a term possesses a primordial simplicity which is not forfeited upon entry into relationships; or that a term possesses a nature in its own right, so to speak, which is prior to all relationships and memberships in any wholes, and

${ }^{2 \pi 7}$ Principia Ethica, p. 33.

${ }^{228}$ Proc. Arist. Soc., Vol. 20, p. 60. Moore's difficulty here seems to be the 'intellectualistic' one of assuming that all necessity must be of the type that formal logic discovers to hold between propositions, as for example that between the premises and conclusions of the syllogism.

${ }^{223}$ Cf. Mind, N. S., Vol. 23, pp. 263, 362.

${ }^{200} \mathrm{~J}$. of Phil., etc., Vol. 8, pp. I58ff.; cf. Essays, pp. I50ff., Principles, pp. $224 \mathrm{ff}$., 448. 
which is not in the least altered when it becomes a member of a relation or whole. ${ }^{231}$ That something like this is supposed to be implied in the Realists' theory of external relations will be evident from a passage in Russell's Principles of Mathematics, which, despite its length, it seems best to quote in full. "Thus the very proposition which was to be non-relational turns out to be, after all, relational, and to express a relation which current philosophical language would describe as purely external. For both subject and predicate are simply what they are-neither is modified by its relation to the other. To be modified by the relation could only be to have some other predicate, and hence we should be led into an endless regress. In short, no relation ever modifies either of its terms. For if it holds between $A$ and $B$, then it is between $A$ and $B$ that it holds, and to say that it modifies $A$ and $B$ is to say that it really holds between different terms $C$ and $D$. To say that two terms which are related would be different if they were not related, is to say something perfectly barren; for if they were different, they would be other, and it would not be the terms in question, but a different pair, that would be unrelated. The notion that a term can be modified arises from neglect to observe the eternal self-identity of all terms and all logical concepts, which alone form the constituents of propositions. What is called modification consists merely in having at one time, but not at another, some specific relation to some other specific term; but the term which sometimes has and sometimes has not the relation in question must be unchanged, otherwise it would not be that term which had ceased to have the relation." ${ }^{232}$

Strictly interpreted, the theory of external relations would seem to lead to the conception of absolutely independent entities, or atomic absolutes. Everything becomes separated from everything else to such an extent that it is impossible to make intelligible the possibility of their co-operating to sustain our one world. Some of the more important separations have been referred to above: (I) the dualism of immediate and mediate experience; (2) the dualism of appearance and reality in the trend of thought repre-

281 The isolated acquaintances and insights which, as we saw above (pp. 92ff.), are to serve as solid foundations for knowledge are examples of such self-identical terms.

${ }^{232}$ Pp. 448-9. 
sented by Russell's The Problems of Philosophy, and (3) the dualism of meaning and existence. Perhaps the fundamental dualism in Realistic thinking is that between mind and its objects. In the extreme form of this dualism, ${ }^{233}$ the objects of mind, whether universals or particulars, whether of the order of transcendent reals or of sense-data, appear to be of a nature totally different from that of mind (with the exception of cases in which mind's object is itself or part of itself). These entities moreover are independent of mind in a number of senses. They are in no way the product of mind. They do not imply mind. They could exist or subsist in the absence of all mind. The self-complete, self-identical nature which an entity possesses before coming into relation to mind is not in the least modified by this

${ }^{232}$ I.e., as it is found in Moore's writings and in Russell's writings before the publication of The Analysis of Mind. In the latter, Russell has tried to identify the mental and the non-mental so far as the stuff of which they are composed is concerned; they are both made out of the same 'neutral' stuff. The same stuff as obeying a certain type of causal law and with reference to a certain type of correlates or a certain grouping is mental, and with reference to another type is physical. We have then an approach to a monism of stuff (largely undifferentiated), and a dualism of ultimate types of laws. It is as yet only an approach to a monism of stuff inasmuch as images do not take their place readily among sensations (the ultimate constituents of the neutral stuff), while the realm of logical entities (universals, relations, etc.) has not yet been definitely assigned to the status of either sensations or images (though an analytic and somewhat nominalistic interpretation of such nities is suggested). Moreover, the two types of causal law may in the end turn out to be fundamentally the same, so that the dualism of laws cannot as yet be said to be fully established. Alexander's recent thought also moves away from an ultimate dualism of stuff in the direction of a monism of stuff (somewhat undifferentiated in its original constitution) in so far as he regards both mind and its objects as reducible to the same 'Space-Time' or 'Motion.' Moreover, no troublesome 'images' are recognized by Alexander, and universals, etc., are given a more or less definite, though not entirely convincing, spatio-temporal interpretation. The absence of organic or internal connections in Alexander's world tend to take the form, not of dualisms of stuff or of law, but dualisms of (I) stuff and quality and (2) of categorical and non-categorical determinations, and (3) multiplisms of quality or of levels of development. And in these dualisms and multiplisms for the most part the terms are not completely external to one another but related by what might be called a relation of one-sided dependence, only one of the terms being completely independent of the other. 
relation. They and mind are mutually exclusive. All this applies not only to objects of perception and thought, but also apparently, for Realists such as Alexander, to those of memory, feeling, imagination, and even of illusory experience. If any dependence is to be admitted at all, it is the mind which is dependent upon its objects, i.e., arises out of them, implies them, and in any case could not exist without them. Thus the relation of mind to its objects is either (I) completely unessential and non-constitutive, and, like all external relations, a secondary addition to independent, self-complete natures, or (2) it is a relation of one-sided dependence, so to speak, mechanical dependence, or logical dependence, or both. The admission of dependence, however, whether causal or of the nature of logical implication, would seem to carry one beyond the standpoint of absolutely independent entities and completely external relations. 


\section{CONCLUSION}

With regard to the object of the present study, it seems necessary to come to the following conclusions. Contemporary English Realism came into existence as a distinctive method of thought at the close of the nineteenth century. There seems to be no reason to consider it an outgrowth of any historical form of Realism such as Scottish Realism or Herbartian Realism; nor does it seem to be indebted in any fundamental way to closely similar contemporary movements in Germany and Austria, and in America. ${ }^{1}$ Its debts are rather to the Rationalists and Empiricists of the seventeenth and eighteenth centuries and tc certain of the special sciences. It arose largely as a protest against Idealism. Many of its criticisms of Idealism are valid criticisms of certain types of Idealism. It is justified, for example, in emphasizing, in opposition to an abstract monism or intellectualism, the reality of the individual, and the necessity of maintaining contact with science and everyday life. It rightly urges against a psychological or existential idealism, such as Berkleyanism or Panpsychism, that rational explanations must recognize a genuine external nature which cannot be reduced to minds or mental states. In opposition to feeling and faith philosophies, it well insists upon the indispensability, in the attainment of truth, of a genuine disinterestedness - a willingness to accept the conclusions that secure the approval of reason, whatever may be their relation to one's cherished dogmas or one's wishes. The Realistic criticism has led the Objective Idealist to define his position more carefully

\footnotetext{
${ }^{1}$ I.e., to such developments of thought as are found in the writings of Kulpe, Mach, Brentano, Stumpf, Lipps, Husserl, Meinong, Ehrenfels, and the American New Realists. The English Realists have been close students of these movements, however, and have without doubt derived assistance from them in matters of detail. See, for example, Alexander's acknowledgement of help derived from the Austrian writers on value, Space, Time, and Deity, Vol. II, p. 307; and evidences of the influence of the American Realists on Russell in The Analysis of Mind, pp. 6, 22, 25, 36, $143-4$.
} 
and to distinguish it more sharply from other types of Idealism. It would seem however that not one of the Realistic criticisms is a valid criticism of Objective Idealism, and that criticisms intended to be such miscarry because of misconceptions as to the meaning of the standpoint of the Objective Idealist. The negative or critical phase of Realism must therefore be regarded as far from complete and far less complete than some of its exponents appear to suppose. Most of the protests which the Realist makes against Idealism, Objective Idealists themselves have made against other types of Idealism. It is admitted, however, that "a good many idealists have given some ground for the misunderstanding by failing to take and maintain from the beginning a standpoint that is objective and genuinely speculative." ${ }^{2}$

The most conspicuous features of the positive or constructive phase of Realism are its intellectualistic mode of approaching and solving philosophical problems and the almost complete reliance which it places upon the process of analysis unaided by synthesis as a means of attaining truth. It tends to view reality and the problems of philosophy through the eyes of the formal logician and mathematician and to solve these problems by means of the methods and conceptions of abstract logic and mathematics. It seems to regard the presuppositions and procedures of these abstract disciplines ${ }^{3}$ and the process of analysis as possessing ultimate validity, i.e., as universally applicable or true in any reference without supplementation or reinterpretation. In other words, it considers these as completely trustworthy means of characterizing ultimate reality. This is equivalent to identifying the method of philosophy with the method of one or more special disciplines. This, together with interpreting 'disinterestedness' to mean (as perhaps it does in the special disciplines just referred to) the attitude of a purely external observer and 'impartial outsider,' 4 appears to be the essence of what is meant by 'scientific method in philosophy'.

${ }^{2}$ See p. 59 above.

"E. g., the "Laws of Thought," and such processes as genus-species definition and substitution.

'I.e., one who, ignoring the fact that he himself is a subject, envisages everything merely as object and who, abstracting from all meaning and value, merely records alike the trivial and the important in the "given" whose exterior he examines. 
The most significant results of taking as final the presuppositions of formal logic and mathematics and such abstracting processes as genus-species definition, substitution, and analysis, would seem to be the following. (I) Differences tend to be ignored and reality tends to be interpreted formalistically and mechanistically, i.e., in terms of the categories of abstract identity, passivity, immutability, and external determination. Universals are made abstract and are particularized, so to speak, and Relations are conceived of as relations of one-sided dependence: causal or logical ${ }^{5}$ or both. (2) Genuine wholes are lost sight of and reality tends to be interpreted atomistically, i. e., in terms of ultimate, absolutely independent simples, solid foundations, mathematical infinites, discontinuities, dualisms, isolations, and perhaps transcendents. Particulars are thus made abstract and absolute-are universalized, as it were. Relations are conceived of as external. (3) The standpoint of meaning gives way to that of existence; reality is identified with its emptiest category, being, or with the comparatively empty categories: space, time, and motion. Degrees of reality and value cannot therefore be admitted. Meaning, having been divorced from reality, if recognized at all, must be regarded either as an accidental character of certain finite existents or as purely subjective. In Alexander's thought the standpoints of empirical psychology, physics, and biology are brought to the aid of those of formal logic and mathematics, and intellectualistic and atomistic tendencies are less prominent or less thorough-going than in the thought of Moore and Russell.

The constructive principles of Realism seem to bear a close resemblance to the presuppositions of Pre-Kantian philosophy against which the critical and speculative philosophies arose as a protest. The latter regard these principles as, by themselves, inadequate and unsatisfactory, because: (I) were they true, the possibility of knowledge, hence the possibility of these principles themselves, would be rendered incomprehensible; (2) they lead to irrationalities and contradictions, and (3) they fail to grasp reality in its wholeness, uniqueness, development, and meaning. How, for instance, it may be asked, can the possibility of knowledge (which at its minimum is a distinguishing within a synthesis of a 'this' and a 'that') be rendered intelligible, if a reality is re-

' I.e., deductive inference, correlation, etc. 
garded as merely an aggregate of externally related abstract particulars and abstract universals? Or, how can we make intelligible the possibility of knowing any kind of a world whatever, as long as the subject is conceived of as a class of psychical existents, a series of perspectives, or a discontinuous series of momentary subjects? Again, how can rational explanation admit such an irrationality as a proposition to be regarded as true in complete isolation from all other truths, i.e., to be taken on faith unsupported by rational grounds? Or, how can it accept as ultimate the apparent absurdities of universals with no particulars, unities that unite nothing, and simple wholes without parts? Or, lastly, how can it admit such an apparent self-contradiction as a relation which does not relate, $i$. e., a relation which is exclusive of the terms related, and which therefore seems to necessitate another relation to unite it with its terms, and then still another and another ad infinitum? 







\section{PLEASE DO NOT REMOVE \\ CARDS OR SLIPS FROM THIS POCKET}

UNIVERSITY OF TORONTO LIBRARY

B

1616

R3H38

1923

C. 1

ROBA 
